\title{
Taxonomy and species diversity of Holocene pylonioid radiolarians from surface sediments of the northeastern Indian Ocean
}

\author{
Lanlan Zhang and Noritoshi Suzuki
}

\begin{abstract}
Pylonioid radiolarians show high species diversity in surface sediments of the northeastern Indian Ocean. They can be applied as important oceanographic indices in tropical and subtropical oceans, but pylonioid radiolarian identification has presented challenges because of major change in the appearances of specimens in different orientations. Examination of their internal structures for precise identification has been considered, but this method is not realistic for examining thousands pylonioid specimens embedded on microscopic slides. Therefore, we have developed practical methods for pylonioid radiolarian identification under transmitted light microscopy with mounted slides. This procedure begins with confirming the orientations of specimens with respect to the shadow of the central combination. After orientations were determined under both absolute (Type 1) and relative (Type 2) coordinate systems, morphological groups were identified based on differences in appearance. Taxonomic names were allocated to these morphological groups with consideration given to morphological variations, ontogenetic changes, and most importantly, whether the holotypes and relevant specimens could be included within these morphological groups. Our study yielded a total of 10 genera and 34 species/subspecies, including three new genera (Sphaeropylolena n. gen., Sphaerolarnacillium n. gen. and Qiuripylolena n. gen.) and 20 new species/subspecies in the superfamily Pylonioidea (Larcospira teres n. sp., $L$. tetragonicentrum n. sp., Larcopyle buetschlii chenmuhongi n. subsp., L. buetschlii orion n. subsp., L. molle n. sp., L. eccentricanoides n. sp., L. pulchella n. sp., Sphaeropylolena laxa n. sp., S. tenellispinosa n. sp., Phorticium itakii n. sp., P. scitulum n. sp., Sphaerolarnacillium cochleatum n. sp., S. exactum n. sp., S. tanzhiyuani n. sp., Qiuripylolena chikuchik n. sp., Q. pompon n. sp., Q.? multiconcentrica n. sp., Circodiscus biorbiculus n. sp., C. pseudomicroporus n. sp., and Tholomura pilula n. sp.). Following this taxonomic scheme, we confirmed the limited geographic distribution of many pylonioid species.
\end{abstract}

http://zoobank.org/50E1E005-7E40-4DF5-A433-4EF50F6A865E

Zhang, Lanlan and Suzuki, Noritoshi. 2017. Taxonomy and species diversity of Holocene pylonioid radiolarians from surface sediments of the northeastern Indian Ocean. Palaeontologia Electronica 20.3.48A: 1-68 palaeo-electronica.org/content/2017/1989-taxonomy-of-holocene-pylonioid

Copyright: September 2017 Paleontology Society. This is an open access article distributed under the terms of AttributionNonCommercial-ShareAlike 4.0 International (CC BY-NC-SA 4.0), which permits users to copy and redistribute the material in any medium or format, provided it is not used for commercial purposes and the original author and source are credited, with indications if any changes are made.

creativecommons.org/licenses/by-nc-sa/4.0/ 
Lanlan Zhang. CAS Key Laboratory of Ocean and Marginal Sea Geology, South China Sea Institute of Oceanology, Chinese Academy of Sciences, Guangzhou 510301, China. Ilzhang@scsio.ac.cn Noritoshi Suzuki. Department of Earth Sciences, Graduate School of Science, Tohoku University, Sendai 980-8578, Japan.norinori@m.tohoku.ac.jp

Keywords: radiolaria; Pylonioidea; new genus; new species; Indian Ocean; tropical surface sediments

\section{INTRODUCTION}

The superfamily Pylonioidea Haeckel, 1882, are a group of radiolarians with skeletons characterized by fenestrate forms or systems of ribbonlike latticed tests (De Wever et al., 2001). Because of the diversity of this clade in the southern Bay of Bengal, northeastern Indian Ocean, pylonioids could play an important role in oceanographic and paleoceanographic studies. Their importance in tropical and subtropical oceans has already been recognized (e.g., Lombari and Boden, 1985; Boltovskoy et al., 2010). For example, they are abundant and show high species diversity (23 species) in the South China Sea (e.g., Chen and Tan, 1996); two pylonioid taxa, Tetrapyle quadriloba (Ehrenberg) and Tetrapyle octacantha Müller, are the first and second most abundant radiolarian species in this sea (Chen et al., 2008). Tetrapyle octacantha Müller has been found to be dominant in the upper waters of the South China Sea and may be an indicator of tropical upwelling (Zhang et al., 2009; Hu et al., 2015). In the Sea of Japan, the T. octacantha species group defined by Itaki (2009) obviously declines from $43.9 \%$ of the radiolarian assemblage in the south $\left(35^{\circ} \mathrm{N}\right)$ to $0-5 \%$ in the north $\left(40^{\circ} \mathrm{N}\right)$, which is in accordance with the position of the warm Tsushima Current, a branch of the Kuroshio Current (Motoyama et al., 2016). Pylonioids also have a great potential for oceanographic analysis in the Indian Ocean because the relative abundance of "pyloniids" shows strong positive correlation $\left(r=0.908, R^{2}=0.8245\right)$ with salinity in July-August (Gupta, 2002) and because their changes in abundance coincide with Milankovitch cycles (Gupta, 2003). However, because the taxonomic concepts of the "Tetrapyle octacantha group" and "pyloniids" are quite different, these findings cannot be directly compared to each other. The abundances of different species in the South China Sea suggest that pylonioids should be differentiated at the species level. Regardless of their potential usefulness, identifying the pylonioids is challenging in practice for many reasons.
One of these reasons is that the taxonomic criteria for the Pylonioidea require examination of their central structures to precisely classify them at the subfamily and genus levels because pyloniids share similar overall appearances with other superfamilies (e.g., the flat radiolarians Circodiscus in the Pylonioidea and Flustrella in the Spongodiscoidea; and the elliptical radiolarians Larcopyle in the Pylonioidea and Lithelius in the Lithelioidea) (Kozlova, 1967; Dumitrica, 1989; De Wever et al., 2001). These structures can be precisely identified by sectioning or splitting specimens (Dumitrica, 1989; De Wever et al., 2001). However, these methods are not realistic for application in paleoceanographic studies in which thousands to millions of radiolarian specimens must be identified under transmitted light microscopy. This difficulty has further led to anguished application of superficially similar generic classifications such as Lithelius (Lithelioidea) and Larcopyle (Pylonioidea) for elliptical specimens with spirally concentric internal structures (Lazarus et al., 2005; Suzuki et al., 2009c). This difficulty has forced many studies to apply species complex names such as "Tetrapyle octacantha Müller group" (Itaki, 2009; Matsuzaki et al., 2015a; Motoyama et al., 2016) or "pyloniids" (Gupta, 2002, 2003).

The second reason why identifying pylonioids is challenging is that pylonioid specimens of the same species show major different appearances in different orientations. Since this issue was first recognized in the mid-nineteenth century (Müller, 1859; Hertwig, 1879; Haeckel, 1882; Jørgensen, 1905; Popofsky, 1912), several attempts have been made to confirm differences in the appearances of these species in different orientations by rotating the same specimens under transmitted light microscopy (Tan and Chen, 1990; Itaki, 2009). "Spiral forms" present another challenge for pylonioid identification. Ogane and Suzuki (2009) used computer software to simulate changes in the appearance of a pyloniid model with varying viewing directions and demonstrated that "some spiral forms" were artificially created in by overlapping skeletal structures. 


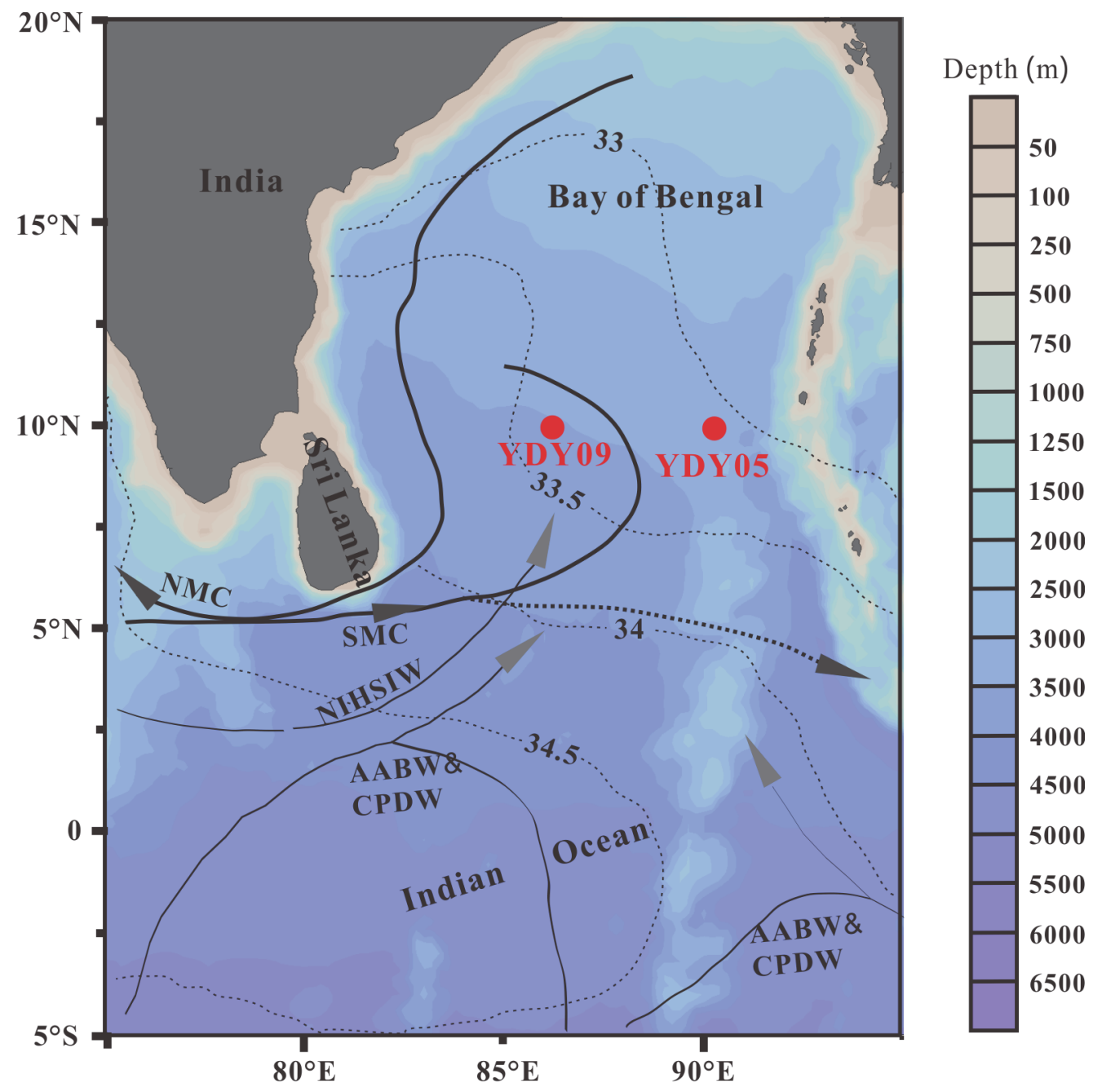

FIGURE 1. Location of the sampling sites in the northeastern Indian Ocean. The surface current (thick arrows) is modified from Peng et al. (2015); the deep circulation (thin arrows) is modified from Kawagata et al. (2006); the isohaline showing surface salinity during June (mean of 93 years) is modified from Gupta et al. (2002). Abbreviations are as follows: AABW, Antarctic Bottom Water; CPDW, Circumpolar Deep Water; NIHSIW, North Indian High-salinity Intermediate Water; NMC, Northeast Monsoon Current; SMC, Southwest Monsoon Current.

For this paper, we have focused on the identification of these radiolarians in routine examination of slides under a typical transmitted light microscope. The purpose of this study was to determine how to identify pylonioids with transmitted light microscopy.

\section{OCEANOGRAPHIC SETTING}

The samples examined for this paper were collected from the southern Bay of Bengal in the northeastern Indian Ocean (Figure 1). This region is mainly affected by the Indian monsoon. In JuneSeptember, the Summer Monsoon Current flows into the southern Bay of Bengal from the highsalinity waters of the Arabian Sea, which leads to heavy rainfall and river influx associated with the Indian summer monsoon, and the surface salinity drops clearly to a seasonal minimum ( 25 psu in the south and $\sim 28 \mathrm{psu}$ in the north) (Prasannakumar et al., 2002; Vinayachandran et al., 2013; Jyothibabu et al., 2015). During the northeastern monsoon (November-February) circulation is weaker and characterized by a north equatorial current (northeastern monsoon drift), and flowing equatorial current to the south and a moderately developed cyclonic gyre in the Bay of Bengal (Gupta et al., 2002). The deep waters of the northeastern Indian Ocean are mainly sourced from circumpolar deep water as a mixture of North Atlantic Deep Water and Southern Ocean Deep Water (Warren, 1981; You, 2000; Ahmad et al., 2012). 
One branch of this circumpolar deep water propagates northward into the deep Bay of Bengal (Ahmad et al., 2012). This oceanographic physical profile of the northeastern Indian Ocean, independent from other oceans, suggests the possibility of locally specific radiolarian faunal assemblages.

\section{MATERIALS AND METHODS}

Two cores, YDY-05 and YDY-09, were collected from water depths of $3310 \mathrm{~m}$ and $3520 \mathrm{~m}$, respectively, from the northeastern Indian Ocean (Figure 1) on the Spring Open Cruise of the Eastern Indian Ocean by RV "Shiyan 1" (South China Sea Institute of Oceanology, Chinese Academy of Sciences) in the spring of 2010. These cores consisted mainly of abyssal ooze. For radiolarian studies, surface samples with weights of $0.15 \mathrm{~g}$ were obtained from these cores, dried at $60^{\circ} \mathrm{C}$, and then processed in a solution of $10 \% \mathrm{H}_{2} \mathrm{O}_{2}$ and $10 \% \mathrm{HCl}$ to remove organic matter and carbonate. The residues were mounted on glass slides following the methodology of Zhang et al. (2009).

The internal structure of pylonioids can only be observed with careful use of microscopy; therefore, we observed the mounted slides under Nikon model $\mathrm{Ci}$ and Nikon model E600 microscopes at Tohoku University, Japan, with carefully selected objective lenses (Plan Fluor 10X/NA $=0.3, \mathrm{WD}=$ $16 \mathrm{~mm}$; S Plan Fluor ELWD 20X/NA = 0.45, WD = 8.2-6.9 mm; S Plan Fluor ELWD 40X/NA $=0.6$, $\mathrm{WD}=3.6-2.8 \mathrm{~mm}$; S Plan Fluor 60X/NA $=0.70$, $W D=1.3-0.1 \mathrm{~mm}$ ). For choosing objective lenses, longer working distance (WD) is given greater weight than higher numerical aperture (NA) because of the necessity for deep focus rather than fine-scale images; lenses with correction rings are also preferred to adjust optical spherical aberration and avoid vague images with higher NA (> 0.4 ), as discussed by Murphey et al. (2001). Photographs were captured with a Canon Kiss EOS X6 camera installed on the Nikon $\mathrm{Ci}$ microscope connected with a Meiji Techno camera adapter system (with a Canon ring T2-9, photo eyepiece MA986 (1.9X), attachment MA150/50, and C-mount phototube MA816/PT\#2) and a Nikon 1 J2 camera installed on the Nikon model E600 microscope that is connected with a C-mount adapter and AF/EXP chip for Nikon 1 Gfoto.

Prior to assigning taxonomic names to pylonioid specimens, we first captured photographs of all morphotypes encountered and divided these into morpho-species based on their morphological continuity. After evaluating the possibilities of ontoge- netic and intraspecific variation, we assigned species names when the holotype and relevant images could be grouped into our working morphospecies.

\section{Morphological Descriptions}

Pylonioid morphology is highly complex, and several terms must be clearly defined. Detailed morphological terminology was proposed by Dumitrica (1989), but not all skeletal structures described in that work are needed to identify pylonioids mounted on slides. Morphological terminology for practical identification under a transmitted microscope is provided in (Table 1, Figure 2).

Relative vs. absolute orientation of pylonioid specimens. Pylonioids show remarkably different appearances in different orientations (Tan and Chen, 1990; Itaki, 2009; Suzuki and Ogane, 2009) as well as remarkably similar appearances in different orientations with different growth stages. Because the biometric orientation is defined by the orientation of the central combination, the biometric direction can be applied regardless of the orientation of the outer girdles (Dumitrica, 1988, 1989). Despite many discussions of the recognition of specimen orientation (Haeckel, 1887; Kozlova, 1967; Dumitrica, 1989; Sugiyama et al., 1992; Tan and Chen, 1990; Ogane and Suzuki, 2009), difficulties persist in identifying pylonioids at both the genus and species level (Itaki, 2009; Matsuzaki et al., 2015; Motoyama et al., 2016). Based on our examination of more than 5,000 photographs, which we have archived, and of the literature referenced herein, this difficulty is attributed to a mixture of both the absolute and relative orientations of specimens in analyses (Figure 3 ). The biometric orientation is determined by the orientation of the central combination (column S1 in Figure 3), whereas the "absolute orientation" is defined herein (Tables 2, 3, Figure 4). By focusing on the orientation at which twin apertures of gates are visible (Figure 2; "frontal view" in Figure 3), the same appearance can be achieved in different absolute orientations. This appearance is termed the "relative orientation" herein.

Describing an orientation requires defining the Cartesian coordinate system, also called the "rectangular coordinate system" or "orthogonal coordinate system," which can be defined as "a system whereby points on plane are identified by an ordered pair of numbers, representing the distances to two perpendicular axes" (Downing, 2009). To define the Cartesian coordinate system, the perpendicular axes, their origin, and the planes 
TABLE 1. Morphological terminology for pylonioids.

\begin{tabular}{|c|c|c|c|}
\hline $\begin{array}{l}\text { Taxonomic } \\
\text { specification }\end{array}$ & Terms & Definition & Reference \\
\hline \multirow{12}{*}{ 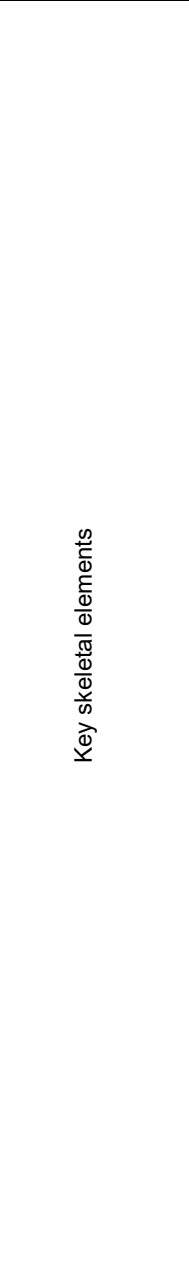 } & microsphere (S1a) & $\begin{array}{l}\text { The innermost shell }(<50 \mu \mathrm{m} \text { in diameter) in Spumellaria. Microsphere is } \\
\text { considered to form at the initial skeletogenesis. It differs from the } \\
\text { macrosphere by its size only. This corresponds to S1a. }\end{array}$ & $\begin{array}{l}\text { De Wever et } \\
\text { al. (2001); } \\
\text { Dumitrica } \\
\text { (1989) }\end{array}$ \\
\hline & girdle & $\begin{array}{l}\text { One of pylonioid multiple shells. A girdle looks like an encircled band, a } \\
\text { triangle outline composed of mutually oriented circular tests, or a set of } \\
\text { large vaulted dome-shaped tests which are orthogonally arranged. For } \\
\text { example, a girdle is constituted with two caps or two wings in Tetrapyle, } \\
\text { with six cupolas in the Tholoniidae. }\end{array}$ & $\begin{array}{l}\text { De Wever et } \\
\text { al. }(2001)\end{array}$ \\
\hline & cap & $\begin{array}{l}\text { Portion of a girdle that develops from a previous skeletal part. The } \\
\text { "circular test", "dome-shaped test" and cupolar is a kind of cap. }\end{array}$ & $\begin{array}{l}\text { Dumitrica } \\
(19895)\end{array}$ \\
\hline & wing & An incomplete cap. & $\begin{array}{l}\text { Haeckel } \\
(1887)\end{array}$ \\
\hline & half girdle & $\begin{array}{l}\text { An abstract word when it is not necessary to differentiate between "cap" } \\
\text { and "wing". }\end{array}$ & $\begin{array}{l}\text { Haeckel } \\
(1887)\end{array}$ \\
\hline & cupola & Large vaulted dome of a cap. This is also termed as "dome-shaped test." & $\begin{array}{l}\text { Dumitrica } \\
\text { (1989) }\end{array}$ \\
\hline & gate & $\begin{array}{l}\text { Gate is defined by the disclosed large space between part of a girdle } \\
\text { and the previous skeleton, in the case of the Pylonioidea. This term is an } \\
\text { abstract noun if it is not necessary to concern on the orientation of a } \\
\text { gate. "Aperture" and "Tunnel" are used when one needs to explain about } \\
\text { gates in consideration with its orientation. }\end{array}$ & $\begin{array}{l}\text { Redefined } \\
\text { herein }\end{array}$ \\
\hline & aperture & An appearance of a gate that one can see an opening. & New \\
\hline & tunnel & An appearance of a gate that one can see the wall that forms a gate. & New \\
\hline & Pylonioid system & $\begin{array}{l}\text { A set of one to four successive outer girdles. One set of the lateral, } \\
\text { transverse and sagittal girdles in the sense of Jørgensen (1905). This } \\
\text { term may be written simply as "system." }\end{array}$ & $\begin{array}{l}\text { Dumitrica } \\
\text { (1989) }\end{array}$ \\
\hline & S1a-girdle & $\begin{array}{l}\text { The pylonioid system that directly develops from the microsphere (S1a). } \\
\text { This corresponds to S1a-girdle. }\end{array}$ & $\begin{array}{l}\text { Dumitrica } \\
\text { (1989) }\end{array}$ \\
\hline & $\begin{array}{l}\text { central } \\
\text { combination }\end{array}$ & $\begin{array}{l}\text { The skeletal structure comprised with a microsphere and the S1a-girdle. } \\
\text { The development pattern of the a-girdle with the S1a is a key to specify } \\
\text { family or subfamily position in Pylonioidea. }\end{array}$ & New \\
\hline
\end{tabular}

must be defined. Sugiyama et al. (1992) proposed a type of Cartesian coordinate system, similar to the "Type 1 coordinates" explained below, to describe the orientations of pylonioid skeletal elements with respect to the orientation of the central combination. However, their Cartesian coordinate system failed to fulfill the mathematical requirement of the origin of the coordinates. We propose two types of Cartesian coordinate systems corresponding to the "absolute orientation" (Table 2, Figure 4.1) and the "relative orientation" (Table 3, Figure 4.2). The absolute Cartesian coordinate system (named herein "Type 1 coordinates") is defined by the orientation of the central combination. The relative Cartesian coordinate system (Type 2 coordinates) is determined based on the outermost pylonioid system.

Recognition of the central combination. The first step when observing a pylonioid is to recog- nize the overall shape based on the outermost pylonioid system; the specimen is thereby realized under Type 2 coordinates. As shown in Figure 4.2, the specimen is then classified as a frontal, profile, or upright view (abbreviated as "Fr-view", "Prview", and "Ug-view", respectively). The next step is to determine the orientation of the specimen under Type 1 coordinates based on the appearance of the central combination. The central combination is situated in the center of the test; therefore, the objective image must be carefully adjusted with the correction ring of the objective lens under complete Khöler illumination to reduce spherical aberration (Murphey, 2001, p. 6). The central combination cannot be seen under an inappropriate configuration of the NA (Murphey, 2001, p. 90, 93). Specimens must be observed with a very shallow depth of focus as much as possible close to the designated NA of the objective lens 
TABLE 1 (continued).

\begin{tabular}{|c|c|c|c|}
\hline $\begin{array}{l}\text { Taxonomic } \\
\text { specification }\end{array}$ & Terms & Definition & Reference \\
\hline \multirow{11}{*}{ 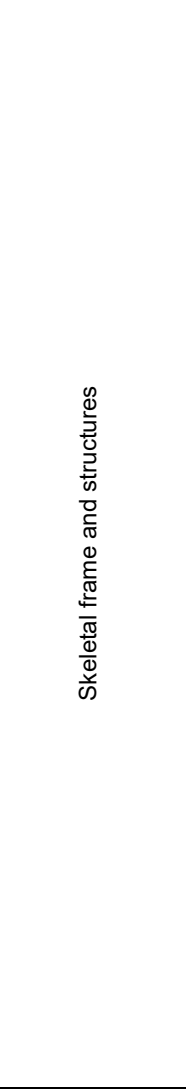 } & band girdle & An encircle girdle to form a ring. & New \\
\hline & joint part & The connection where two or more caps share. & New \\
\hline & ring & One of Circodiscus multiple shells. A ring is encircled. & New \\
\hline & $\begin{array}{l}\text { di-clade corner/ } \\
\text { junction }\end{array}$ & A corner resulting from bending of a microspheric bar. & $\begin{array}{l}\text { Dumitrica } \\
\text { (1989) }\end{array}$ \\
\hline & $\begin{array}{l}\text { tri-clade corner/ } \\
\text { junction }\end{array}$ & $\begin{array}{l}\text { A kind of a triple-junction on pore frame. An edged corner or a nodal } \\
\text { point where three bars of pore frame unit. }\end{array}$ & $\begin{array}{l}\text { Dumitrica } \\
\text { (1989) }\end{array}$ \\
\hline & pillar & $\begin{array}{l}\text { A kind of bar, beam, rod and spine that are arisen from cupolas of an } \\
\text { inner girdle. }\end{array}$ & $\begin{array}{l}\text { Dumitrica } \\
(1989)\end{array}$ \\
\hline & $\begin{array}{l}\text { primary ray/spine } \\
\text { (RB) }\end{array}$ & $\begin{array}{l}\text { A kind of bar, beam, rod and spine that directly extends from a tri-clade } \\
\text { corner. RL-primary ray (spines) originating in a di-clade bar } \\
\text { corresponding to one of the lateral edges of the hypothetical prism. }\end{array}$ & $\begin{array}{l}\text { Dumitrica } \\
\text { (1991) }\end{array}$ \\
\hline & $\begin{array}{l}\text { dimensive beams/ } \\
\text { rods/spines (DR) }\end{array}$ & $\begin{array}{l}\text { A kind of beam, rod and spine that orthogonally extends from the S1a. } \\
\text { The term DR is mainly used if its orientation is not concerned. If its } \\
\text { orientation is concerned under some coordinates, they are called like "a } \\
\text { sagittal beam". }\end{array}$ & $\begin{array}{l}\text { Dumitrica } \\
\text { (1989) }\end{array}$ \\
\hline & $\begin{array}{l}\text { polar beam/rod/ } \\
\text { spine }(\mathrm{PN})\end{array}$ & $\begin{array}{l}\text { The straight heavy beam/rod/spine on the top of a cap. A PN is not } \\
\text { always connected to a DR. This term includes "a sagittal septum" in the } \\
\text { concept of Haeckel }(1887, \text { p. } 650)\end{array}$ & Benson (1966) \\
\hline & $\begin{array}{l}\text { pseudo-concentric } \\
\text { shell }\end{array}$ & $\begin{array}{l}\text { This term is named for "concentric appearance" of girdles under } \\
\text { transmitted light microscope. Although pyloniid skeleton is made of one } \\
\text { or more systems of girdles, the skeleton looks like having "concentric" } \\
\text { structure. The quick recognition of "pseudo-concentric shell" without } \\
\text { regard to the number of a system and the orientation of the central } \\
\text { combination is useful in observing mounted slides }\end{array}$ & New \\
\hline & portal-main spines & $\begin{array}{l}\text { Generally, eight long and thin cylindrical radial spines from the edges of } \\
\text { girdle, lying in two crossed diagonal planes, opposite direction. }\end{array}$ & New \\
\hline
\end{tabular}

based on its optical design. The central combination appears as a combination of a microsphere (S1a) and a half girdle (S1a-girdle). And a successive girdle is perpendicular to the half girdle in the genera Tetrapyle and Larcopyle (Pyloniidae) (Figure 5.1-5.4) but lacks a half girdle (S1a-girdle) in the genera Circodiscus (Figure 5.5) and Phorticium (Larnacillidae). Figure 4 shows the differences and the relationship between Type 1 and Type 2 coordinates.

How to specify the girdles and gates of interest. In the cases of Tetrapyle and Phorticium, a single pylonioid system comprises a set of three successive girdles (Figure 3 ). Thus, one girdle shows the same orientation as four successive girdles under Type 1 coordinates because each girdle is oriented perpendicular to the previous girdle. As shown in Table 4, it is convenient to designate a single pylonioid system as " $\mathrm{S} n$ " [ $\mathrm{n}=1,2,3, \ldots]$. It is also useful to denote each girdle in a single pylonioid system as "k-girdle" $[k=a, b, c, \ldots]$ from the innermost to outermost girdle within the same pylonioid system. This counting system is useful to deter- mine which girdles belong to the same pylonioid system. For practical use, a simple counting method from the innermost girdle outward is appropriate because Cartesian coordinates need not be specified. We propose the notation " $G n$ " $[n=1,2$, $3, \ldots]$ for this counting method. In contrast to the "Snk-girdle" notation, G1 refers to the innermost girdle outside of the S1a-girdle, the half girdle unique to the Pyloniidae, or outside of S1a (a microsphere) in the Larnacillidae, and can therefore be applied for the broadest possible range of taxa within the Pylonioidea. The counting system of "Sn" and " $k$-girdle" is herein termed the "pylonioid system counting method", whereas the "Gn" notation is called the "successive girdle counting method". The pylonioid system counting method must be evaluated in the context of Type 1 coordinates, whereas the successive girdle counting method can be applied without reference to either coordinate system.

Following the recognition of Type 1 and Type 2 coordinates, the orientation of a specimen is classified as PI-, Sg-, or Lt-view under Type 1 coor- 

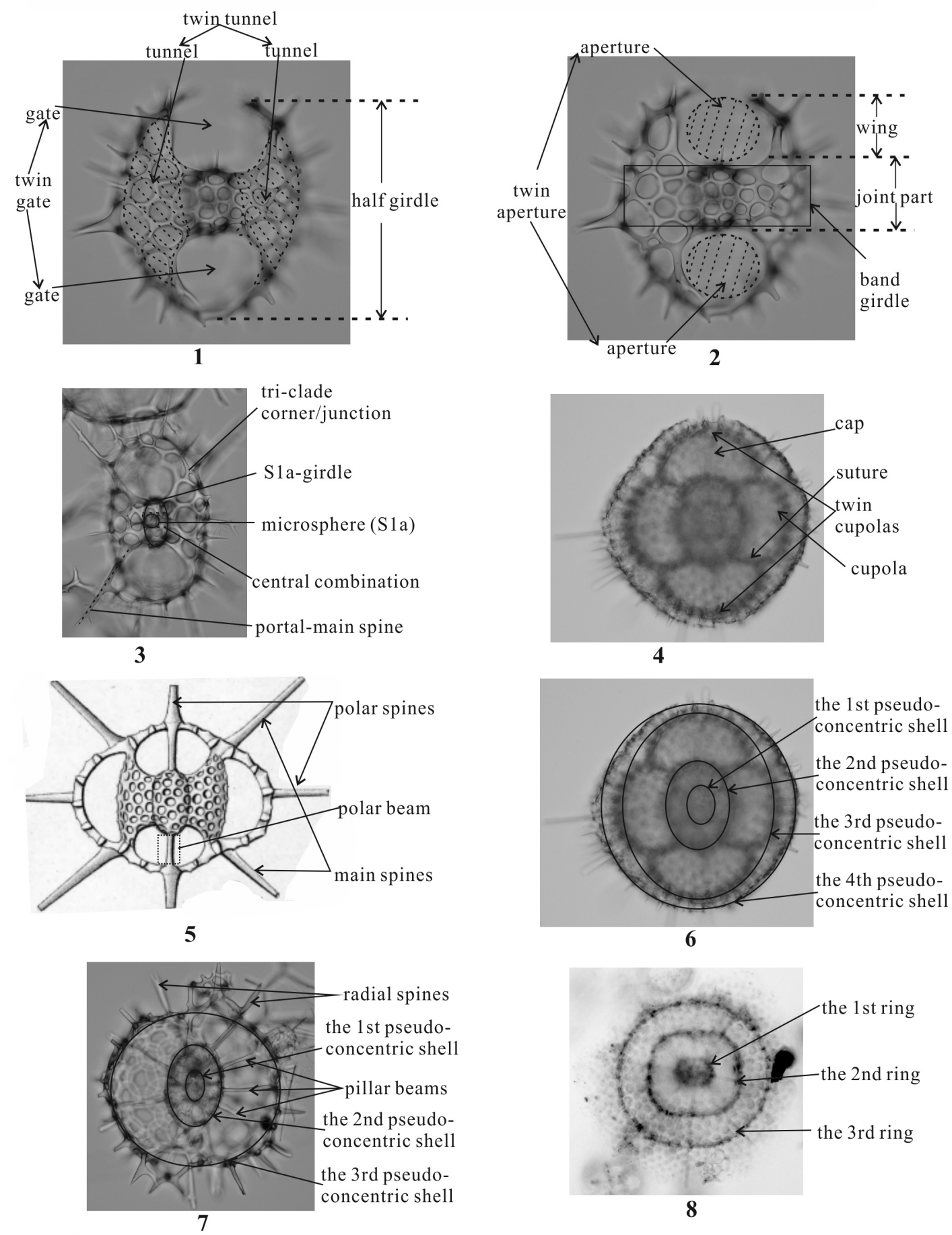

FIGURE 2. Morphological terminology under a transmitted light microscope. 1-2, for gate and girdle; 3-8, for different pylonioid systems.

dinates (Figure 3, Table 2), as Fr-, Pr-, or Ug-view under Type 2 coordinates (Figure 3, Table 3). Based on the Type 2 view, the possible number under the successive girdle counting method can be narrowed down. In the case of the Fr-view under Type 2 coordinates, the outermost girdle shows the G2 and G5 in Pl-view, the G4 in Sgview, or the $\mathrm{G} 3$ in Lt-view under Type 1 coordinates (Figure 3 ). If the number of girdles can be counted following the successive girdle counting method, the exact code of the outermost girdle can be specified to determine the orientation of the specimen 


\begin{tabular}{|c|c|c|c|c|c|c|c|}
\hline & \multicolumn{7}{|c|}{ Number to the Pylonioid system of girdles } \\
\hline \multirow{5}{*}{ 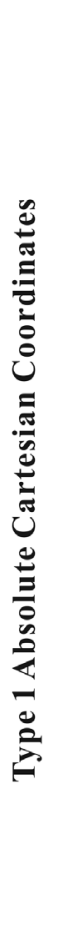 } & & $\mathrm{S} 1$ & \multicolumn{3}{|c|}{ Number to each girdle for S2 } & \multicolumn{2}{|c|}{ Number to each girdle for S3 } \\
\hline & & & G1 & $\mathrm{G} 2$ & G3 & G4 & G5 \\
\hline & Pl-view & 0 & -8 & *Fr-view & $\begin{array}{l}\text { twin tunnel } \\
\text { *Ug-view }\end{array}$ & 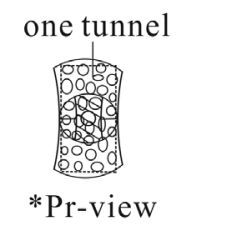 & 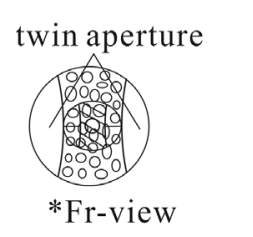 \\
\hline & Sg-view & 皿 & 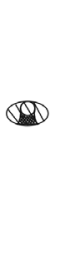 & $\begin{array}{l:}\text { twin tunnel } \\
\text { *Ug-view }\end{array}$ & $\begin{array}{l}\text { one tunnel } \\
\text { *Pr-view }\end{array}$ & Fr-view & twin tunnel \\
\hline & Lt-view & $\theta$ & 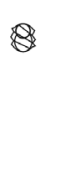 & $\begin{array}{c}\text { one } \\
\text { *Pr-view } \\
\text { * }\end{array}$ & $\begin{array}{l}\text { twin } \\
\text { *Fr-view }\end{array}$ & $\begin{array}{l}\text { twin } \\
\text { *Ug-view }\end{array}$ & 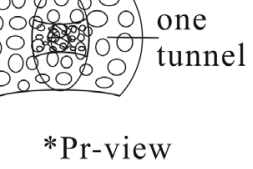 \\
\hline
\end{tabular}

FIGURE 3. The absolute and relative orientations of specimens under the pylonioid system. The symbol "*” indicates Type 2 Relative Cartesian Coordinates.

under Type 1 coordinates without observation of the central combination. If the central combination is recognizable, observations can be made under Type 2 coordinates.

Special cases. These rules are not without exceptions, however; rules for special cases are needed for the family Tholoniidae, as well as the subfamilies Pylodiscinae (Pyloniidae) and Circodiscinae (Larnacillidae) (Figure 2). The skeletal architecture of these clades follows the characteristic architecture of the Pylonioidea, but the practical recognition of their skeletal structures differs to an extent from the more typical pyloniids and larnacillids. Members of the Tholoniidae are characterized by the repetition of a group of six dome-shaped cups. This structure can be viewed as the repetition of several pylonioid systems; each pylonioid system comprises twin cupolas, and pairs of cupolas are arranged perpendicular to each other. However, this complex description is not needed to evaluate these taxa because each pylonioid system within a tholoniid resembles a single cortical shell, herein named a "pseudo-concentric shell" (Figure 2.6; Table 1). The concept of the pseudo-concentric shell also applies for other pylonioids such as the
Pylodiscus (Pylodiscinae), Phorticium, and Larcospira (Larnacillidae) (Figure 2.7). Another exception is the Circodiscinae, the tests of which consist of concentric tubes that form flat shapes similar to the genus Flustrella (Euchitonidae, Spongodiscoidea) (Figure 2.8). The designation to distinguish a ring in a system of a specimen within the Circodiscinae is " $x$ ring" $[x=1 s t, 2 n d, 3 r d, . .$.$] , i.e., 1st$ ring, 2nd ring, and 3rd ring denote the inner, middle, and outer ring, respectively.

\section{SYSTEMATIC PALEONTOLOGY}

Higher classification of the Pylonioidea based on the integration of morphological taxonomy and molecular phylogeny has been described by Matsuzaki et al. (2015a).

Infrakingdom RHIZARIA Cavalier-Smith, 2002 sensu emend. Cavalier-Smith, 2003

Phylum RETARIA Cavalier-Smith, 1999

Class POLYCYSTINA Ehrenberg, 1839

Order SPUMELLARIA Ehrenberg, 1876

Superfamily PYLONIOIDEA Haeckel, 1882 sensu Dumitrica, 1989 
TABLE 2. The definitions of the Type 1 absolute Cartesian coordinate systems for pylonioids.

\begin{tabular}{|c|c|c|c|c|}
\hline $\begin{array}{l}\text { Newly defined } \\
\text { three } \\
\text { coordinate } \\
\text { systems }\end{array}$ & Terms & Sub-terms & Definition & Reference \\
\hline \multirow{10}{*}{ 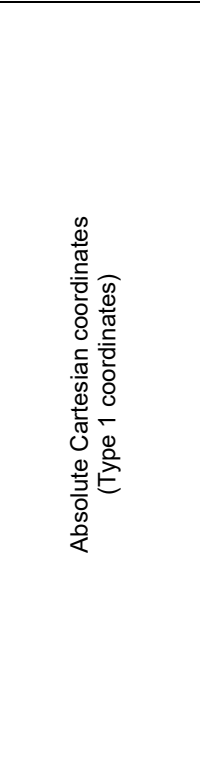 } & Origin & & $\begin{array}{l}\text { The center of the microsphere (S1a). This origin is } \\
\text { critical when inner pylonioid systems are } \\
\text { concerned. }\end{array}$ & New \\
\hline & \multirow{3}{*}{$\frac{\infty}{x}$} & polar axis (PI-axis) & $\begin{array}{l}\text { The axis that crosses the longest orientation of } \\
\text { the central combination. }\end{array}$ & $\begin{array}{l}\text { Sugiyama et al. } \\
\text { (1992) }\end{array}$ \\
\hline & & lateral axis (Lt-axis) & $\begin{array}{l}\text { The axis in parallel to the maximum width of S2a } \\
\text { girdle. }\end{array}$ & $\begin{array}{l}\text { Sugiyama et al. } \\
\text { (1992) }\end{array}$ \\
\hline & & sagittal axis (Sg-axis) & $\begin{array}{l}\text { The axis which orthogonally crosses both the PI- } \\
\text { axis and Lt-axis. }\end{array}$ & $\begin{array}{l}\text { Sugiyama et al. } \\
\text { (1992) }\end{array}$ \\
\hline & \multirow{3}{*}{ 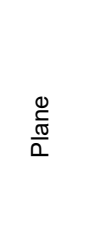 } & polar plane (PI-plane) & $\begin{array}{l}\text { The plane vertical to } \mathrm{Pl} \text {-axis includes both } \mathrm{Sg} \text {-axis } \\
\text { and Lt-axis. }\end{array}$ & $\begin{array}{l}\text { Sugiyama et al. } \\
(1992)\end{array}$ \\
\hline & & lateral plane (Lt-plane) & $\begin{array}{l}\text { The plane vertical to Lt-axis includes PI-axis and } \\
\text { Sg-axis. }\end{array}$ & $\begin{array}{l}\text { Sugiyama et al. } \\
(1992)\end{array}$ \\
\hline & & sagittal plane (Sg-plane) & $\begin{array}{l}\text { The plane vertical to } \mathrm{Sg} \text {-axis includes both } \mathrm{Pl} \text {-axis } \\
\text { and Lt-axis. }\end{array}$ & $\begin{array}{l}\text { Sugiyama et al. } \\
(1992)\end{array}$ \\
\hline & \multirow{3}{*}{$\stackrel{3}{3}$} & polar view (PI-view) & The view that one can see PI-plane. & Defined here \\
\hline & & lateral view (Lt-view) & The view that one can see Lt-plane. & Defined here \\
\hline & & sagittal view (Sg-view) & The view that one can see Sg-plane. & Defined here \\
\hline
\end{tabular}

Remarks. The taxonomic framework of the superfamily Pylonioidea was well documented by De Wever et al. (2001, p. 148-158). Our re-examination of the internal structures of members of this superfamily has largely confirmed their descriptions.

Subsuperfamily PYLONIILAE Haeckel, 1882

Family PYLONIIDAE Haeckel, 1882

Subfamily PYLONIINAE Haeckel, 1882 sensu emend. De Wever et al., 2001

Genus TETRAPYLE Müller, 1859 sensu emend. herein

*1859 Tetrapyle Müller, p. 33.

1861b Schizomma Ehrenberg, p. $822-833$ (type species: Schizomma quadrilobum Ehrenberg, 1862).

1882 Octopyle Haeckel, p. 464 (type species: Octopyle [Octopylissa] ovulina Haeckel, 1887).

1887 Tetrapyle Müller; Haeckel, p. 644.

1887 Octopyle Haeckel; Haeckel, p. 650.

1887 Octopylura Haeckel, p. 651 (type species: Octopyle [Octypylura] stenozona Haeckel, 1887).

1954 Tetrapyle Müller; Campbell, p. D96.

1954 Octopyle Haeckel; Campbell, p. D96.

1954 Octopylura Haeckel; Campbell, p. D96.

1979 Octopylura Haeckel; Kozur and Mostler, p. 40.
1979 Octopyle Haeckel; Kozur and Mostler, p. 46. Type species. Tetrapyle octacantha Müller, 1859 (monotypy).

Description. Test comprises a central combination and the repeating symmetry of four girdles. The central combination consists of a spherical S1a (microsphere) and an S1a-girdle. The S2a-girdle (G1 girdle) and S2b-girdle (G2 girdle) are joined at the Ug-axis. The G2 girdle and S2c-girdle (G3 girdle) are joined at the Fr-axis. The G3 girdle and S3a-girdle (G4 girdle) are joined at the Pr-axis. The G4 girdle is parallel to the $\mathrm{G} 1$ girdle. Girdles are latticed, and elliptical to rounded quadrangular in Frview. The shapes of the girdles are homologous. A polar beam may be present along the Lt-axis from one or both sides of the central combination. A polar beam appears to extrude from each girdle.

Remarks. Ogane and Suzuki (2009) simulated the "ever-changing appearance" of pyloniid specimens with a three-dimensional computer model and warned that an "artificial" torsional state appears at any orientation except for the $\mathrm{Fr}$-, Ugand Pr-views. In this study, the Fr-, Ug- and Prviews correspond to the "dorsal," "apical," and "lateral" views. The overlapping wings and the both sides of girdles create a false illusion of deep focal depths under a microscope. Octopyle was distinguished from Tetrapyle based on that the former has polar beams that connect with two girdles. In practice, however, this criterion is problematic 
TABLE 3. The definitions of the Type 2 relative Cartesian coordinate systems for pylonioids.

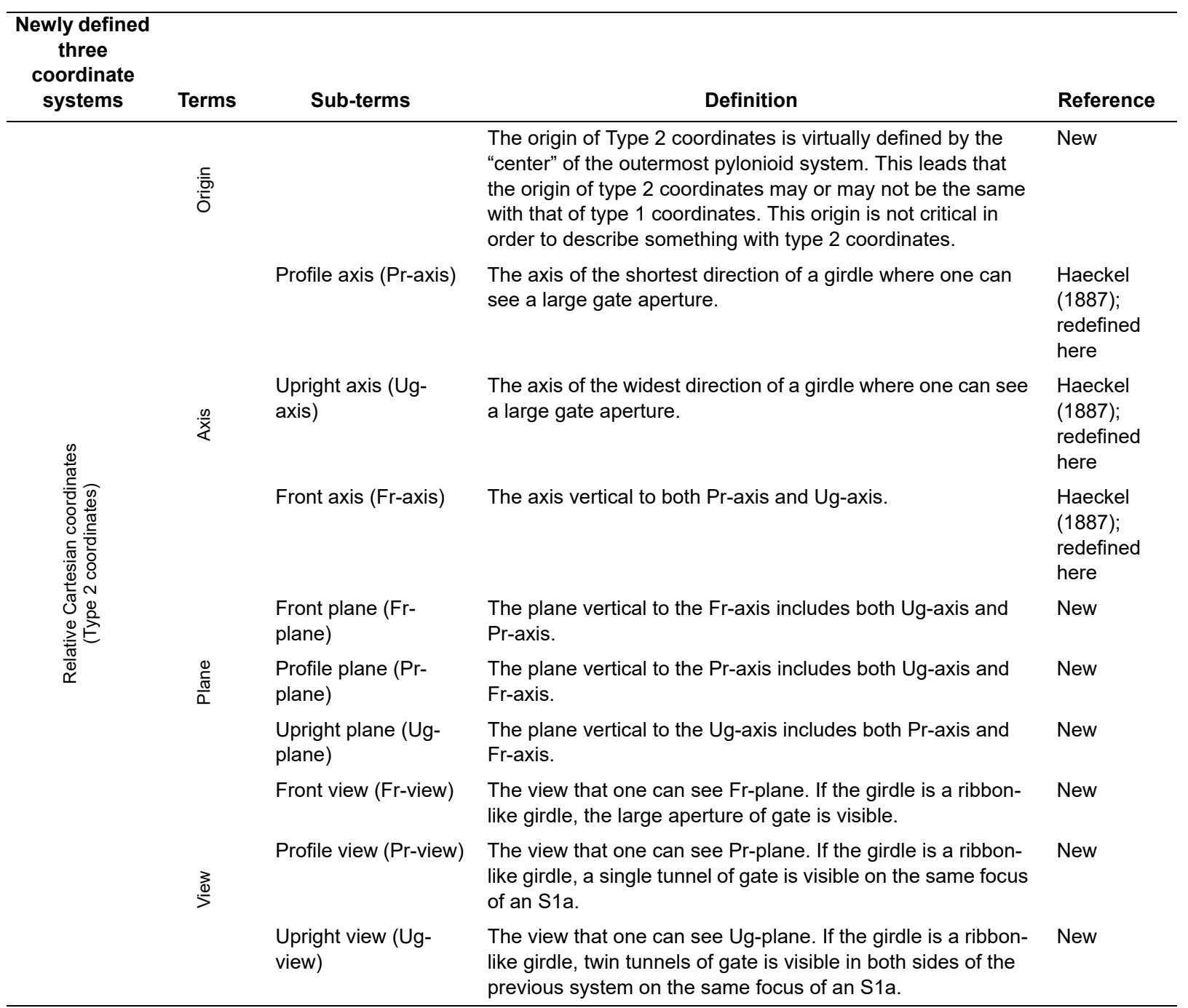

because of ontogenetic change from Tetrapyletype to Octopyle-type morphology with the development of polar beams. Therefore, we synonymize Octopyle with Tetrapyle in this study.

Tetrapyle octacantha Müller 1859 sensu stricto Figures 6 and 7

1859 Tetrapyle octacantha Müller, p. 33-35, pl. 2, figs. 12, 13, pl. 3, figs. 1-12.

non 1879 Tetrapyle octacantha Müller; Hertwig, pl. 6, figs. 2, 5 (only).

non 1972 Tetrapyle octacantha Müller; Ling, p. 168, pl. 2, fig. 3.

1976 Octopyle octospinosa; Tan and Tchang, p. 262, text-fig. 32a-e.

non 1977 Tetrapyle sp. cf. T. octacantha Müller; Kling, pl. 1, fig. 14. non 1977 Tetrapyle octacantha (Müller) (erroneous parentheses to the author's name); MolinaCruz, p. 335, pl. 5, fig. 5 (only).

? 1977 Tetrapyle octacantha (Müller) (erroneous parentheses to the author's name); MolinaCruz, p. 335, pl. 5, fig. 6 (only).

1977 Tetrapyle octacantha (Müller) (erroneous parentheses to the author's name); MolinaCruz, p. 335, pl. 5, fig. 7 (only).

non 1979 Tetrapyle octacantha Müller; Kling, p. 311, pl. 1, fig. 13.

1979 Tetrapyle octacantha Müller; Nigrini and Moore, p. S125-126, pl. 16, fig. 3a, b.

non 1980 Tetrapyle octacantha Müller; Boltovskoy and Riedel, p. 120, pl. 4, fig. 11.

non 1981 Tetrapyle octacantha Müller; Takahashi and Honjo, p. 150, pl. 6, figs. 5, 6.

non 1982 Tetrapyle octacantha Müller; Molina-Cruz, p. 995, pl. 2, figs. 10, 11. 

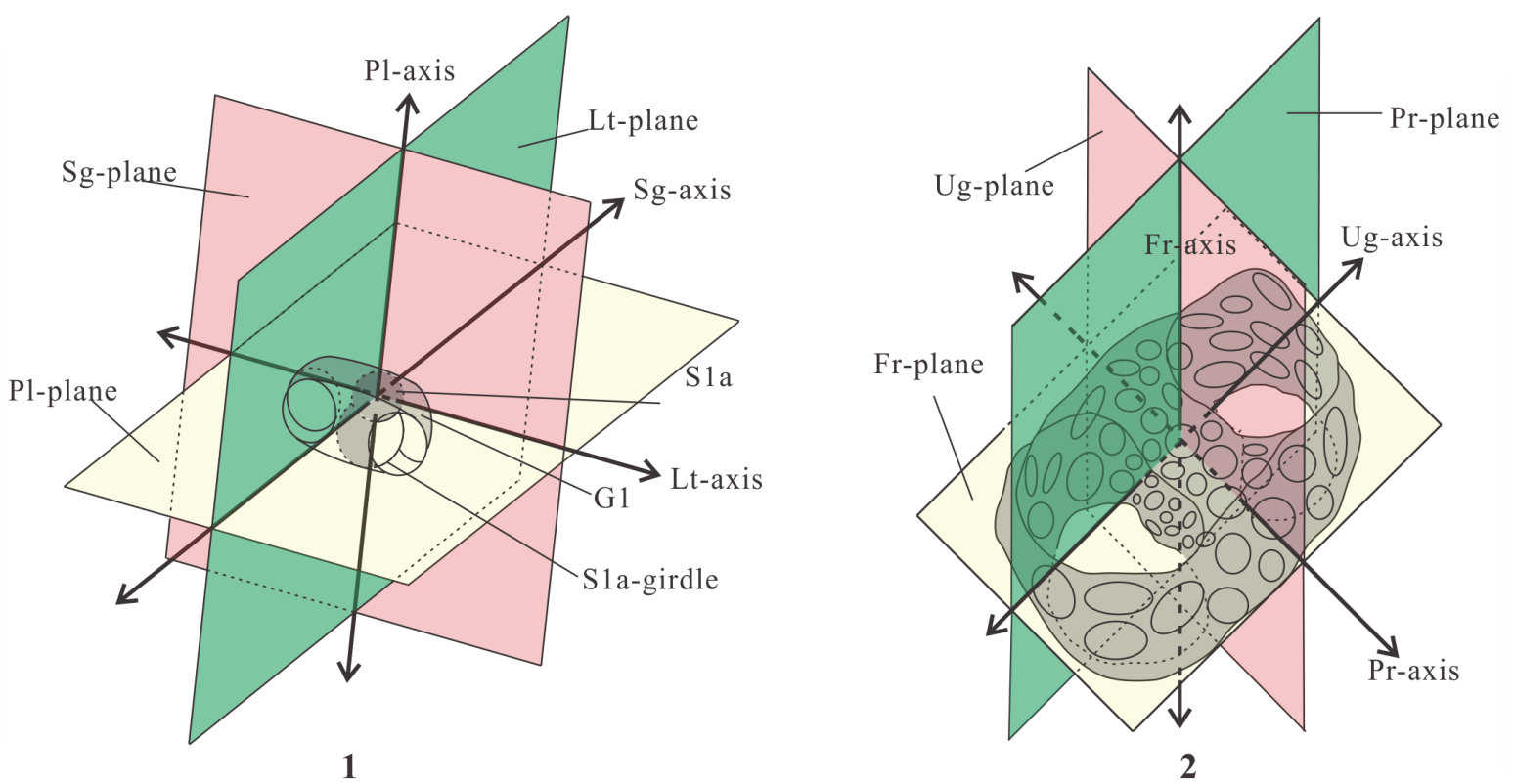

FIGURE 4. The diagrams of the absolute Cartesian coordinate (Type 1) and the relative Cartesian coordinate (Type 2). 1, Type 1; 2 , Type 2.

non 1982 Tetrapyle octacantha Müller; Poluzzi, p. 59, pl. 19, figs. 3-6, 10.

non 1983 Tetrapyle octacantha Müller; Robson, pl. 1, fig. 12.

non 1984 Tetrapyle octacantha Müller; Nigrini and Lombari, p. S87-88, pl. 12, fig. 3a, b.

1984a Larnacalpis sp. Nishimura and Yamauchi, pl. 16, fig. 14.

1984a Tetrapyle octacantha Müller; Nishimura and Yamauchi, p. 42, pl. 17, figs. 2, 6, 9 (only).

non 1984a Tetrapyle sp. aff. T. octacantha Müller; Nishimura and Yamauchi, p. 42, pl. 17, fig. 4.

non 1984a Tetrapyle octacantha Müller; Nishimura and Yamauchi, p. 42, pl. 17, figs. 7, 12, 14, pl. 43, fig. 13 (part).

non 1984b Tetrapyle octacantha Müller; Nishimura and Yamauchi, pl. 1, fig. 11.

non 1985 Tetrapyle octacantha Müller; Boltovskoy and Jankilevich, pl. 3, fig. 26.

non 1986 Tetrapyle octacantha Müller; Morley and Kohl, pl. 2, fig. 1.

non 1986 Tetrapyle octacantha Müller; Yamauchi, pl. 4, fig. 13.

non 1987 Tetrapyle octacantha Müller; Dworetzky and Morley, pl. 2, fig. 1.

1989 Tetrapyle octacantha Müller; Dumitrica, pl. 12, figs. 3,4 .

non 1990 Tetrapyle octacantha Müller; Fujioka, pl. 42, fig. 6.

1990 Octopyle octospinosa Tan and Chen, p. 117-118, text-fig. 9, pl. 1, figs. 10-12. non 1991 Tetrapyle octacantha Müller; Takahashi, p. 90, pl. 23, figs. 9, 10.

non 1992 Tetrapyle octacantha Müller; Alexandrovich, pl. 4, figs. 1, 2.

non 1992 Tetrapyle octacantha Müller; Haslett, fig. 1.a.

non 1992 Tetrapyle octacantha Müller; Ling, pl. 2, fig. 8.

non 1993 Tetrapyle octacantha Müller; Hull, pl. 3, fig. 2.

non 1993 Tetrapyle octacantha Müller; Matsuoka, fig. 3.4 .

non 1993 Tetrapyle octacantha Müller; Sharma and Singh, pl. 2, fig. 22.

non 1994 Tetrapyle octacantha Müller; Haslett, p. 132-133, pl. 2, fig. 4.

non 1994 Tetrapyle octacantha Müller; lijima, Takahashi, Ittekkot, and Nair, figs. 5.3, 5.4.

non 1994 Tetrapyle octacantha Müller; Kim, Park, and Park, pl. 2, fig. 5.

non 1994 Tetrapyle octacantha Müller; Sashida and Uematsu, fig. 3.12.

1995 Tetrapyle octacantha Müller; van de Paverd, p. 193, pl. 56, figs. 8, 11-13 (only).

non 1995 Tetrapyle octacantha Müller; van de Paverd, p. 193 , pl. 55 , figs. 11,12 , pl. 56 , figs. $1-7,9$, 10 (only).

non 1996 Tetrapyle octacantha Müller; Brathauer, pl. 2, fig. 2.

1996 Octopyle octospinosa Tan and Tchang; Chen and Tan, p. 194, pl. 21, fig. 7, pl. 45, figs. 10-12. 


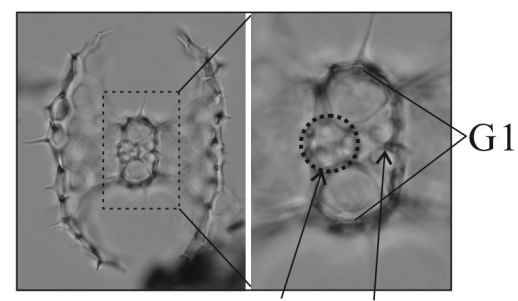

S1a S1a-girdle

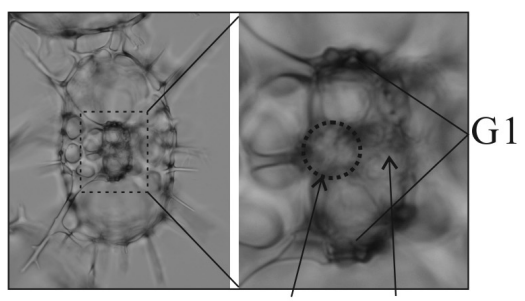

S1a S1a-girdle

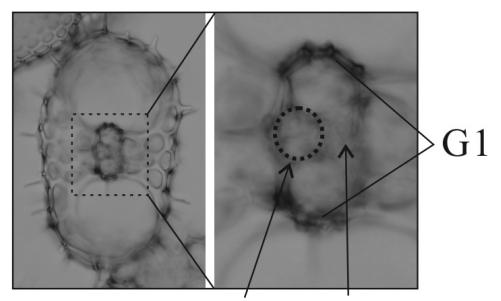

S1a S1a-girdle

1

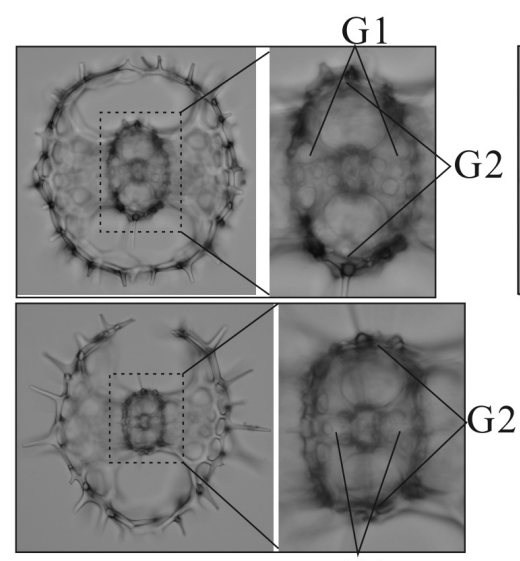

G1

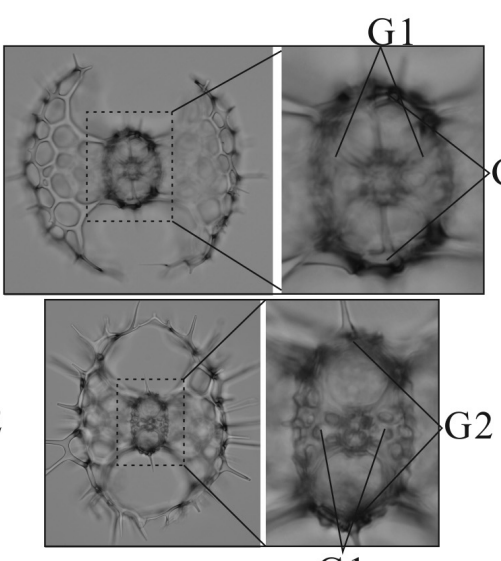

G1

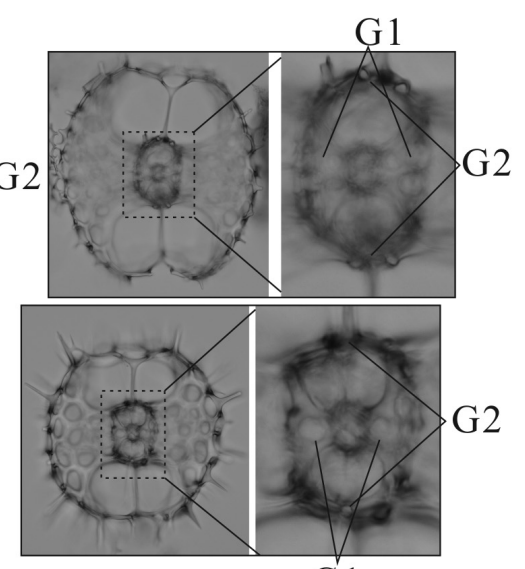

G1

2

S1aS1a-girdle
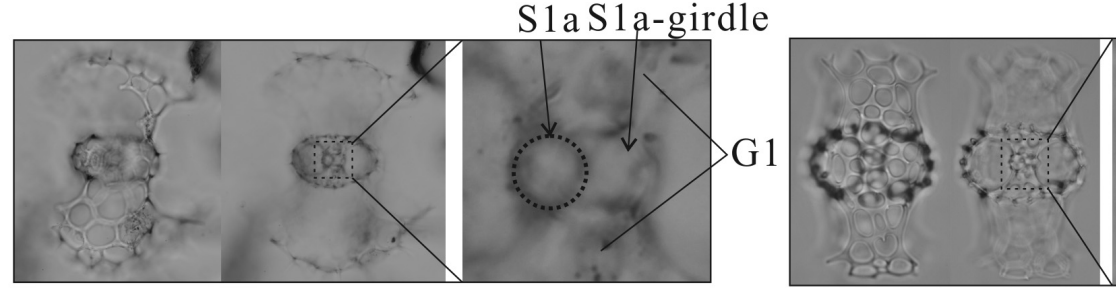

S1a S1a-girdle

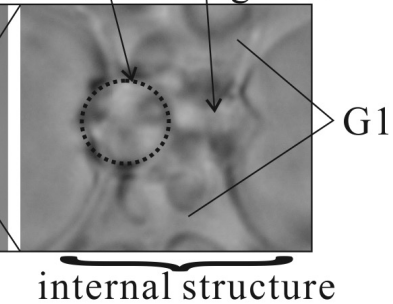

3

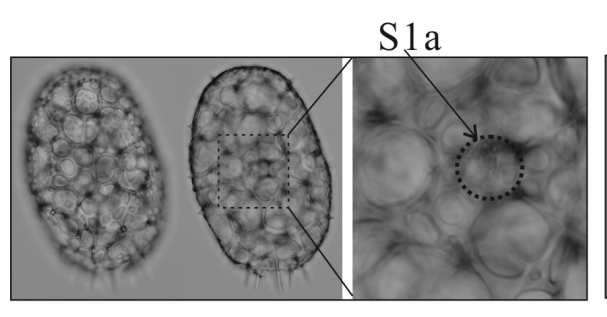

4

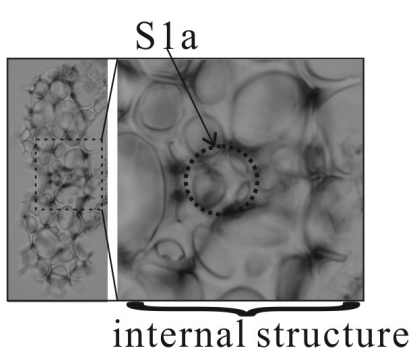

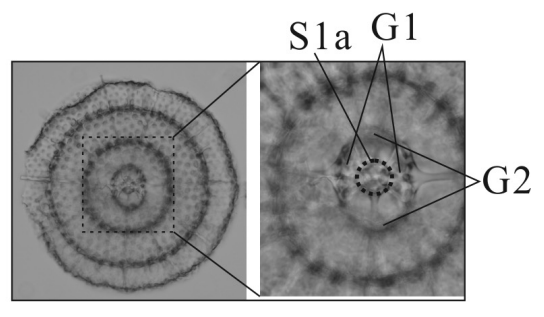

5

FIGURE 5. The structure of central combination in genera Tetrapyle (1-3), Larcopyle (4) and Circodiscus (5). 1, Sgview at Type 1, Fr-view at Type 2; 2, Pl-view at Type 1, Fr-view at Type 2; 3, Lt-view at Type 1, Pr-view at Type 2. G1, G2, S1a, and S1a-girdle are the morphological terminology, of which the definitions have been shown in Table 1. 
TABLE 4. The counting rules for pylonioids.

\begin{tabular}{|c|c|c|}
\hline Terms & Definition & Reference \\
\hline $\mathrm{Gn}[\mathrm{n}=1,2,3 \ldots]$ & $\begin{array}{l}\text { The distinguishing code of a gate in a pylonioid system }(\mathrm{Gn})[\mathrm{n}=1,2,3 \ldots] \text { : } \\
\mathrm{G} 1, \mathrm{G} 2 \text {, and } \mathrm{G} 3 \text { are coded from the inner gate to outer gate. }\end{array}$ & Definition herein \\
\hline$x \operatorname{ring}[x=1 s t, 2 n d, 3 r d . .]$. & $\begin{array}{l}\text { The distinguishing code of a ring in a Circodiscus system ( } x \text { ring) }[x=1 \mathrm{st} \text {, } \\
2 \text { nd, 3rd...]: 1st ring, } 2 \text { nd ring, and 3rd ring are coded from the inner ring to } \\
\text { outer ring. }\end{array}$ & Definition herein \\
\hline $\operatorname{Sn}[n=1,2,3 \ldots]$ & $\begin{array}{l}\text { The numbering system for the pylonioid system }(\mathrm{Sn})[\mathrm{n}=1,2,3 \ldots]: \text { From } \\
\text { the first system, systems are coded as } \mathrm{S} 1, \mathrm{~S} 2 \text {, and } \mathrm{S} 3 \ldots\end{array}$ & Dumitrica (1989) \\
\hline k-girdle $[k=a, b, c \ldots]$ & $\begin{array}{l}\text { The distinguishing code of a girdle in a pylonioid system (k-girdle) }[k=a, b \text {, } \\
c, d . . .] \text { : a-girdle, b-girdle, c-girdle, and d-girdle are coded from the inner (or } \\
\text { early developmental) girdle to outer (or later developmental) girdle in the } \\
\text { same system }\end{array}$ & Dumitrica (1989) \\
\hline Snk girdle & $\begin{array}{l}\text { The combination of } \mathrm{Sn} \text { and } \mathrm{k} \text {-girdle (Snk girdle): The code Snk-girdle is } \\
\text { defined as the } k(k=a, b, c . .) \text { girdle of } S n(n=1,2,3) . \text { For example, the } \\
\text { second girdle of the } 3 \text { rd system is coded as " } S_{3} b \text { girdle". The microsphere is } \\
\text { coded as " } S_{1} \text { a." }\end{array}$ & Dumitrica (1989) \\
\hline
\end{tabular}

1998 Pyloniid group. Danelian and Frydas, p. non 2006 140, pl. 3, fig. 14.

non 1998 Tetrapyle octacantha Müller; Shinjo, Motoyama, Nakamura, Takaki, Nishida, Morii, and Tanaka, pl. 1, fig. 7.

1998 Octopyle octospinosa Tan and Tchang; Tan, p. 258, text-fig. 244.

non 1999 Tetrapyle octacantha Müller; Molina-Cruz, Welling, and Caudillo-Bohorquez, pl. 1, figs. 1-3.

non 1999 Tetrapyle octacantha Müller; Sashida and Kurihara, p. 139, 141, figs. 8.1-5, 8.8-9, 8.11-12, 12.2, 12.15-17.

1999 Octopyle octospinosa Tan and Tchang; Tan and Chen, p. 247-248, text-fig. 5.158.

non 2001 Tetrapyle octacantha Müller; Itaki, pl. 2, fig. 5.

2001 Tetrapyle octacantha Müller; Matsuoka, Yoshida, Hasegawa, Shinzawa, Tamura, Sakumoto, Yabe, Niikawa, and Tateishi, pl. 1, fig. 2 (only).

non 2001 Tetrapyle octacantha Müller; Matsuoka, Yoshida, Hasegawa, Shinzawa, Tamura, Sakumoto, Yabe, Niikawa, and Tateishi, pl. 2, fig. 2 (only).

non 2002 Tetrapyle octacantha Müller; Cortese and Abelmann, pl. 2, fig. 24.

2002 Tetrapyle octacantha Müller; Matsuoka, Shinzawa, Yoshida, Machidori, Kurita, and Todo, pl. 2, fig. 4.

non 2003 Tetrapyle octacantha Müller; Itaki and Ikehara, fig. 4.g.

non 2003 Tetrapyle octacantha Müller; Itaki, Matsuoka, Yoshida, Machidori, Shinzawa, and Todo, pl. 1, figs. 17-22.

non 2005 Tetrapyle octacantha Müller; Motoyama and Nishimura, fig. 9.12-13. non 2006 Tetrapyle octacantha Müller; Kurihara, Shimotani, and Matsuoka, pl. 2, fig. 7.

non 2007 Tetrapyle octacantha Müller; Ishitani and Takahashi, pl. 2, figs. d-f.

2007 Tetrapyle octacantha Müller group; Itaki, Komatsu, and Motoyama, pl. 1, fig. 11 (only).

non 2007 Tetrapyle octacantha Müller group; Itaki, Komatsu, and Motoyama, pl. 1, figs. 6-10, 12 ?

non 2007 Tetrapyle octacantha Müller; Kurihara, Uchida, Shimotani, and Matsuoka, fig. 5.2.

non 2008 Tetrapyle octacantha Haeckel (wrong author's name); Itaki, Minoshima, and Kawahata, pl. 2, figs. 8, 9.

non 2008 Tetrapyle octacantha Müller; Kamikuri, Motoyama, and Nishimura, pl. 1, fig. 33.

non 2008 Tetrapyle octacantha Müller; Okazaki, Takahashi and Asahi, pl. 1, figs. 7-12.

non 2009 Tetrapyle octacantha Müller; Matsuoka, fig. 2.21.

2009 Tetrapyle octacantha Müller group; Itaki, pl. 10, figs. 1a-1b, 10a-10d (only).

non 2009 Tetrapyle octacantha Müller group; Itaki, pl. 10, figs. 2a-9d.

2009 Tetrapyle octacantha Müller; Sakai, Suzuki, Ogane, Lazarus, Breidbach, and Bach, p. 53, pl. 3, fig. 7 (topotype from Messina).

non 2009 Tetrapyle octacantha Müller; Sono, Suzuki, Yoshimura, Kano, and Takeda., pl. 1, fig. 16.

2009 Tetrapyle octacantha Müller; Zhang, Chen, Xiang, Zhang, Liu, Huang, and Lu, pl. 1, fig. f.

2009 Octopyle octospinosa Tan and Tchang; Zhang, Chen, Xiang, Zhang, Liu, Huang, and Lu, pl. 1, fig. q. 

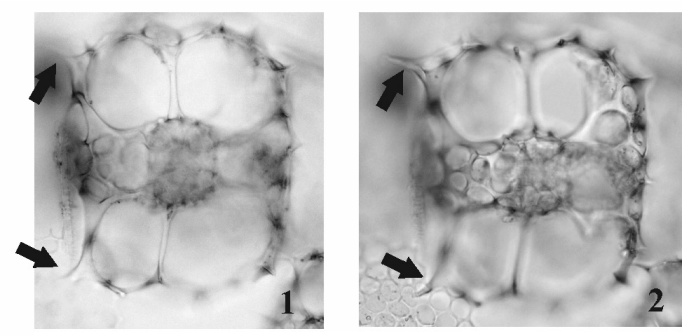

$1 . . .1 . . .+1$
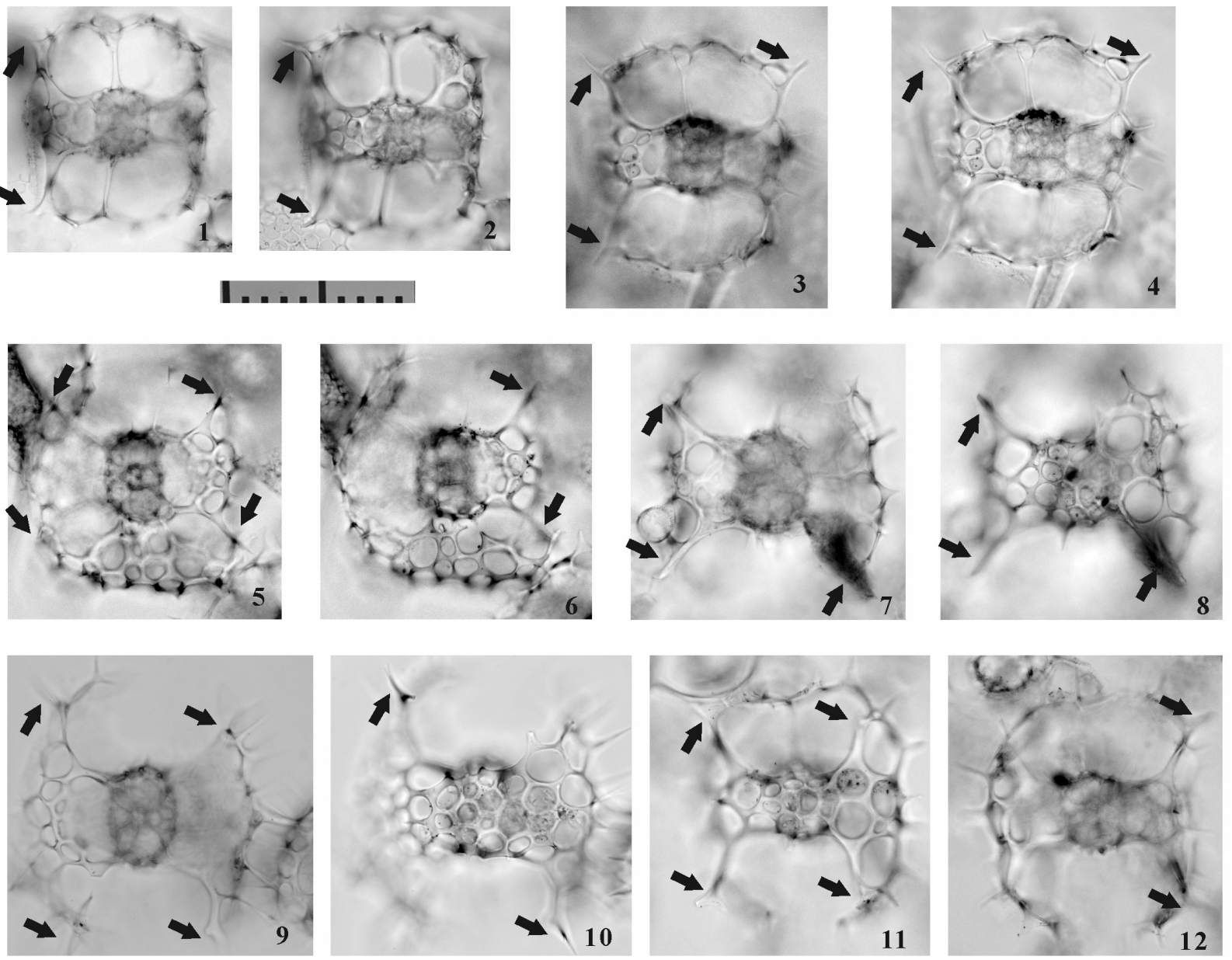

FIGURE 6. Photographs of the encountered morphotypes of Tetrapyle octacantha Müller 1859 sensu stricto. All are $\mathrm{Pl}$-view at Type 1, Fr-view at Type 2. Scale bar equals $0.1 \mathrm{~mm}$. The arrow marks indicate the major portal-spines. All specimens are from YDY05-01.

non 2010 Tetrapyle octacantha Müller group; Itaki, Kimoto, and Hasegawa, fig. 4.12.

non 2010 Tetrapyle octacantha Müller; Kurihara, and Matsuoka, fig. 2.12.

non 2010 Tetrapyle octacantha Müller; Suzuki and Kanie, pl. 9, fig. 15.

non 2011 Tetrapyle octacantha Müller; Pandey, p. 48, pl. 3, figs. K, L.

? 2012 Tetrapyle octacantha Müller; Kršinić and Kršinić, pl. 3, fig. 33.

non 2012b Tetrapyle octacantha Müller; Suzuki and Kanie, fig. 5.23a, b.

non 2014a Tetrapyle octacantha Müller group; Matsuzaki, Nishi, Hayashi, Suzuki, Ikehara, Gyawali, Tanaka, and Takashima, fig. 2.11, 2.12.

non 2014c Tetrapyle octacantha Müller group; Matsuzaki, Nishi, Suzuki, Kawate, Takashima, and Sakai, pl. 1, figs. 21, 22. non 2014d Tetrapyle octacantha Müller group; Matsuzaki, Nishi, Suzuki, Takashima, Kawate, and Sakai, pl. 2, figs. 1, 2.

non 2015a Tetrapyle octacantha Müller group; Matsuzaki, Suzuki, and Nishi, p. 34-35, fig. 6.1-6 (only).

2015a Tetrapyle octacantha Müller group; Matsuzaki, Suzuki, and Nishi, p. 34-35, fig. 6.7-8 (only).

non 2015b Tetrapyle octacantha Müller group; Matsuzaki, Suzuki, Nishi, Hayashi, Gyawali, Takashima, and Ikehara, fig. 7.8-12.

non 2016 Tetrapyle octacantha Müller group; Matsuzaki, Itaki, and Kimoto, fig. 8.5-7.

? 2016 Tetrapyle octacantha Müller group; Matsuzaki, Itaki ,and Kimoto, fig. 8.8 (only).

Description. The test is rounded quadrangular in shape in Fr-view (ratio of length to width: ca. 1.2) and comprises five girdles. Numerous fine spines are scattered on the surface of the outermost gir- 

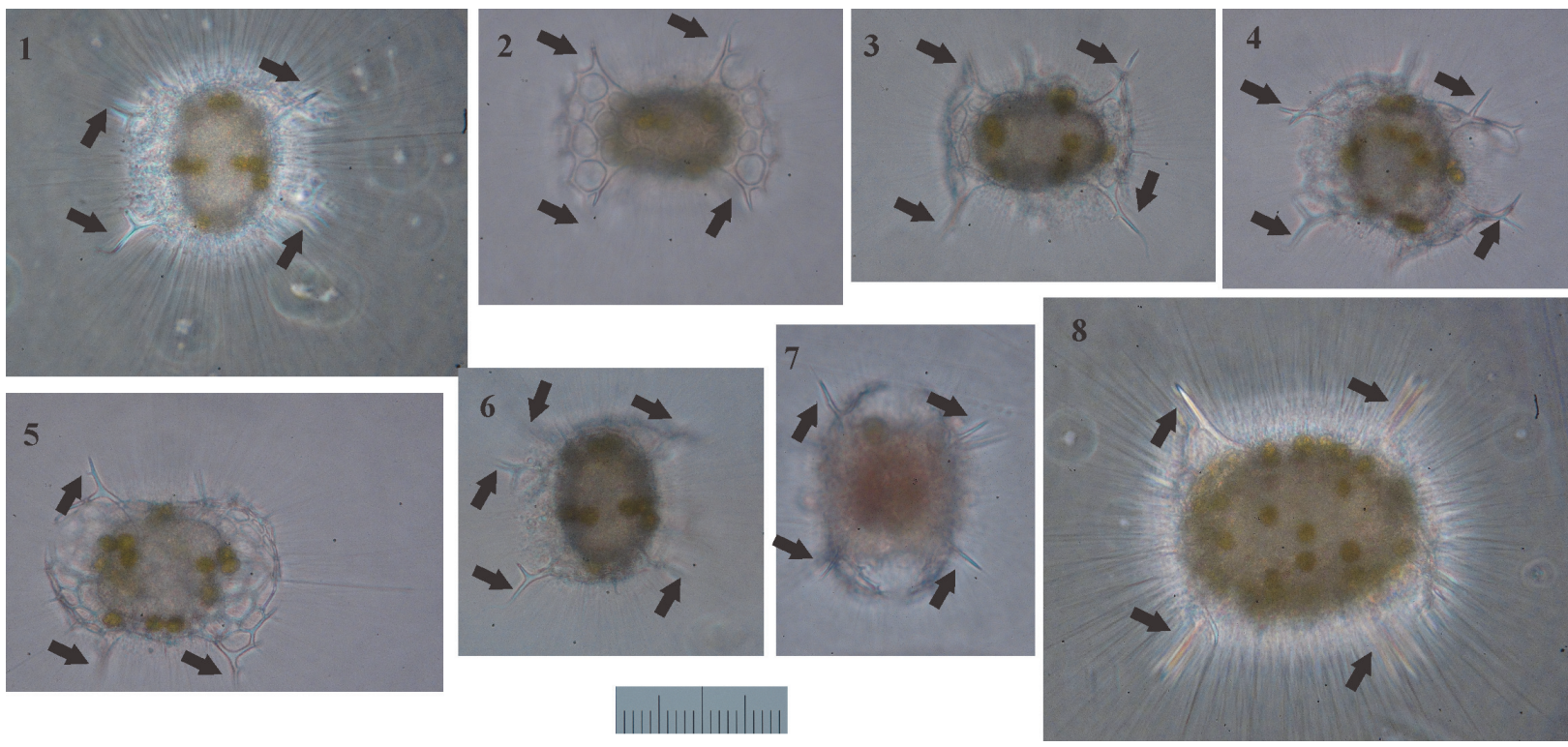

FIGURE 7. The typical Tetrapyle octacantha specimens from the surface water from the southern Villefranche-surMer. 1 and 6, Ug-view at Type 2; 2-3 and 8, Pr-view at Type 2; 4-7, Fr-view at Type 2. Scale bar equals $0.1 \mathrm{~mm}$. The arrow marks indicate the major portal-spines.

dle. Eight major portal-spines develop along the periphery of the outermost girdle during each ontogenetic stage. The twin gates within each girdle appear as elliptical or almost sub-triangular apertures (ratio of width to height: ca. 1.7-2.0) in Frview. Three to four roundish, and irregularly arranged pores are visible on each girdle in Prview.

Remarks. Topotypic material from Messina, the site of the specimens on which Haeckel's original slides were shown in Sakai et al. (2009, plate 3, figure 7), which shows major portal-spines. Because the type specimens illustrated by Müller (1859) have never been rediscovered, the specimen illustrated by Sakai et al. (2009) is a practical referential specimen to represent this species. We identified numerous typical Tetrapyle octacantha specimens with eight major portal-spines from the surface water south of Villefranche-sur-Mer $\left(43^{\circ} 36^{\prime} \mathrm{N}, 7^{\circ} 20^{\prime} \mathrm{E}\right), 900 \mathrm{~km}$ northwest of Messina $\left(38^{\circ} \mathrm{N}, 15^{\circ} 30^{\prime} \mathrm{E}\right)$ in the Mediterranean Sea (Figure 7). Because no Tetrapyle specimens without portal-spines were found in samples from Villefranchesur-Mer, the presence of portal-spines is an important distinguishing feature of Tetrapyle species. Subsequently, the species name $T$. octacantha is strictly applied to those with eight major portal spines. As shown in the synonym list, T. octacantha may be easily confused with Tetrapyle circularis and Tetrapyle fruticosa. Tetrapyle circularis can be distinguished from $T$. octacantha based on the former's circular girdles in Fr-view and lack of the eight portal-spines. Tetrapyle octacantha also differs from $T$. fruticosa, because the latter shows quadrangular girdles in $\mathrm{Fr}$-view and lacks the eight long portal-spines along the periphery of its outermost girdle. Several Japanese workers (Itaki, 2009; Matsuzaki et al., 2015a; Motoyama et al., 2016) grouped together Tetrapyle and "Octopyle" species as the "Tetrapyle octacantha Müller group" because of the practical difficulties in identification when a large number of samples must be examined in a short time. This grouping may be convenient in temperate and colder regions such as the Sea of Japan (Itaki, 2003, 2009; Motoyama et al., 2016) and the Northwest Pacific (Matsuzaki et al., 2016) because the number of these taxa is abundant or rare in middle-high latitude regions. However, members of the "Tetrapyle octacantha group" are dominant in subtropical to tropical regions like the South China Sea (Tan and Chen, 1990; Zhang et al., 2009; Hu et al., 2015) and Indian Sea (this study), and should therefore be identified to the species level.

\section{Tetrapyle circularis Haeckel, 1887}

Figures 8, 9

1887 Tetrapyle circularis Haeckel, p. 645, pl. 9, fig. 8.

1912 Spironium cochelarium Popofsky, p. 153, text-fig. 74.

1972b Tetrapyle octacantha Müller; Ling, p. 168, pl. 2 , fig. 3. 

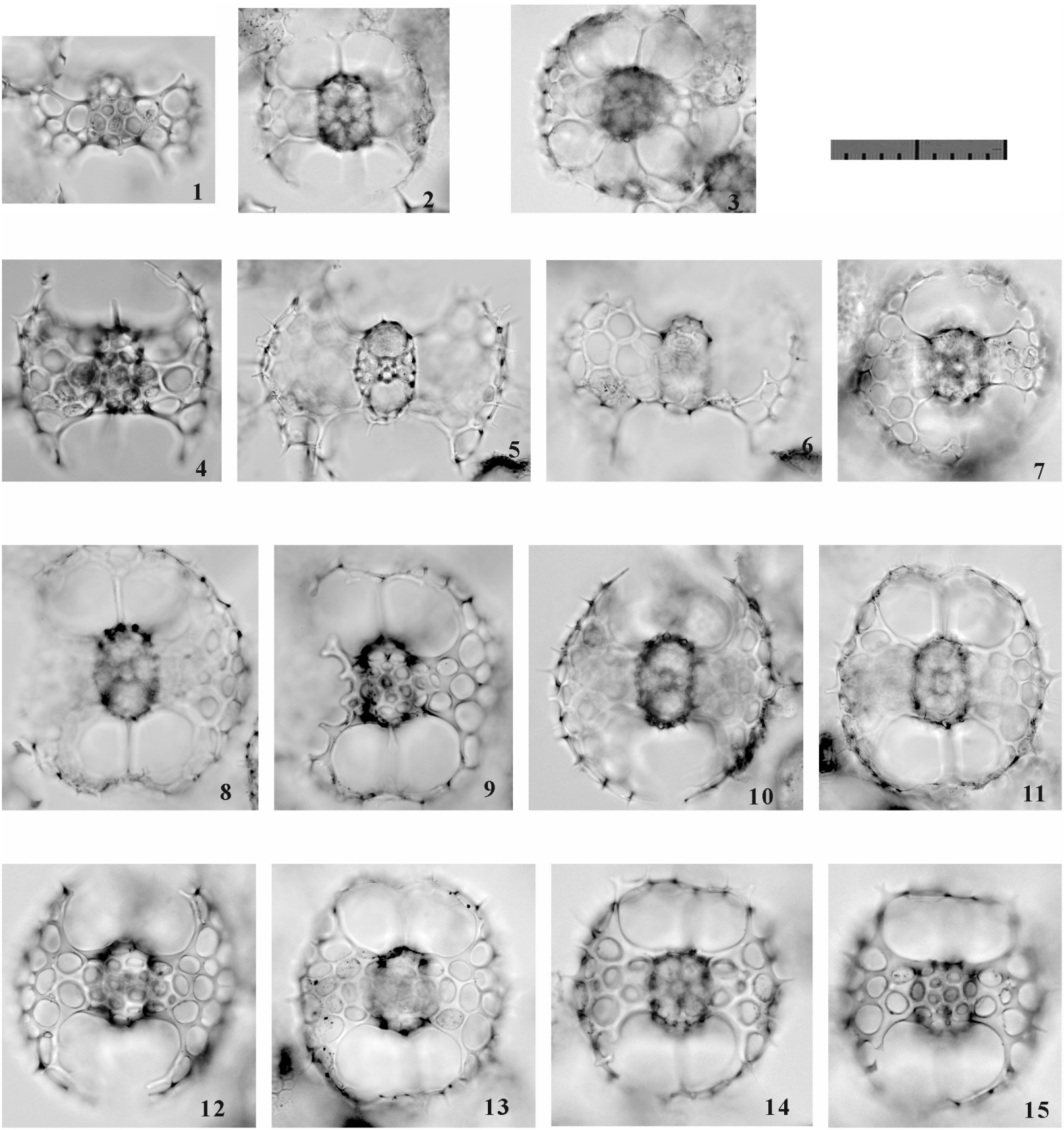

FIGURE 8. Photographs of the encountered morphotypes of Tetrapyle circularis Haeckel, 1887. All are Pl-view at Type 1, Fr-view at Type 2. Scale bar equals $0.1 \mathrm{~mm}$. All specimens are from YDY05-01.

1977

Tetrapyle sp. cf. T. octacantha Müller; Kling, pl. 1, fig. 14.

1980 Tetrapyle octacantha Müller; Boltovskoy and Riedel, p. 120, pl. 4, fig. 11.

1981 Tetrapyle octacantha Müller; Takahashi and Honjo, p. 150, pl. 6, fig. 6 (only).

1982 Tetrapyle octacantha Müller; Poluzzi, p. 59, pl. 9, figs. 3, 6, 10 (only).

1984 Tetrapyle octacantha Müller; Nigrini and Lombari, p. S87-88, pl. 12, figs. 3a, b.
$1984 a$

$1984 b$

1985

? 1984b

1986
Octopyle stenozona Haeckel; Nishimura and Yamauchi, pl. 3, fig. 13.

Tetrapyle octacantha Müller; Nishimura and Yamauchi, p. 42, pl. 17, figs. 7, 12.

Octopyle stenozona Haeckel; Boltovskoy and Jankilevich, pl. 3, fig. 22.

Tetrapyle octacantha Müller; Nishimura and Yamauchi, pl. 43, fig. 13.

Tetrapyle octacantha Müller; Yamauchi, pl. 4, fig. 13. 

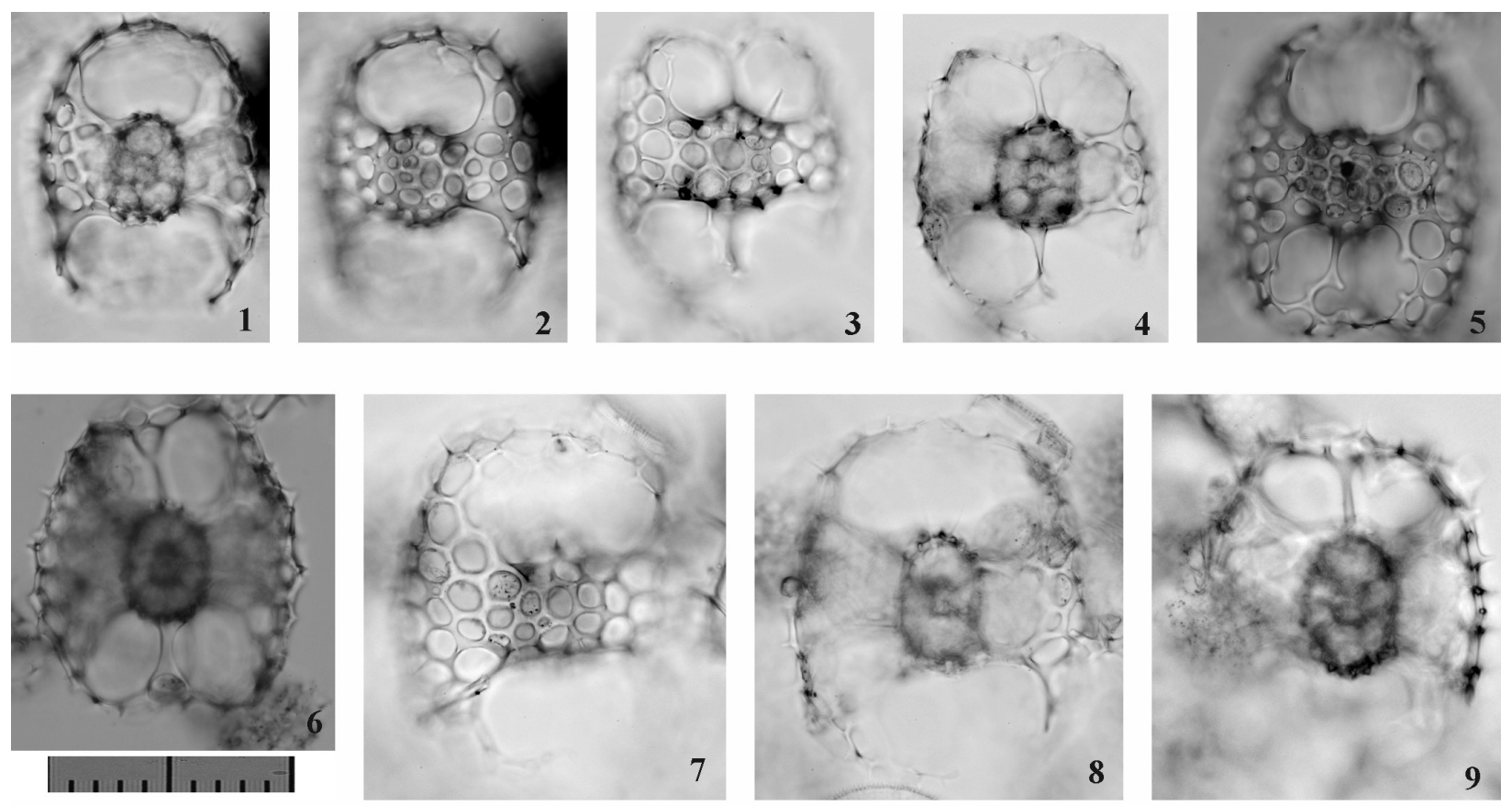

FIGURE 9. Photographs of the encountered morphotypes of Tetrapyle circularis Haeckel, 1887. All are PI-view at Type 1, Fr-view at Type 2. Scale bar equals $0.1 \mathrm{~mm}$. All specimens are from YDY05-01.

1990

Octopyle stenozona Haeckel; Blueford, Gonzales, and Scoy, pl. 1, fig. 7.

sensu emend.

1990 Tetrapyle circularis Haeckel; Tan and Chen, p. 113-114, text-fig. 4, pl. 2, figs. 1-3.

1990 Octopyle circinata Tan and Chen, p. 118, text-fig. 10.

1990 Tetrapyle circularis Haeckel; Yeh and Chen, pl. 3, fig. 10.

1991 Tetrapyle octacantha Müller; Takahashi, $p$. 90, pl. 23, fig. 10.

1992 Tetrapyle octacantha Müller; Alexandrovich, pl. 4, fig. 2.

? 1992 Tetrapyle octacantha Müller; Haslett, fig. 1.a.

1993 Octopyle stenozona Haeckel; Sharma and Singh, pl. 2, fig. 19.

1994 Octopyle stenozona Haeckel; Haslett, p. 132, pl. 5 , fig. 3 (only).

1994 Pyloniid, gen. et sp. Kim and Kim, pl. 1, fig. 14.

1994 Tetrapyle octacantha Müller; lijima, Takahashi, Ittekkot, and Nair, fig. 5.4 (only).

1994 Tetrapyle octacantha Müller; Kim, Park, and Park, pl. 2, fig. 5.

1995 Tetrapyle octacantha Müller; van de Paverd, p. 193-194, pl. 56, figs. 1, 4, 7.

1996 Tetrapyle circularis Haeckel; Chen and Tan, p. 193-194.
1996

1998

1998

1998

1999

1999

2001

2003

2005

2007

2007

2008
Octopyle circinata Tan and Chen; Chen and Tan, p. 194, pl. 21, figs. 9, 10.

Pyloniid group. Danelian and Frydas, $p$. 140, pl. 1, fig. 7.

Tetrapyle octacantha Müller; Shinjo, Motoyama, Nakamura, Takaki, Nishida, Morii, and Tanaka, pl. 1, fig. 7.

Tetrapyle circularis Haeckel; Tan, p. 253254, text-fig. 238.

Tetrapyle octacantha Müller; Molina-Cruz, Welling, and Caudillo-Bohorquez, pl. 1, figs. $1,2$.

Tetrapyle octacantha Müller; Sashida, and Kurihara, p. 139,141 , figs. $8.3,8.4$ ?, 8.11, 8.12?

Tetrapyle octacantha Müller; Matsuoka, Yoshida, Hasegawa, Shinzawa, Tamura, Sakumoto, Yabe, Niikawa, and Tateishi, pl. 2, fig. 2 (only).

Octopyle stenozona Haeckel; Itaki and Ikehara, fig. 4.h.

Tetrapyle octacantha Müller; Motoyama, and Nishimura, fig. 9.12 (only).

Tetrapyle octacantha Müller group; Itaki, Komatsu, and Motoyama, pl. 1, figs. 8-10 (only).

Tetrapyle octacantha Müller; Kurihara , Uchida, Shimotani, and Matsuoka, fig. 5.2.

Tetrapyle octacantha Haeckel (wrong author's name); Itaki, Minoshima, and Kawahata, pl. 2, fig. 9 (only). 
2008 Tetrapyle octacantha Müller; Kamikuri, Motoyama, and Nishimura, pl. 1, fig. 33.

2008 Tetrapyle octacantha Müller; Okazaki, Takahashi, and Asahi, pl. 1, figs. 11-12

2009 Tetrapyle octacantha Müller group; Itaki, pl. 10 , figs. $2 a-c, 6,8$.

2009b Schizomma quadrilobum Ehrenberg; Suzuki, Ogane, Aita, Sakai, and Lazarus, pl. 70, figs. 6a-7d (type specimen in the Ehrenberg collection).

2010 Tetrapyle circularis Haeckel; Suzuki, and Kanie, pl. 9, fig. 15.

2011 Octopyle stenozona Haeckel; Pandey, p. 44 , pl. 2, fig. $\mathrm{H}$.

2014c Tetrapyle octacantha Müller; Matsuzaki, Nishi, Suzuki, Kawate, Takashima, and Sakai, pl. 1, fig. 21.

2015a Tetrapyle octacantha Müller group; Matsuzaki, Suzuki, and Nishi, p. 34-35, figs. 6.1, 6.3, 6.5.

2015b Tetrapyle octacantha Müller group; Matsuzaki, Suzuki, Nishi, Hayashi, Gyawali, Takashima, and Ikehara, figs. 7.8, 7.11, 7.12 .

Description. The test is circular in Fr-view (ratio of length to width: ca. 1.0-1.3) and comprises the pyloniid central combination and five girdles. Some fine and short spines are scattered across the ourtermost girdle surface. The polar beams are not always connected to the outermost girdle. The twin gates of the S3a-girdle (G4 girdle) appear kidneyshaped (ratio of width to height: ca. 1.4-2.0) in Frview. Two to three roundish and relatively large pores are visible from Pr-view for each girdle.

Remarks. Tetrapyle circularis is characterized by a curved outline on both its joint and cap components; this curved outline is an important feature for distinguishing this taxon from other Tetrapyle species. Tetrapyle circularis was previously regarded as Tetrapyle octacantha or "Schizomma quadriloba." The taxon name "Schizomma quadriloba" has been used to refer to any kidney-shaped pyloniids without portal-spines, but the lectotype of this species from the Ehrenberg collection illustrated by Suzuki et al. (2009b) consists of only a central combination and G1 and G2 girdles; thus, T. circularis is fully differentiated from "Schizomma quadriloba." This species apparently represents a juvenile form of pylonioids. Tetrapyle circularis is easily distinguished from $T$. octacantha based on the four long portal-spines of the latter along the periphery of its outermost girdle. Tetrapyle circularis is differentiated from Tetrapyle fruticosa based on the straighter outline on both joint and cap com- ponents in the latter. The oldest record of a probable $T$. circularis is from the lower Pliocene Ikego Formation of the Miura Group, Kanto, Japan (Suzuki and Kanie, 2010), but this specimen differs slightly from typical $T$. circularis from the modern ocean in that the former's outermost girdle is more elongate. The "Tetrapyle octacantha" specimens from the Southern Ocean (Brathauer, 1996, plate 2, figure 2) and the Southwest Pacific (Cortese and Abelmann, 2002, plate 2, figure 24) are similar to $T$. circularis with a rounded outermost girdle on Frview; however, the former differs from the latter in its notably spiny appearance and more spherical pseudo-concentric shells in its inner side. "Spironium cochearium Popofsky, 1912" seemed to be differentiated from $T$. circularis by its more elongated outline. However, we measured the ratio of the test between probable "S. cochelarium" and $T$. octacantha, concluding in the same species due to their gradual changes.

Tetrapyle fruticosa (Tan and Chen, 1990) new combination

Figure 10

? 1887 Tetrapyle (Tetrapylissa) nephropyle Haeckel, p. 645.

1976 Tetrapyle nephropyle Haeckel; Tan and Tchang, p. 260, text-fig. 29.

1984b Tetrapyle sp. aff. T. octacantha Müller; Nishimura, and Yamauchi, p. 42, pl. 17, fig. 4.

1984b Tetrapyle octacantha Müller; Nishimura and Yamauchi, p. 42, pl. 17, fig. 14.

1990 Octopyle stenozona Haeckel; Fujioka, pl. 42, fig. 4.

*1990 Octopyle fruticosa Tan and Chen, p. 120, text-fig. 13.

1990 Octopyle stenozona Haeckel; Yeh and Cheng, pl. 3, fig. 9.

1992 Octopyle stenozona Haeckel; Haslett, fig. 1.b.

1994 Octopyle stenozona Haeckel; Haslett, pl. 2, fig. 3.

1996 Octopyle quadrata Haeckel; Chen and Tan, p. 194 , pl. 21 , fig. 8 .

2009 Tetrapyle octacantha Müller group; Itaki, pl. 10, figs. $7,9$.

2009 Phorticium pylonium Haeckel; Sono, Suzuki, Yoshimura, Kano, and Takeda, pl. 1, fig. 23a-b.

2014a Tetrapyle octacantha Müller group; Matsuzaki, Nishi, Hayashi, Suzuki, Ikehara, Gyawali, Tanaka, and Takashima, fig. 2.1112. 


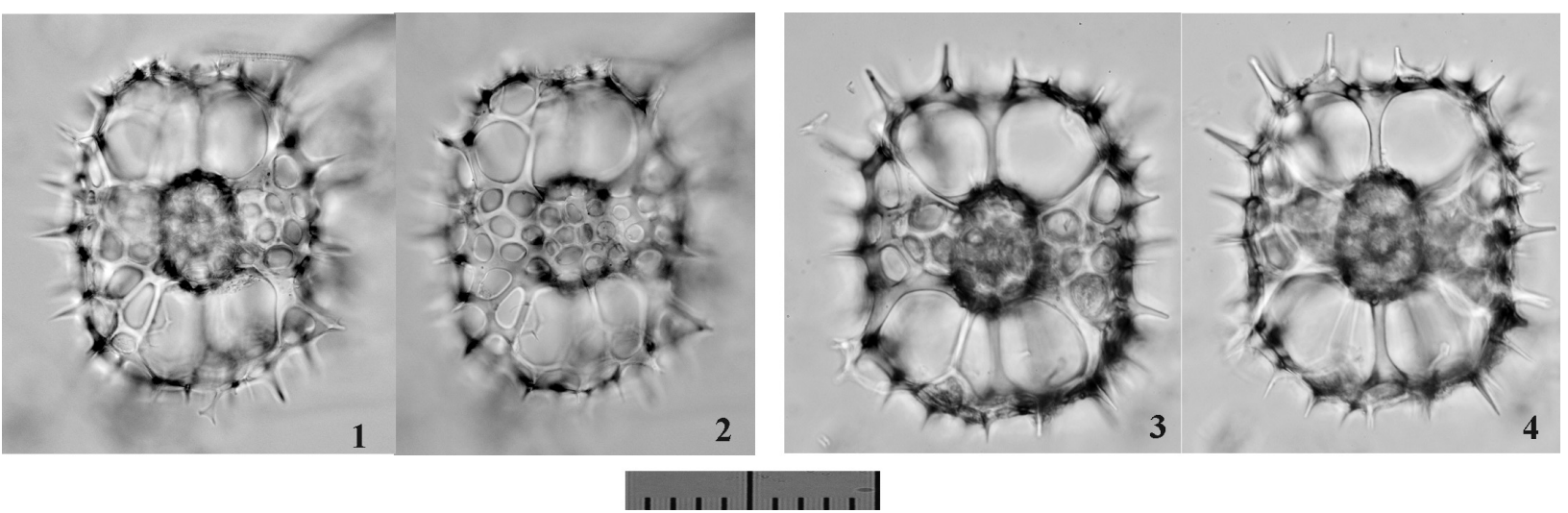

FIGURE 10. Photographs of the encountered morphotypes of Tetrapyle fruticosa (Tan and Chen, 1990) new combination. All are PI-view at Type 1, Fr-view at Type 2. Scale bar equals $0.1 \mathrm{~mm}$. All specimens are from YDY05-01.

2014c Tetrapyle octacantha Müller; Matsuzaki, Nishi, Suzuki, Kawate, Takashima, and Sakai, pl. 1, fig. 22.

2014d Tetrapyle octacantha Müller group; Matsuzaki, Nishi, Suzuki, Takashima, Kawate, and Sakai, pl. 2, figs. 1-2.

2015a Tetrapyle octacantha Müller group; Matsuzaki, Suzuki, and Nishi, p. 34-35, figs. 6.4, 6.6.

2016

Tetrapyle octacantha Müller group; Matsuzaki, Itaki, and Kimoto, fig. 8.5-8.

Description. Test comprises a pyloniid central combination and four to five girdles. The girdles appear quadrangular-shaped in Fr-view (ratio of length to width: ca. 0.8-1.3) with or without polar beams at the outermost gate. Fine and short spines are scattered over the outermost girdle test surface. The twin gates of the girdles show quadrangular apertures (ratio of width to height: ca. 2.02.4) in Fr-view. Three to four roundish to irregularly shaped pores occur on the side of a girdle.

Remarks. Tetrapyle fruticosa is easily distinguished from $T$. octacantha based on the former's lack of main portal-spines, and from $T$. circularis based on the latter's circular shape in Fr-view.

Tetrapyle spp. (juvenile form)

Figure 11

nomen nudum

1861a Schizomma quadrilobum Ehrenberg, p. 769.

1873 Schizomma quadrilobum Ehrenberg, pl. 10, figs. 12-14.

1862 Tetrapyle quadriloba (Ehrenberg); Haeckel, p. 436.

1953 Tetrapyle quadriloba (Ehrenberg); Riedel, p. 809-810.

non 1912 Tetrapyle quadriloba (Ehrenberg); Popofsky, p. 150-151.
1937

1979

1981

1982

$1984 a$

1985

1985

1987

1990

non 1990

1992

1993

1994

1994

1994

1998

1999

2003
Trizonium constrictum Haeckel; Sugano, p. 72, fig. 37.1-3.

Tetrapyle octacantha Müller; Kling, p. 311, pl. 1, fig. 13.

Tetrapyle octacantha Müller; Takahashi and Honjo, p. 150, pl. 6, fig. 5 (only).

Tetrapyle octacantha Müller; Molina-Cruz, p. 995, pl. 2, figs. 10-11.

Tetrapyle octacantha Müller; Nishimura and Yamauchi, pl. 1, fig. 11.

Tetrapyle octacantha Müller; Boltovskoy and Jankilevich, pl. 3, fig. 26.

Tetrapyle sp. Cachon and Cachon, p. 290, fig. 47.

Tetrapyle octacantha Müller; Dworetzky and Morley, pl. 2, fig. 1.

Tetrapyle octacantha Müller; Fujioka, pl. 42, fig. 6.

Tetrapyle quadriloba (Ehrenberg); Tan and Chen, p. 114, text-fig. 5.

Tetrapyle octacantha Müller; Gupta and Srinivasan, pl. 2, fig. 16.

Tetrapyle octacantha Müller; Matsuoka, fig. 3.4.

Tetrapyle octacantha Müller; Haslett, p. 132-133; pl. 2, fig. 4.

Tetrapyle octacantha Müller; lijima, Takahashi, Ittekkot, and Nair, fig. 5.5 (only).

Pyloniid. gen. et sp. indet. Kim and Kim, pl. 1, fig. 6.

Tetrapyle octacantha Müller; Sharma and Sharma, pl. 2, fig. 2.

Tetrapyle octacantha Müller; Sashida and Kurihara, p. 139,141 , figs. 8.1, 8.8, 12.2, 12.17 (only).

Tetrapyle octacantha Müller; Itaki, Matsuoka, Yoshida, Machidori, Shinzawa, and Todo, pl. 1, figs. 17-22. 

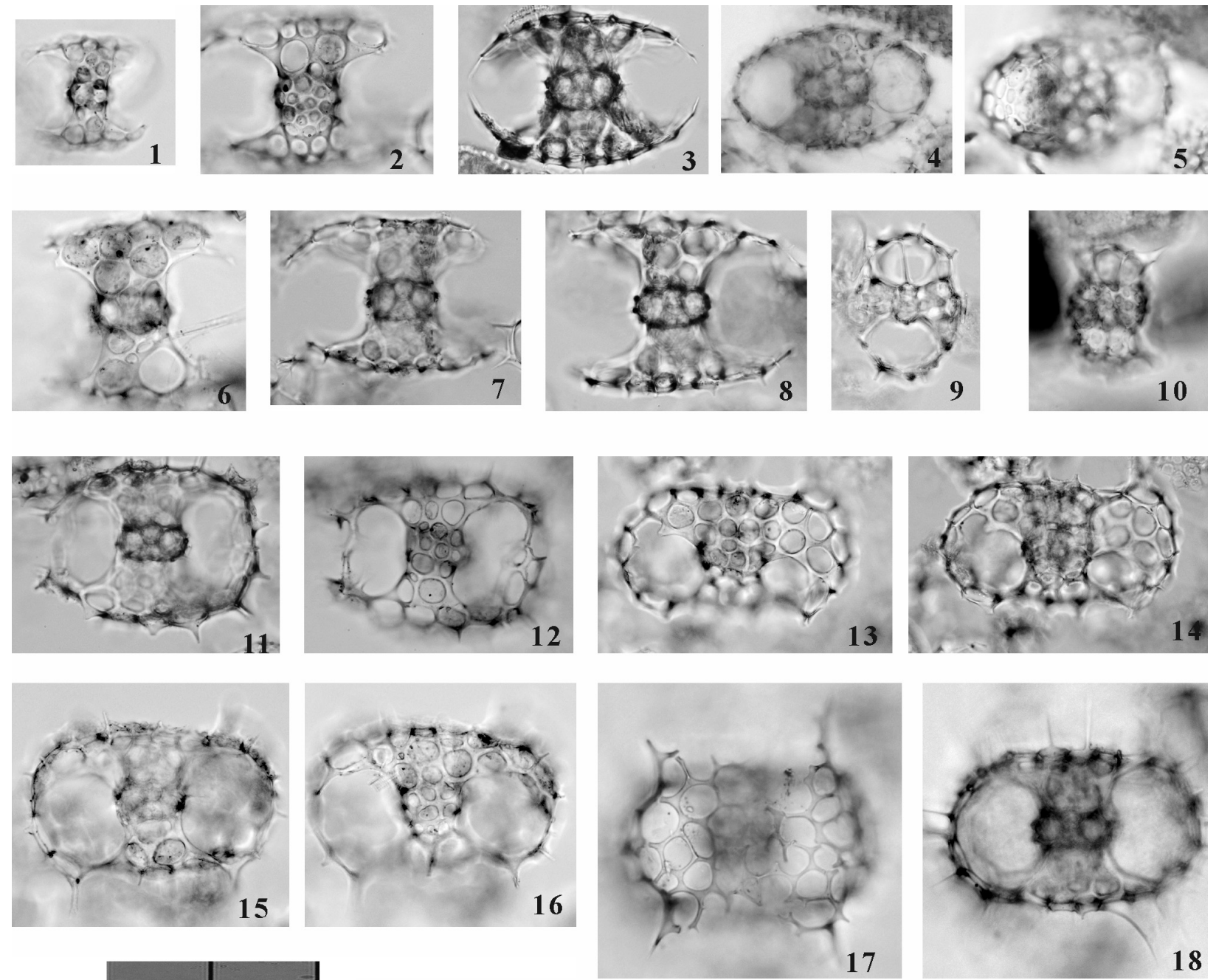

FIGURE 11. Photographs of the encountered morphotypes of Tetrapyle spp. (juvenile form). 1-2 and 9, Lt-view at Type 1, Fr-view at Type 2; 3-5, 7-8, 11-12, Sg-view at Type 1, Fr-view at Type 2; 6 and 10, PI-view at Type 1, Fr-view at Type 2; 13-14, Pl-view at Type 1, Ug-view at Type 2; 15-16, Sg-view at Type 1, Fr-view at Type 2; 17-18, Sg-view at Type 1, Ug-view at Type 2. Scale bar equals $0.1 \mathrm{~mm}$. All specimens are from YDY05-01.

2005

2006

2007

2008

non 2009 Tetrapyle quadriloba (Ehrenberg); Zhang,
Chen, Xiang, Zhang, Liu, Huang, and Lu, pl.

Tetrapyle octacantha Müller; Motoyama and Nishimura, fig. 9.12 (only).

Tetrapyle octacantha Müller; Kurihara, Shimotani, and Matsuoka, pl. 2, fig. 7.

Tetrapyle octacantha Müller; Ishitani and Takahashi, pl.2, figs. d-f.

Tetrapyle octacantha Müller; Okazaki, Takahashi, and Asahi, pl. 1, figs. 7-8 (only). 1, fig. a.

2010 Tetrapyle octacantha Müller; Kurihara, and Matsuoka, fig. 2.12.

1996 Tetrapyle sp. 1. Brathauer, pl. 2, fig. 3.
2007 Tetrapyle octacantha Müller group; Itaki, Komatsu, and Motoyama, pl. 1, figs. 6-7 (only).

2009 Tetrapyle octacantha Müller group; Itaki, pl. 10, figs. 3a-d, 5a-b (only).

2009b Schizomma sp. Suzuki, Ogane, Aita, Sakai, and Lazarus, pl. 58, figs. 12a-b (the Ehrenberg collection).

2009b Schizomma quadrilobum Ehrenberg; Suzuki, Ogane, Aita, Sakai, and Lazarus, pl. 70, figs. 5a-c (only), (type specimen in the Ehrenberg collection).

non 2009b Schizomma quadrilobum Ehrenberg; Suzuki, Ogane, Aita, Sakai, and Lazarus, pl. 70, figs. 6a-7d (type specimen in the Ehrenberg collection). 
2010 Tetrapyle octacantha Müller group; Itaki, Kimoto, and Hasegawa, fig. 4.12.

2015a Tetrapyle octacantha Müller group; Matsuzaki, Suzuki, and Nishi, p. 34-35, figs. 6.2 (only).

2015b Tetrapyle octacantha Müller group; Matsuzaki, Suzuki, Nishi, Hayashi, Gyawali, Takashima, and Ikehara, figs. 7.9, 7.10 (only).

Remarks. Tetrapyle spp. (juvenile form) herein includes the "Schizomma quadrilobum" in the type slides (See Suzuki et al., 2009b, plate 70, figure $5 a-e)$. This specimen of the Ehrenberg collection is small, less than $100 \mu \mathrm{m}$ in width, and comprises a central combination and G1 to G3 girdles. This lower number of girdles is interpreted as indicative of a juvenile Tetrapyle form. Such juvenile forms are generally abundant in subtropical to tropical oceans; therefore, these forms must be counted for paleoceanographic/oceanographic studies. As illustrated by Itaki (2009), the same specimen identifiable as "Schizomma quadrilobum" has a notably different appearance under Type 2 coordinates. Such specimens are particularly challenging to classify taxonomically. In practice, it is unproductive to separate them at the species level for oceanographic studies; therefore, they are regarded as Tetrapyle spp. (juvenile form). These specimens may tentatively be called "Tetrapyle quadrilobum", but we chose not to utilize this taxon name because these specimens may in fact represent a juvenile form of another species.

Genus LARCOSPIRA Haeckel, 1887

*1887 Larcospira Haeckel, p. 695-696.

2001 Larcospira Haeckel; De Wever, Dumitrica, Caulet, Nigrini, and Caridroit, fig. 88.5, 88.6.

Type species. Larcospira (Larcospirema) quadrangular Haeckel (SD by Campbell, 1954).

Description. Test is flat and either spindle-shaped or rounded quadrangular in shape, and has spiral spindle-shaped girdles along a single long axis. This axis is equivalent to the Lt-axis under Type 1 coordinates. The central part consists of a pyloniid central combination and $\mathrm{G} 1$ girdle, which form the first pseudo-concentric shell. The Lt-axis of the central combination is equivalent to the revolving axis of the test and parallel to the longest axis of the test. Because there are no twin gates, the Frview cannot be separated from the Pr-view. The S1a-girdle encircles the central combination along the Lt-axis (Fig. 11.6, 7). The S1a-girdle are ellipsoid in shape, and the Ug-axis under Type 2 coordinates is parallel to the long axis of the test (see Sugiyama et al., 1992, plate 9, figures $2 \mathrm{~b}$ and 4c;
De Wever et al., 2001, figure 88.5). The girdles coil to form the 2nd and 3rd pseudo-concentric shells. The previous girdles are attached at both ends of the Lt-axis with the successive girdles. Several pillar beams emerge vertically from the 1st pseudoconcentric shell, extending to but not penetrating the 3rd one.

Remarks. Despite detailed examination of the internal structure of the genus Larcospira (e.g., Sugiyama et al., 1992), formally updating its description has been suspended. It may be essential to examine the internal structure to determine whether a species belongs to the genus Larcospira, but Larcospira species can be determined without examining the internal structure. Larcospira is easily distinguished from Tetrapyle based on its coiled girdles without gates. The known ancestor species of Larcospira, Larcospira moschkovskii Kruglikova, 1978, is characterized by very tight coils, the same numbers of pseudo-concentric shells and a lack of radial spines, which suggests that Larcospira specimens may be distinguished from each other at the species level based on the shapes of their central parts, the numbers of revolving spiral girdles, the tightness of revolution, and the roughness of the outermost girdles in relation to pillar beams.

Larcospira quadrangula Haeckel, 1887 sensu stricto

\section{Figure 12}

1887 Larcospira (Larcospirema) quadrangula Haeckel, p. 696, pl. 49, fig. 3.

non 1970 Larcospira quadrangula Haeckel; Nigrini, p. 169, pl. 2, fig. 9.

1971 Larcospira quadrangula Haeckel; Casey, pl. 23.3, fig. 8.

1972 Larcospira quadrangula Haeckel; Ling, p. 168, pl. 2, fig. 4.

1976 Larcospira quadrangula Haeckel; Renz, 1976, p. 90, pl. 1, fig. 12.

non 1976 Larcospira quadrangula Haeckel; Tan and Tchang, p. 264-265, text-fig. 36.

non 1977 Larcospira quadrangula Haeckel; Kling, p. 217, pl. 2, fig. 18.

non 1978 Larcospyra quadrangula Haeckel (wrong spelling for the genus name); McMillen and Casey, pl. 3, fig. 18.

aff. 1978 Pyloniidae gen. et spp. indet. Riedel and Sanfilippo, pl. 3, fig. 19 (only).

? 1979 Larcospira quadrangula Haeckel; Kling, p. 309, pl. 1, fig. 14.

non 1979 Larcospira quadrangula Haeckel; Nigrini and Moore, S133-134, pl. 17, fig. 2. 

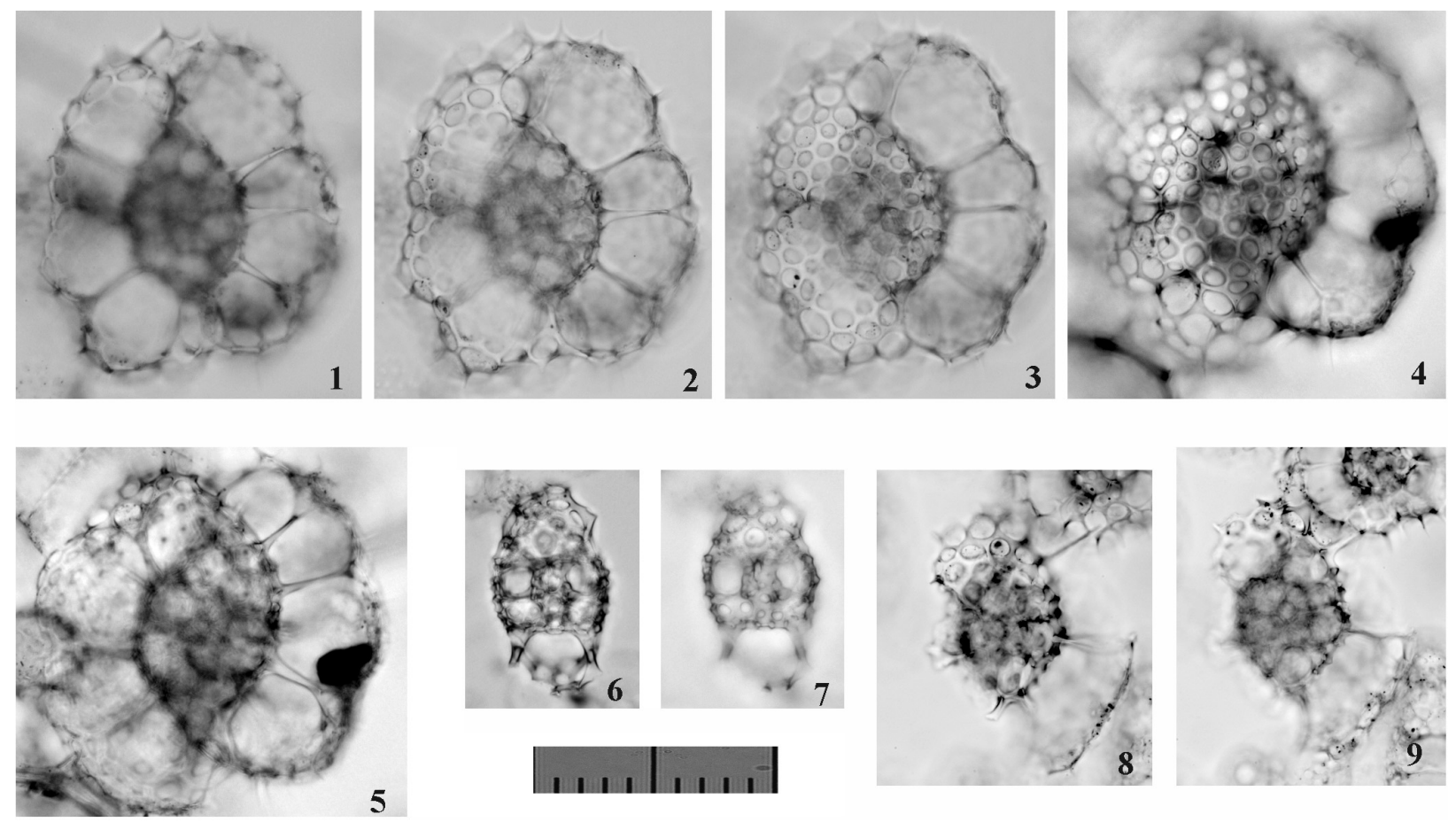

FIGURE 12. Photographs of the encountered morphotypes of Larcospira quadrangula Haeckel, 1887 sensu stricto. All are PI-view at Type 1. Scale bar equals $0.1 \mathrm{~mm}$. All specimens are from YDY05-01.

non 1980 Larcospira quadrangula Haeckel; Johnson and Nigrini, p. 127, text-fig. 9a, pl. 2, fig. 15.

non 1981 Larcospira quadrangula Haeckel; Takahashi and Honjo, p. 150, pl. 6, fig. 2.

1984 Larcospira quadrangula Haeckel; Nigrini and Lombari, p. S93-94, pl. 13, fig. 3a-c.

non 1984b Larcospira quadrangula Haeckel; Nishimura and Yamauchi, p. 41, pl. 17, fig. 11, pl. 43, fig. 12.

non 1985 Larcospira quadrangula Haeckel; Boltovskoy and Jankilevich, pl. 3, fig. 15.

non 1985 Larcospira quadrangula Haeckel; Morley, p. 410, pl. 3, fig. 9.

non 1986 Larcospira quadrangular Haeckel (wrong spelling for the species name); Morley and Kohl, 1986, pl. 1, fig. 9.

non 1986 Larcospira quadrangula Haeckel; Yamauchi, pl. 1, fig. 17.

non 1987 Larcospira quadrangula Haeckel; Bjørklund and de Ruiter, fig. 2.18.

non 1987 Larcospira quadrangula Haeckel; Dworetzky and Morley, pl. 2, fig. 9.

non 1990 Larcospira quadrangula Haeckel; Yeh and Cheng, pl. 6, fig. 7.

non 1991 Larcospira quadrangula Haeckel; Takahashi, p. 92, pl. 23, figs. 11-12.
1992 Larcospira quadrangula Haeckel; Sugiyama, Nobuhara, and Inoue, p. 13-16, pl. 8, fig. 13, pl. 9, figs. 1-5c.

1993 Larcospira quadrangula Haeckel; Sharma and Singh, pl. 2, fig. 25.

non 1994 Larcospira quadrangula Haeckel; Kim, Park, and Park, pl. 2, fig. 11.

non 1995 Larcospira quadrangula Haeckel; van de Paverd, p. 188-190, pl. 55, figs. 1-2, 4-5.

non 1996 Larcospira quadrangula Haeckel; Chen and Tan, p. 198, pl. 23, figs. 1-3, pl. 46, figs. 2, 3.

non 1996 Larcospira quadrangula Haeckel; Haslett, pl. 1, fig. 1.

non 1998 Larcospira quadrangula Haeckel; Tan, p. 280-281, text-fig. 270.

non 1999 Larcospira quadrangula Haeckel; Tan and Chen, p. 265-266, text-fig. 5.182.

non 2008 Larcospira quadrangula Haeckel; Kamikuri, Motoyama, and Nishimura, pl. 3, fig. 13.

non 2009 Larcospira quadrangula Haeckel; Hatakeda and Bjørklund, pl. 3, fig. 4.

2009 Larcospira quadrangula Haeckel; Itaki, p. 48, pl. 10, figs. 14-15.

2009 Larcospira quadrangula Haeckel; Sono, Suzuki, Yoshimura, Kano, and Takeda, pl. 1, figs. $14 a-15$. 
non 2015a Phorticium pylonium Haeckel group; Matsuzaki, Suzuki, and Nishi, p. 32, fig. 6.11 (only).

Description. Test is cornered-square or slightly oblong in shape, and consists of a spindle-like center and lobate, latticed girdles. The length ratio of the $\mathrm{Sg}$-axis to the Lt-axis is $0.9-1.0$. Because of the revolving patterns, no gates develop in the 1st pseudo-concentric shell. The 2nd pseudo-concentric shell has twin outer girdles connected with the opposite ends of the 1st pseudo-concentric shell along the Lt-axis in Type 1 coordinates and the Ugaxis in Type 2 coordinates. The width ratio of the 3rd pseudo-concentric shell to the 2nd pseudoconcentric shell is 2.5-2.7. Several pillar beams from 2nd pseudo-concentric shell are bifurcated distally extending to the 3rd pseudo-concentric shell. These bifurcated pillar beams form convex depressions on the 3rd pseudo-concentric shell for a lobate appearance. Radial spines are somewhat developed on the surface of the 3rd pseudo-concentric shell. Pores are similarly small on the central combination and the S1a-girdles. Pores on the 2nd and 3rd pseudo-concentric shells are large and circular to subcircular in shape with fine pore frames.

Remarks. The Indian samples include three independent morphotypes of Larcospira. We evaluated illustrations of Larcospira quadrangula in published papers to examine their independence. Almost all illustrated Larcospira quadrangula show smooth, spherical outermost pseudo-concentric shells, and several specimens show morphological similarity to the type image of $L$. quadrangula (Haeckel, 1887 , plate 49 , figure 3 ). Based on these differences, these three morphotypes are separated. Larcospira quadrangula is easily distinguished from Larcospira teres $\mathrm{n}$. $\mathrm{sp}$. in that the former has a cornered quadrangular to sub-quadrangular overall shape from the Sg- and Pl-views and lobate outermost girdles with clearly visible pillar beams. Larcospira quadrangula is similar to Larcospira tetragonicentrum n. sp. in the former's lobate outermost girdles, but the former is differentiated from the latter based on the former's spindle-like central part in contrast to a quadrangular center, as well as the former's presence of a 2 nd pseudo-concentric shell.

Larcospira teres n. sp.

Figure 13

zoobank.org/CE058DC9-B18D-4884-9009-35692F668CD2

1970 Larcospira quadrangula Haeckel; Nigrini, p. 169, pl. 2, fig. 9.
1976 Larcospira quadrangula Haeckel; Tan and Tchang, p. 264-265, text-fig. 36.

1977 Larcospira quadrangula Haeckel; Kling, p. 217, pl. 2, fig. 18.

1978 Larcospyra quadrangula Haeckel (wrong spelling for the genus name); McMillen and Casey, pl. 3, fig. 18.

1979 Larcospira quadrangula Haeckel; Nigrini and Moore, p. S133-134, pl. 17, fig. 2.

1980 Larcospira quadrangula Haeckel; Johnson, and Nigrini, p. 127, text-fig. 9a, pl. 2, fig. 15.

1981 Larcospira quadrangula Haeckel; Takahashi and Honjo, p. 150, pl. 6, fig. 2.

1984b Larcospira quadrangula Haeckel; Nishimura and Yamauchi, p. 41, pl. 17, fig. 11, pl. 43, fig. 12.

1985 Larcospira quadrangula Haeckel; Boltovskoy and Jankilevich, pl. 3, fig. 15.

1985 Larcospira quadrangula Haeckel; Morley, p. 410, pl. 3, fig. 9.

1986 Larcospira quadrangular Haeckel (wrong spelling for the species name); Morley and Kohl, pl. 1, fig. 9.

1986 Larcospira quadrangula Haeckel; Yamauchi, pl. 1, fig. 17.

1987 Larcospira quadrangula Haeckel; Bjørklund and de Ruiter, fig. 2.18.

1987 Larcospira quadrangula Haeckel; Dworetzky and Morley, pl. 2, fig. 9.

1990 Larcospira quadrangula Haeckel; Yeh and Cheng, pl. 6, fig. 7.

1991 Larcospira quadrangula Haeckel; Takahashi, p. 92, pl. 23, figs. 11-12.

1995 Larcospira quadrangula Haeckel; van de Paverd, p. 188-190, pl. 55, figs. 1-2, 4-5.

1996 Larcospira quadrangula Haeckel; Chen and Tan, p. 198, pl. 23, figs. 1-3, pl. 46, figs. 2, 3.

? 1996 Larcospira quadrangula Haeckel; Haslett, pl. 1, fig. 1.

1998 Larcospira quadrangula Haeckel; Tan, p. 280-281, text-fig. 270.

1999 Larcospira quadrangula Haeckel; Tan and Chen, p. 265-266, text-fig. 5.182.

2008 Larcospira quadrangula Haeckel; Kamikuri, Motoyama, and Nishimura, pl. 3, fig. 13.

2015a Phorticium pylonium Haeckel group; Matsuzaki, Suzuki, and Nishi, p. 32, fig. 6.11 (only).

Etymology. The Latin adjective "teres" (-retis), meaning smoothly rounded.

Holotype. Specimen in Figure 13.1-2 from the sample YDY05-01.

Paratype. Specimen in Figure 13.6-7 from the sample YDY05-01. 

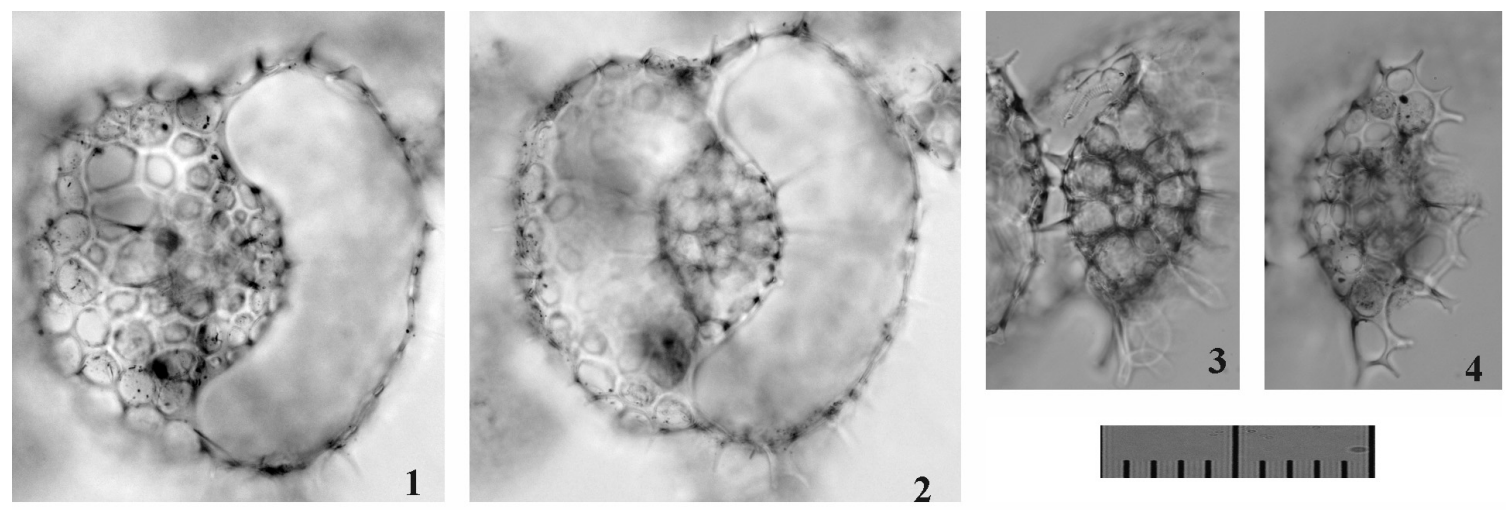

2
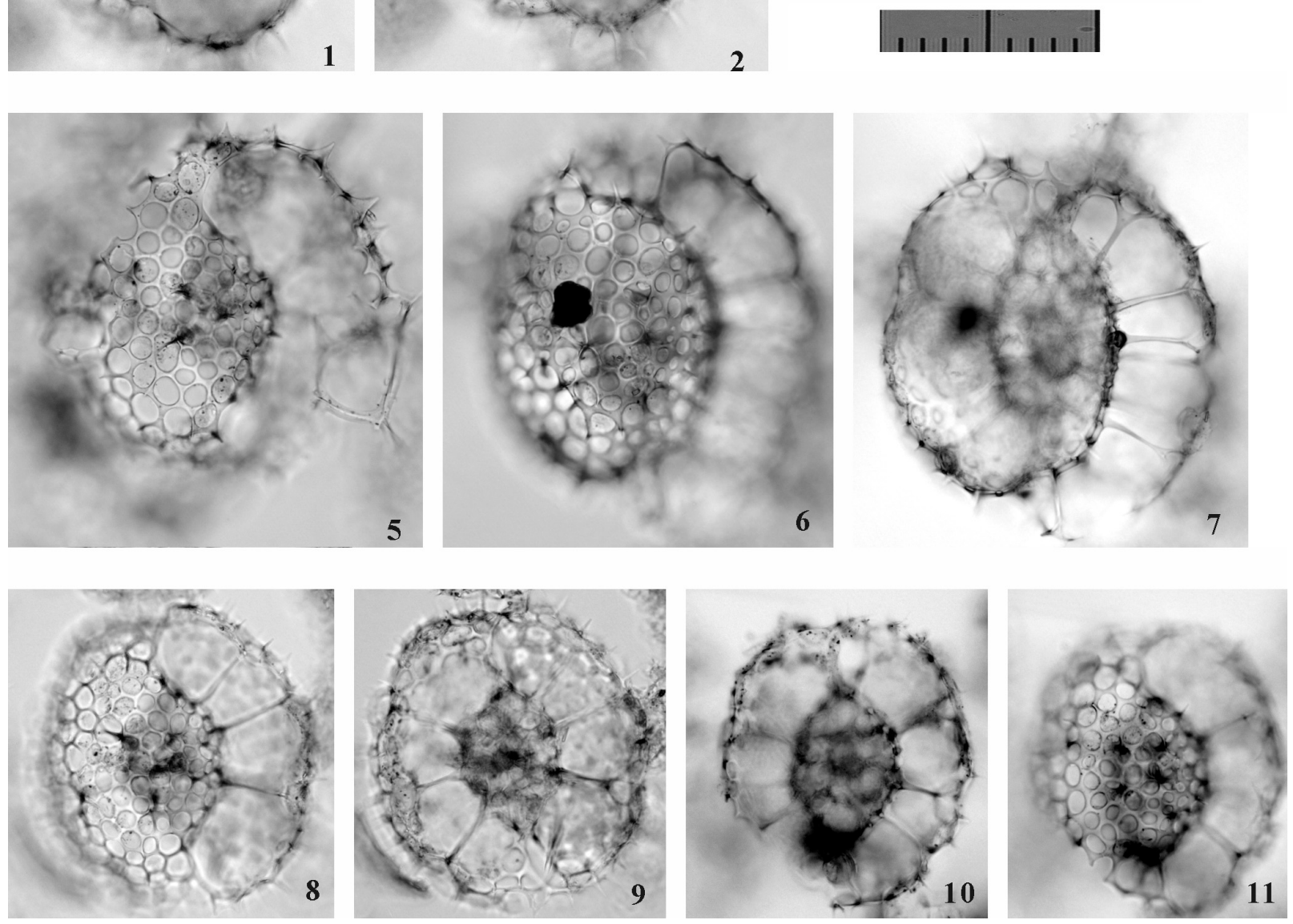

FIGURE 13. Photographs of the encountered morphotypes of Larcospira teres n. sp. All are Pl-view at Type 1. Scale bar equals $0.1 \mathrm{~mm}$. All specimens are from YDY05-01.

Description. Test is oval in shape, and consists of a spindle-like central part and smooth, latticed girdles. The length ratio of the Sg-axis to the coiling axis (the Lt-axis) is 0.9-1.1. The 2nd pseudo-concentric shell is characterized by twin outermost girdles connected with the opposite ends of the 1st pseudo-concentric shell along the Lt-axis. Both ends of the 3rd pseudo-concentric shell along the Lt axis are depressed. Several pillar beams connecting an inner girdle to the outer girdle are bifurcated distally. These pillar beams are thin or poorly developed, and therefore do not to create any major convex depressions on the 3rd pseudo-con- centric shell; the 3rd pseudo-concentric shell therefore has a smooth surface. The width ratio of the 3rd pseudo-concentric shell to the 2nd pseudoconcentric shell is 2.7-3.2. Rarely, radial spines develop somewhat on the surface of the 3rd pseudo-concentric shell. Pores are small on the central combination and the S1a-girdles. They are large and rounded polygonal in shape with fine pore frames on the 2 nd and outer pseudo-concentric shells.

Remarks. All specimens of "Larcospira quadrangula" with smooth 3rd pseudo-concentric shells illustrated in previous papers (see the synonym 
list) are identified as this new species. Larcospira teres $\mathrm{n}$. sp. differs from $L$. quadrangula based on the smooth surface of former's 3rd pseudo-concentric shell with thin pillar beams. The width ratio of the 3rd pseudo-concentric shell to the 2nd pseudo-concentric shell is larger in $L$. teres $\mathrm{n}$. $\mathrm{sp}$. (2.7-3.2 in L. teres n. sp. vs. 2.5-2.7 in L. quadrangula). All fossil "L. quadrangula" specimens older than Pliocene in age illustrated in previous papers (Nigrini and Lombari, 1985; Levyikina, 1986; Sugiyama et al., 1992) have spiral girdles with smooth surfaces like those of $L$. teres $n \mathrm{sp}$. However, these fossil specimens differ from the representative species in that they have narrow outermost spiral girdles and that both ends of the test are acute. Therefore, these fossil species are considered to belong to an undescribed species.

Dimensions. Based on the holotype specimen. The length and width of pseudo-concentric shell: $27.2 \mu \mathrm{m}$ and $12.2 \mu \mathrm{m}$ (1st pseudo-conentric shell), $66.7 \mu \mathrm{m}$ and $46.5 \mu \mathrm{m}$ (2nd pseudo-concentric shell), and $139.5 \mu \mathrm{m}$ and $150.8 \mu \mathrm{m}$ (3rd pseudoconcentric shell). The ratio of the length to the width: 2.2 (1st pseudo-conentric shell), 1.4 (2nd pseudo-conentric shell), and 0.9 (3rd pseudo-concentric shell). The width ratio of the 3rd pseudoconcentric shell to the 2nd pseudo-concentric shell is ca. 3.2. The width ratio of the 2 rd pseudo-concentric shell to the 1 st pseudo-concentric shell is ca. 3.8.

\section{Larcospira tetragonicentrum n. sp. Figure 14}

\section{zoobank.org/B201D0B4-5D56-42DA-8758-7A439673EE2E}

1995 Phorticium? sp. van de Paverd, pl. 57, fig. 5.

1994 Larcospira quadrangula Haeckel; Kim, Park, and Park, pl. 2, fig. 11.

1994 Larcospira quadrangula Haeckel; Hatakeda and Bjørklund, pl. 3, fig. 4.

Etymology. The Latin adjective "tetragonus" (-a, um) and neutral noun "centrum", meaning quadrangular center.

Holotype. Specimen in Figure 14.3-4 from the sample YDY05-01.

Paratype. Specimen in Figure 14.1-2 from the sample YDY05-01.

Description. Test is oblong in shape and consists of a square central part and lobate latticed girdles (1st pseudo-concentric shell). The length ratio of the axis to the coiling axis (the Lt-axis) is 0.8 . The 1st pseudo-concentric shell has twin outermost girdles connected with the opposite ends of the central part along the Lt-axis. The width ratio of the 1st pseudo-concentric shell to the central part is 3.2.
Several pillar beams are directly connected to the 1st pseudo-concentric shell. These beams form convex depressions on the 1st pseudo-concentric shell that give the shell a lobate appearance. These pillar beams may or may not penetrate. Secondary spines develop somewhat on the surface of the 1st pseudo-concentric shell. Pores are small on the central part and are large on the 1st pseudoconcentric shell. Pores on the 1st pseudo-concentric shell are polygonal in shape with fine pore frames.

Remarks. Larcospira tetragonicentrum $\mathrm{n}$. sp. is similar to Larcospira quadrangula except that the former has only a single pseudo-concentric shell and a quadrangular central part. No other Larcospira species have a square central part; consequently, we concluded that this morphotype belongs to a new species.

Dimensions. Based on the holotype specimen. The length and width of pseudo-concentric shell: $9.5 \mu \mathrm{m}$ and $9.1 \mu \mathrm{m}$ (microsphere), $31.1 \mu \mathrm{m}$ and $26.9 \mu \mathrm{m}$ (central part), and $106.5 \mu \mathrm{m}$ and $84.8 \mu \mathrm{m}$ (1st pseudo-concentric shell). The ratio of the length to the width: 1.0 (microsphere), 1.2 (central part), and 1.3 (1st pseudo-concentric shell). The width ratio of the 1st pseudo-concentric shell to the central part is ca. 3.2. The width ratio of the central part to the microsphere is ca. 3.0.

\section{Subfamily PYLODISCINAE Haeckel, 1887 sensu \\ Dumitrica in De Wever et al., 2001 \\ Genus PYLODISCUS Haeckel, 1887 sensu emend.}

nomen dubium

1882 Hexapyle Haeckel, p. 464 (type species: Hexapyle triangula Haeckel).

nomen dubium

1882 Triopyle Haeckel, p. 464 (type species: Triopyle circulus Haeckel).

*1887 Pylodiscus Haeckel, p. 570.

1887 Pylolena Haeckel, p. 567 (type species: Pylolena armata Haeckel).

1887 Hexapyle Haeckel; Haeckel, p. 568

1887 Triopyle Haeckel; Haeckel, p. 565

1954 Hexapyle Haeckel; Campbell, p. D92.

1954 Pylodiscus Haeckel; Campbell, p. D92.

1954 Pylolena Haeckel; Campbell, p. D72.

1954 Triopyle Haeckel; Campbell, p. D92.

1979 Hexapyle Haeckel; Kozur and Mostler, p. 46.

1979 Triopyle Haeckel; Kozur and Mostler, p. 46.

1979 Pylodiscus Haeckel; Kozur and Mostler, p. 46.

1979 Pylolena Haeckel; Kozur and Mostler, p. 46. 

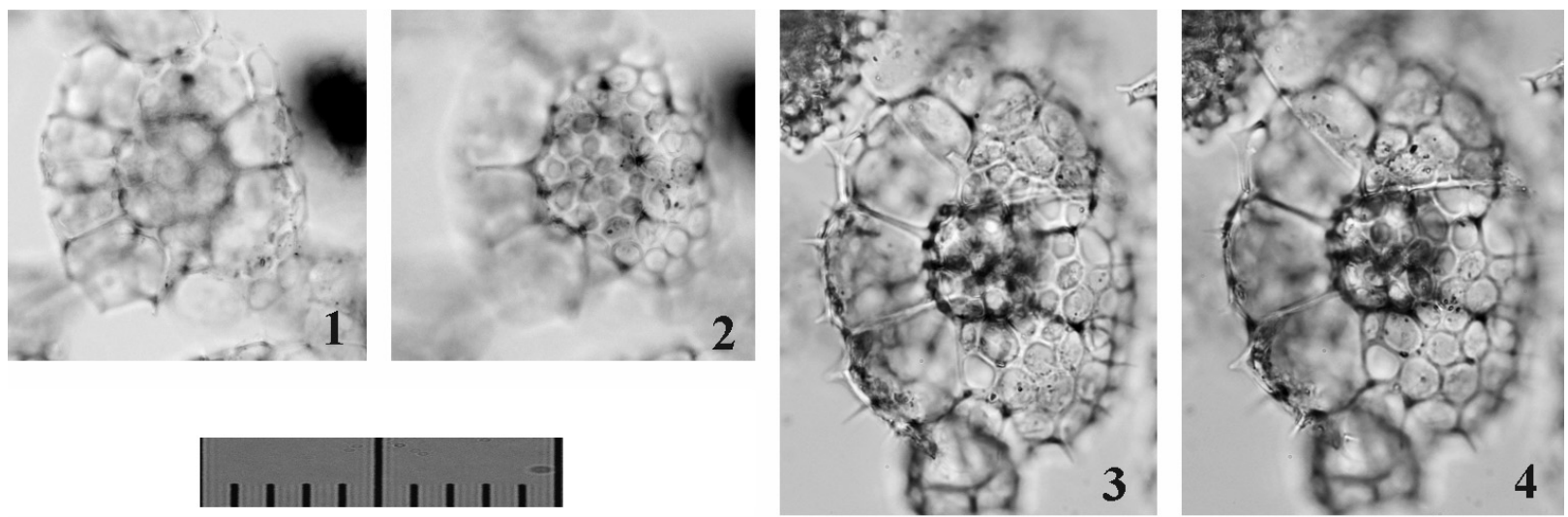

FIGURE 14. Photographs of the encountered morphotypes of Larcospira tetragonicentrum $\mathrm{n}$. $\mathrm{sp}$. All are $\mathrm{PI}$-view at Type 1. Scale bar equals $0.1 \mathrm{~mm}$. All specimens are from YDY05-01.

Type species. Pylodiscus triangularis Haeckel, 1887 (SD by Campbell, 1954).

Description. Test is flat and triangular in shape with a central combination and one or two triangular pseudo-concentric shells. The 1st pseudo-concentric shell consists of five girdles. The gates of the two girdles show their tunnel view, and those of the other three girdles show their aperture view in Fr-view in Type 2 coordinates to form a flat, triangular, pseudo-concentric shell. The two gates with aperture view in Fr-view are directly connected with the S1a (microsphere) (Figure 15.3). Thus, the Lt-axis passes through the center of S1a and these two gates. The other gate with aperture view in Frview occurs beneath the $\mathrm{S} 1 \mathrm{a}$ along the $\mathrm{PI}$-axis, and the Sg-axis under Type 1 coordinates is therefore equivalent to the $\mathrm{Fr}$-axis of the 1st pseudo-concentric shell in Type 2 coordinates. The 2 nd pseudoconcentric shell also has a flat, triangular appearance and is arranged upside-down relative to the 1st pseudo-concentric shell. The Fr-axis of each pseudo-concentric shell is identical to the Sg-axis with Fr-view in the same direction. Latticed cover may develop on both flattened sides of the test in fully mature specimens of some species. Specimens with latticed cover look inflated, and flat triangular in shape.

Remarks. The definition of Pylodiscus has been revised to include all flat triangular pylodiscid species that have pylodiscid 1st pseudo-concentric shells. Species with such morphology have been considered to belong to Hexapyle Haeckel, 1882, Triopyle Haeckel, 1882, Pylodiscus Haeckel, 1887, and Pylolena Haeckel, 1887. However, species of these genera can be placed into a single genus. The type species of Pylolena, Pylolena armata Haeckel, 1887, is a younger stage of some species of Pylodiscus that has an incomplete triangular 2nd pseudo-concentric shell. Our definition includes socalled Hexapyle species because of the nomen dubium status of Hexapyle Haeckel, 1882 (Campbell [1954] designated an un-illustrated species as the type species of this genus). The genus name Hexapyle has been applied in practice with Hexapyle dodecantha Haeckel, 1887, and Hexapyle spinulosa Chen and Tan, 1990. These two species are similar to Pylodiscus triangularis Haeckel, 1887, the type species of Pylodiscus, except for their closed/open gates with latticed cover and the presence/absence of polar-beams in the gates. These differences are inferred to be the results of differences in ontogenetic growth. The genus names Triopyle Haeckel, 1882, and Pylolena Haeckel, 1887, are unsuitable for practical use with real specimens because their type species have not yet been illustrated. Triopyle hexagona Haeckel, 1887, and Pylolena armata Haeckel, 1887, were illustrated as members of Triopyle and Pylolena, respectively, but these species are now considered to be younger stages of Pylodiscus species.

Pylodiscus spinulosus (Chen and Tan, 1989) Figure 15

1976 Hexapyle dodecantha Haeckel; Renz, p. 113-114, pl. 1, fig. 11.

1987 Hexapyle spp. Dworetzky and Morley, pl. 2, fig. 2.

*1989 Hexapyle spinulosa Chen and Tan, p. 3-4, pl. 1, fig. 8.

1991 Hexapyle sp. Takahashi, pl. 23, fig. 7.

1995 Hexapyle armata (Haeckel); van de Paverd, p. 191, pl. 55, figs. 7-8, 10.

1996 Hexapyle spinulosa Chen and Tan; Chen and Tan, p. 188, pl. 17, figs. 6-7. 

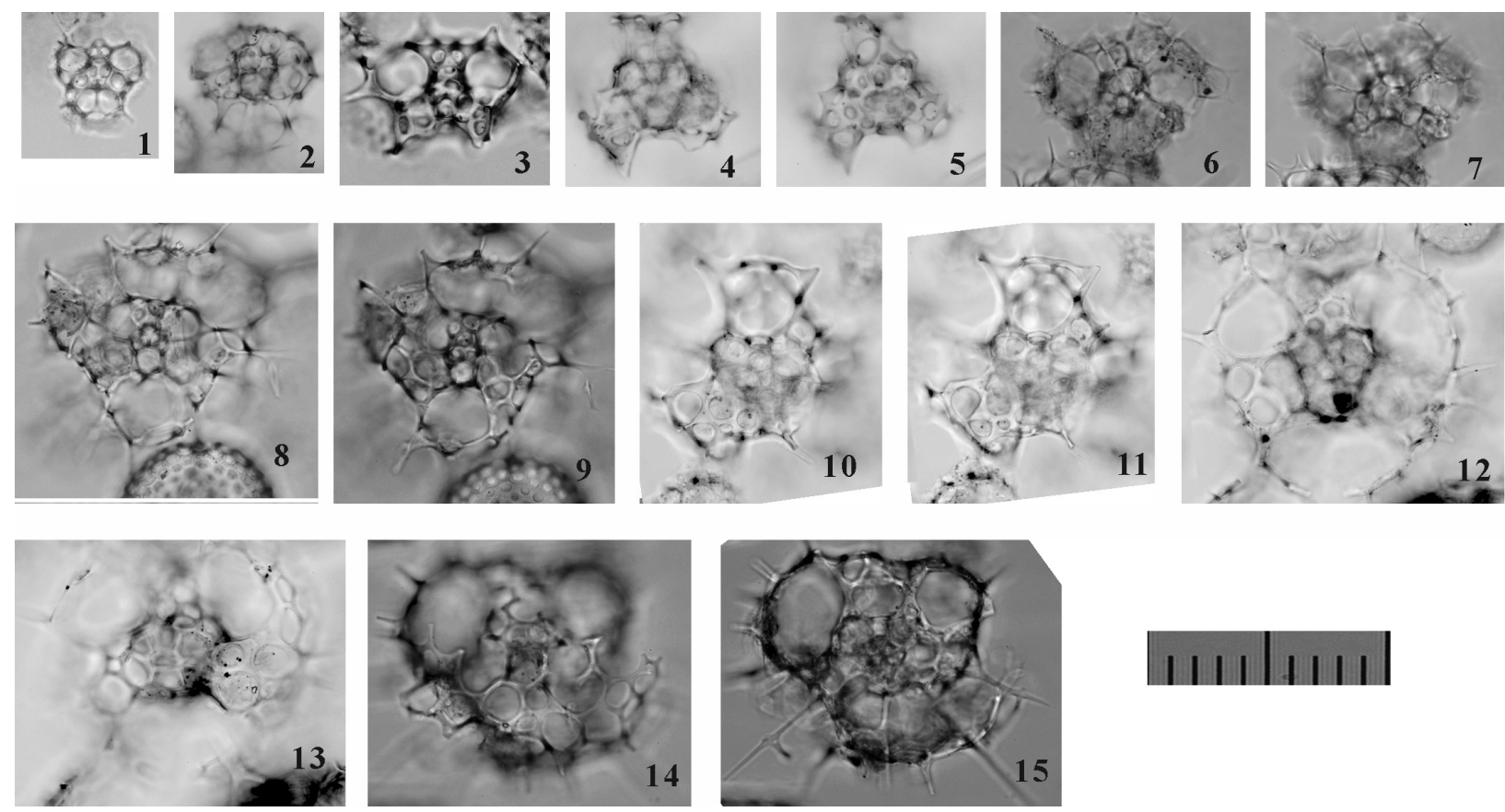

FIGURE 15. Photographs of the encountered morphotypes of Pylodiscus spinulosus (Chen and Tan, 1989). All are Frview at Type 2. Scale bar equals $0.1 \mathrm{~mm}$. All specimens are from YDY05-01.

1998

Hexapyle spinulosa Chen and Tan; Tan, p. 233, text-fig. 220.

1999

Hexapyle spinulosa Chen and Tan; Tan and Chen, p. 227-228, text-fig. 5.136.

1999

Tetrapyle octacantha Müller; Sashida and Kurihara, fig. 12.16.

2002 Spumellaria gen. et spp. indet. Anma, Kawakami, and Yamamoto, fig. 12.14.

2005 Hexapyle armata (Haeckel); Okazaki, Takahashi, Onodera, and Honda, fig. 10.10.

Remarks. This taxonomic name was selected from the described species with two triangular pseudoconcentric shells. Our sample did not include the Pylodiscus morphotype with latticed cover on both sides of a flat test or with rods from each side of the 1st triangular pseudo-concentric shell. The former is named Pylodiscus triangularis Haeckel, 1887, whereas the latter is Pylodiscus dodecantha (Haeckel, 1887). These two species are regarded as a different species from Pylodiscus spinulosus (Chen and Tan, 1989).

\section{Genus LARCOPYLE Dreyer, 1889 sensu emend. herein}

*1889 Larcopyle Dreyer, p. 128.

1954 Larcopyle Dreyer; Campbell, p. D96.

2005 Larcopyle Dreyer; Lazarus, Faust, and Popova-Goll, p. 106.

2015a Larcopyle Dreyer; Matsuzaki, Suzuki, and Nishi, p. 33 (See full synonymy).
Type species. Larcopyle buetschlii Dreyer (SD by Campbell, 1954).

Description. Test is ellipsoid to spherical in shape, and comprises a central combination and continuous or intermittent spiral girdles. Robust or fragile coverage develops in the fully mature forms of some species. A bore pylome may be present on one end of the test, but no specific internal structure associated with the pylome has been recognized inside the test. The bore pylome, if present, opens along the Lt-axis. A bore pylome may be surrounded by spinules. The longest direction of the $\mathrm{Ug}$-axis is parallel to the Lt-axis. A central combination consists of an S1a and a pylodiscid-type triangular G1 girdle (see the type specimen image shown in figure 70 in Dreyer [1889]). Based on the definitions, both the Pl- and Sg-axes in Type 1 coordinates can be determined based on the central combination, but the Pr- and Fr-axes cannot be differentiated without pyloniid-type gates. Single or twin girdles coil variably several times from the central combination. The G1 girdle consists of three caps placed on the Sg-plane, and two of these caps develop from both lateral ends of the central combination along the Lt-axis, while the remaining cap is below the S1a (microsphere) along the Pl-axis in Type 1 coordinates. The S1a and $\mathrm{G} 1$ girdle form the 1st pseudo-concentric shell, which resembles an elongated ellipse from the PI- 
view and a rounded triangle from the Sg-view or another oblique view.

Remarks. The original definition of the genus Larcopyle puts emphasis on the presence of a pylome, but this structure is only present in the fully mature morphotypes with discrete outermost coverage shell. Even if the outermost coverage shell has a pylome, no special related structures have been recognized inside the outermost coverage shell, as described above. In addition, the outermost coverage shell does not always have a pylome even in the same species. Therefore, the presence or absence of a pylome is not used as a taxonomic criterion for this genus. Following this revised definition, Tholospira dendrophora Haeckel, 1887, moves into the same genus as Larcopyle buetschlii Dreyer, 1889. The former is the type species of Tholospira Haeckel, 1887, whereas the latter is that of the genus Larcopyle Dreyer, 1889, which suggests that Larcopyle would logically be synonymized with Tholospira. However, because the internal structure of Tholospira dendrophora has not been well examined, the name Tholospira has not been formally prioritized over Larcopyle. The internal structures of $L$. buetschlii and $L$. cervicornis are shown in Figure 5.4. The genus name is derived from the grammatical Latin female noun "pyle"; therefore, this genus is a grammatically female noun.

Larcopyle cervicornis (Haeckel, 1887) sensu stricto Figures 16, 17.1-6

1887 Tholospira (Tholospironium) cervicornis Haeckel, p. 700, pl. 49, fig. 5.

1912 Tholospira cervicornis Haeckel; Popofsky, p. 152, text-fig. 73.

1981 Tholospira cervicornis Haeckel; Takahashi and Honjo, p. 150, pl. 5, figs. 16-17 (only).

non 1981 Tholospira cervicornis Haeckel; Takahashi and Honjo, p. 150, pl. 5, fig. 18.

non 1984b Larcopyle sp. aff. L. bütschlii Dreyer (wrong spelling of the species name according to ICZN Article 32.5.2.1); Nishimura and Yamauchi, p. 41, pl. 16, fig. 10.

non 1984b Tholospira cervicornis Haeckel; Nishimura and Yamauchi, p. 41, pl. 17, fig. 10.

non 1985 Tholospira cervicornis Haeckel; Boltovskoy and Jankilevich, pl. 3, fig. 20.

non 1987 Tholospira cervicornis Haeckel; Dworetzky and Morley, pl. 2, fig. 3.

non 1991 Tholospira cervicornis Haeckel; Takahashi, p. 91, pl. 22, figs. 7-9, 12.

1995 Tholospironium cervicorne Haeckel; van de Paverd, p. 185-186, pl. 54, figs. 1-4, 6-10, pl. 58 , fig. 7 (not), pl. 59 , fig. 6 . non 2009 Tholospira cervicornis Haeckel; Itaki, p. 48, pl. 11, figs. 14-18.

2009 Tholospira cervicornis Haeckel; Matsuoka, fig. 3.18.

2009 Larcopyle buetschlii Dreyer; Zhang, Chen, Xiang, Zhang, Liu, Huang, and Lu, pl. 1, fig. $\mathrm{L}$.

non 2012 Tholospira cervicornis Haeckel; Ikenoue, Takahashi, and Tanaka, pl. 2, fig. 16.

non 2014a Larcopyle cervicorne (Haeckel); Matsuzaki, Nishi, Hayashi, Suzuki, Ikehara, Gyawali, Tanaka, and Takashima, fig. 2.10.

non 2015a Larcopyle cervicorne (Haeckel); Matsuzaki, Suzuki, and Nishi, p. 33-34, fig. 6.15-16.

non 2014c Larcopyle cervicorne Haeckel (no parenthesis to the author's name); Matsuzaki, Nishi, Suzuki, Kawate, Takashima, and Sakai, pl. 1, fig. 19.

non 2014d Larcopyle cervicorne Haeckel (no parenthesis to the author's name); Matsuzaki, Nishi, Suzuki, Takashima, Kawate, and Sakai, pl. 2, fig. 8.

non 2015b Larcopyle cervicornis Haeckel (no parenthesis to the author's name); Matsuzaki, Suzuki, Nishi, Hayashi, Gyawali, Takashima, and Ikehara, fig. 7.7.

Description. Test is spiny and elongated with very coarse pores and consists of a relatively large pylodiscid-type central combination and one or two very coarse pseudo-concentric shells or spiny surroundings. The Lt-axis in Type 1 coordinates is parallel to the longest axis of the test. The ratio of the longest axis (Lt-axis in Type 1 coordinates and Ugaxis in Type 2 coordinates) to the shortest axis of the 1st pseudo-concentric shell is ca. 1.5-1.7. Outer part of the 1st pseudo-concentric shell is surrounded with irregularly spiraled girdles, which form the 2nd pseudo-concentric shells to an extent. Pores of the 2nd pseudo-concentric shell are polygonal in shape, and the triple junction of the pore frame is always connected with the inner part of the test by a pillar beam. The 2 nd pseudo-concentric shell develops from both ends of the longest direction (Lt-axis) of the test to revolve around the short axis-side of the test. The 2nd pseudoconcentric shell consists of with two girdles that encircle the longest axis of the test and two other girdles along the shortest axis of the test. Spinelike spinules tend to extend from both sides along the longest axis of the test from the 2nd pseudoconcentric shell. Pores of the 2 nd pseudo-concentric shell and outer test are as large as $15-25 \mu \mathrm{m}$ in diameter.

Remarks. The species name "Tholospira cervicornis" has been applied for two distinct morphotypes: 

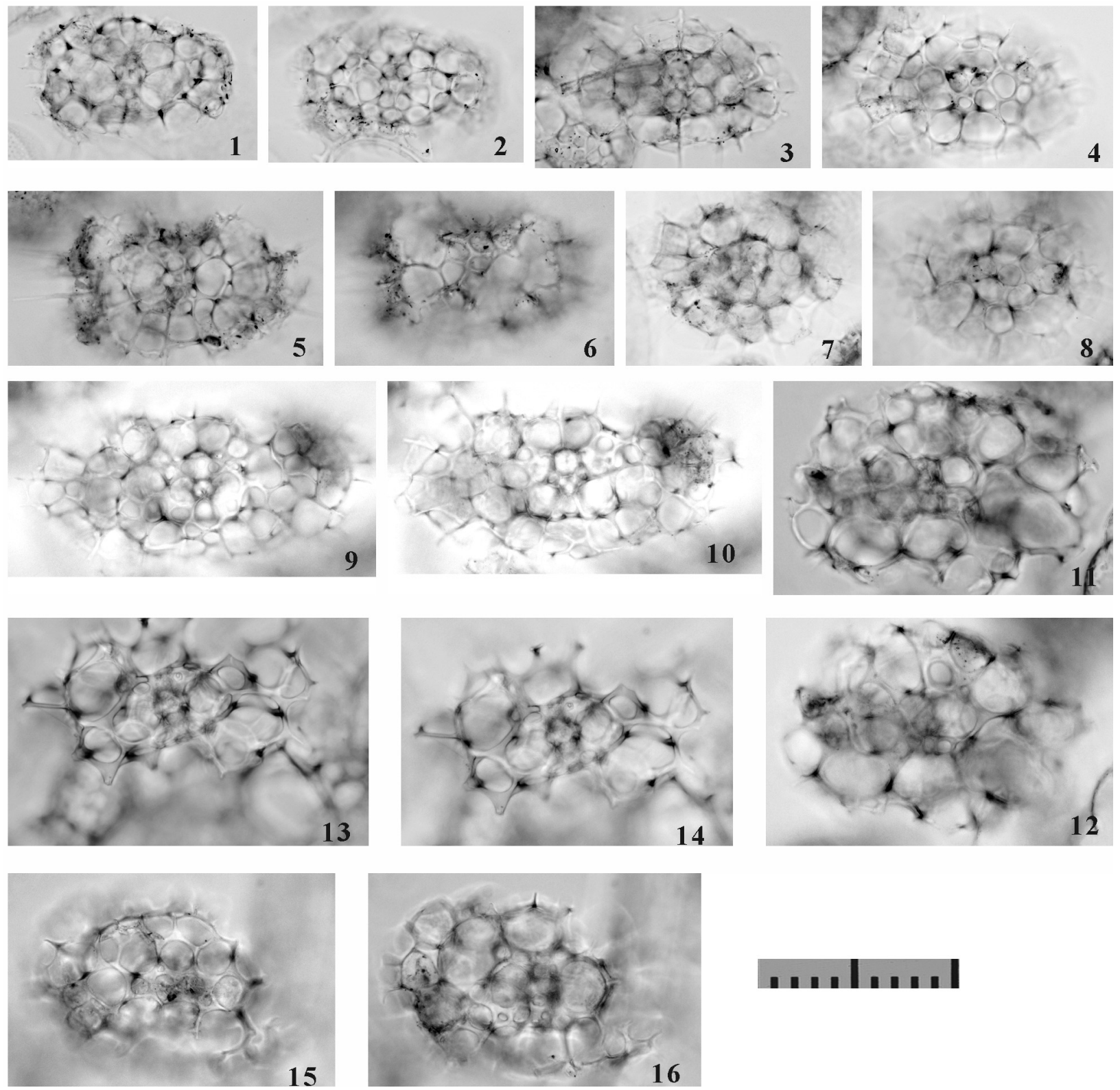

FIGURE 16. Photographs of the encountered morphotypes of Larcopyle cervicornis (Haeckel, 1887) sensu stricto. All are PI-view at Type 1. Scale bar equals $0.1 \mathrm{~mm}$. All specimens are from YDY05-01.

one shown on plate 5 , figures 16 and 17 and the other on plate 15, figure 18 of Takahashi and Honjo (1981), for example. The detailed skeletal characteristics in the type image of this species by Haeckel (1887) are somewhat unclear. According to the original description of this species by Haeckel $(1887$, p. 700$)$, this species has "perimeter of the lateral plane elliptical, one and a third times as long as broad. Four internal kidney-shaped gates, as in Tetrapyle. Both wings of the sagittal girdle turn round one another in one and a half to two double spiral turns." Here, the topotypes from the H.M.S.
Challenger Station 271, housed at Tohoku University, are shown in Figure 17.1-6 to more clearly represent this species. The features of these specimens are consistent with those in plate 5 , figures 16 and 17 of Takahashi and Honjo (1981). The internal structures of these topotypes were similar to the specimen illustrated in text-figure 73 of Popofsky (1912). Larcopyle cervicornis (Haeckel, 1887 ) is easily distinguished from other Larcopyle species based on its elongate form, the distinctive pylodiscid central part that is parallel to the shortest axis, the twin G2-gates aligned along the longest 

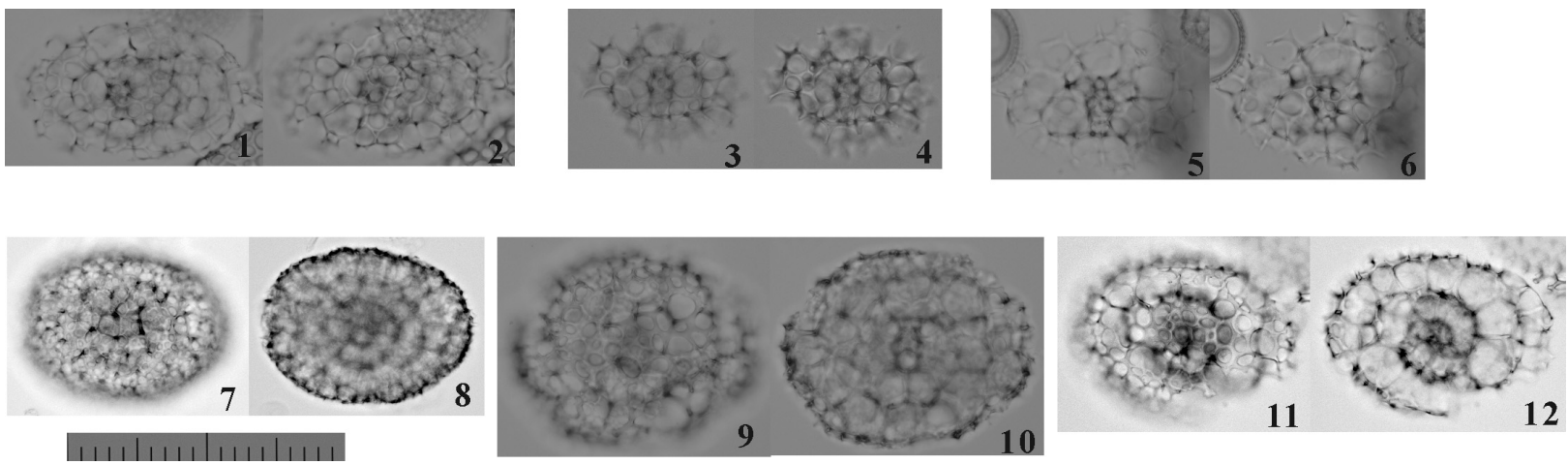

FIGURE 17. The topotypes from the H.M.S. Challenger station 271. 1-6, Larcopyle cervicornis (Haeckel, 1887); 7-12, Larcopyle buetschlii buetschlii Dreyer, 1889. All are Pl-view at Type1. Scale bar equals $0.1 \mathrm{~mm}$. All specimens are from H.M.S. Challenger Station 271 sample.

axis of the test, and its very coarse pores. This species has multi-branched (fork-shaped) spines according to original description and drawing by Haeckel (1887), and such characteristic has been shown in Takahashi and Honjo (1981, plate 5, figure 17) and Itaki (2009, plate 11, figures 14, 18). However, it isn't always clear in microphotographs showing in Figure 16.

Larcopyle variabile (Dreyer, 1889) sensu emend. Figure 18.1-6

1889 Ommatodiscus (Ommatodisculus) variabilis Dreyer, p. 109-110, fig. 58.

?1995 Spongurus ellipticus (Ehreberg); van de Paverd, p. 151, pl. 53, fig. 13 (only).

? 1995 Tholospironium cervicorne Haeckel; van de Paverd, p. 185-186, pl. 54, fig. 12 (only).

Description. Test has a spindle-like to ellipsoid shape without a tube around the bore pylome, and consists of a pylodiscid-type central combination, two spherical pseudo-concentric shells, and an outermost coverage shell. The Lt-axis of the central combination is oblique to the longest axis of the overall test. The 1st pseudo-concentric shell is connected with the 2nd pseudo-concentric shell by numerous straight pillar beams. The 2 nd pseudoconcentric shell ranges from spherical to ellipsoid in shape and is connected with the outermost coverage shell by straighter pillar beams. The pillar beams between the 1st and 2nd pseudo-concentric shells are generally disconnected from those between the 2nd pseudo-concentric shell and the outermost coverage shell. The outermost coverage shell has a rough surface with circular to subcircular pores of variable sizes. The wall of the outermost coverage shell tends to be in direct contact with part of the 2nd pseudo-concentric shell at the mid-portion of the test. The ratio of the short and long diameters of the outermost shell is ca. 0.6. Both the apex and pylomate-ends of the test tend to have a space between the 2 nd pseudo-concentric shell and the outermost coverage shell.

Remarks. The type illustration shown in figure 58 of Dreyer (1889) does not show the central combination. Our specimen can be classified as this species based on its relatively large, spherical 1st pseudo-concentric shell, spherical 2nd pseudoconcentric shell, and its very little to no space between the 2nd pseudo-concentric shell and the outermost coverage shell at the mid-portion of the test. Larcopyle variabile (Dreyer, 1889) is distinguishable from Larcopyle nebulum Lazarus, Faust and Popova-Goll, 2005, based on the former's rougher surface of the outermost coverage shell, former's more concentric or spiraled internal structures, and the spongy structure inside the space in the apex and pylomate ends of the test between the outermost coverage shell and the final pseudoconcentric shell of the former.

\section{Larcopyle buetschlii buetschlii Dreyer, 1889 sensu stricto}

Figures 17.7-12, 19

1889 Larcopyle buetschlii Dreyer, p. 124-125, fig. 70.

non 1977 Larcopyle butschlii Dreyer (wrong spelling of the species name); Kling, pl. 1, fig. 11.

1979 Larcopyle butschlii Dreyer (wrong spelling of the species name); Nigrini and Moore, $p$. S131-132, pl. 17, fig. 1a, b.

1979 Pylospira octopyle Haeckel?; Nigrini and Moore, p. S139-140, pl. 17, fig. 6a (only).

non 1981 Larcopyle butschlii Dreyer (wrong spelling of the species name); Takahashi and Honjo, p. 150 , pl. 5, fig. 15.

1984 Larcopyle buetschlii Dreyer; Nigrini and Lombari, p. S89-90, pl. 13, fig. 1a, b. 

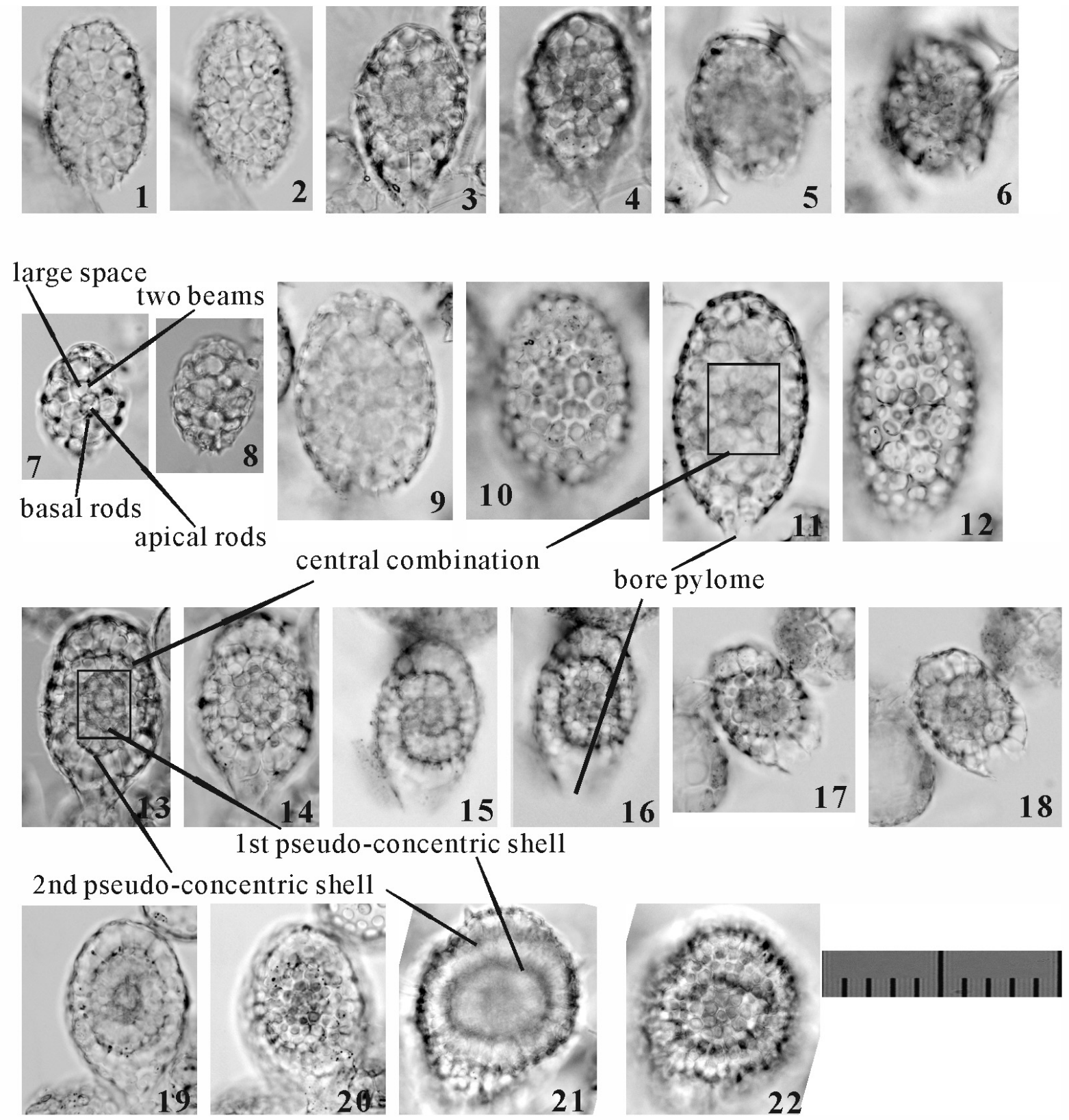

FIGURE 18. Photographs of the encountered morphotypes of Larcopyle. 1-6, Larcopyle variabile (Dreyer, 1889) sensu emend.; 7-12, Larcopyle molle n. sp.; 13-18, Larcopyle eccentricanoides n. sp.; 19-22, Larcopyle pulchella $\mathrm{n}$. $\mathrm{sp}$. All are Fr-view at Type 2. Scale bar equals $0.1 \mathrm{~mm}$. All specimens are from YDY05-01.

1984

Pylospira octopyle Haeckel; Nigrini and Lombari, p. S101-102, pl. 14, fig. 4.

1984b Larcopyle butschlii Dreyer (wrong spelling of the species name); Nishimura and Yamauchi, p. 41, pl. 48, fig. 8a-b.

non 1984b Larcopyle sp. aff. L. bütschlii Dreyer (wrong spelling of the species name according to ICZN Article 32.5.2.1); Nishimura and Yamauchi, p. 41, pl. 16, fig. 10. non 1985 Larcopyle buetschlii Dreyer; Boltovskoy and Jankilevich, pl. 3, fig. 14.

non 1991 Larcopyle butschlii Dreyer (wrong spelling of the species name); Takahashi, p. 91, pl. 22 , figs. $1-4$.

non 1993 Larcopyle buetschlii Dreyer; Sharma and Singh, pl. 2, fig. 23.

non 1996 Larcopyle bütschlii Dreyer (wrong spelling of the species name according to ICZN Arti- 

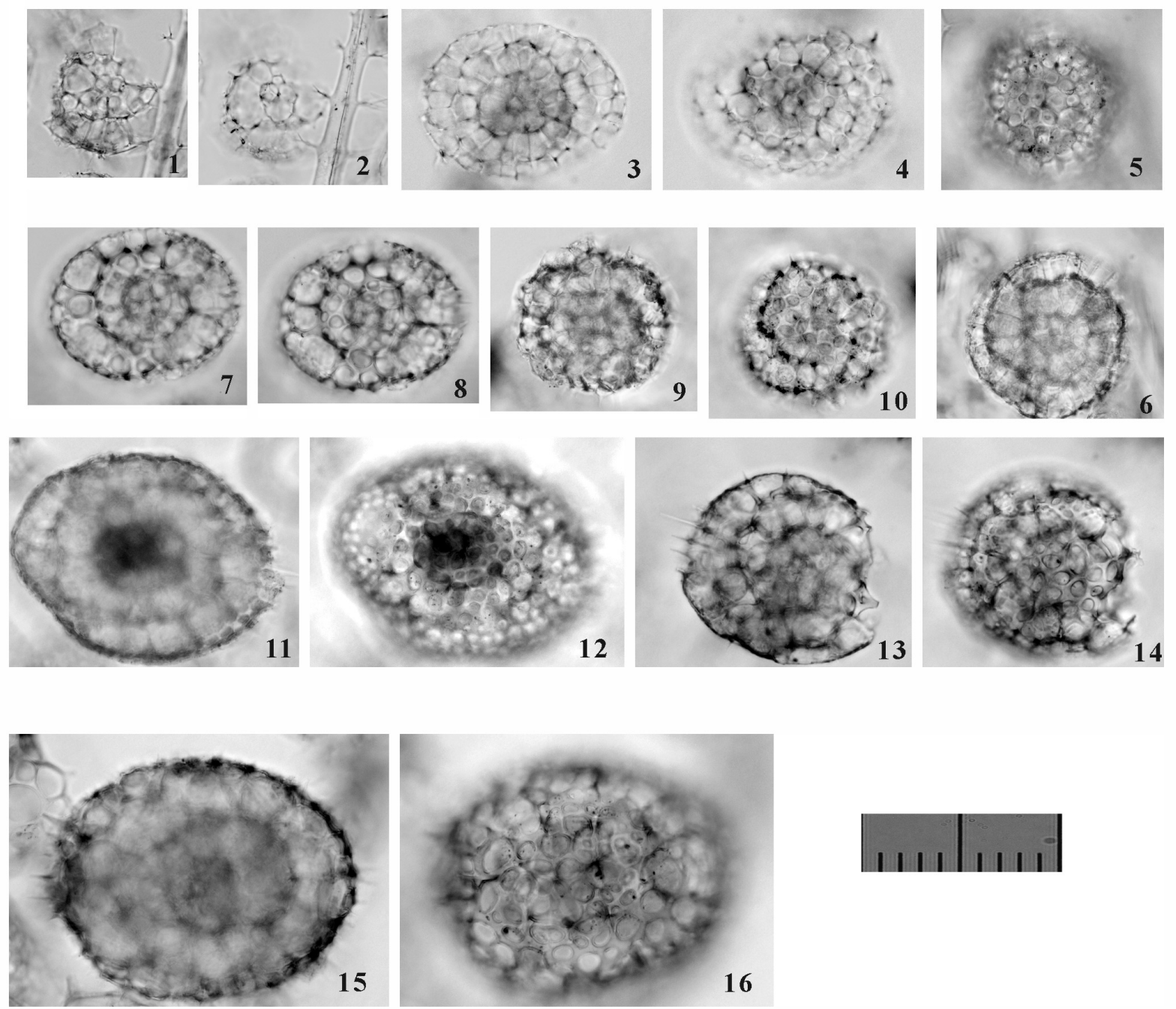

FIGURE 19. Photographs of the encountered morphotypes of Larcopyle buetschlii buetschlii Dreyer, 1889, sensu stricto. All are Fr-view at Type 2. Scale bar equals $0.1 \mathrm{~mm}$. All specimens are from YDY05-01.

cle 32.5.2.1); Bak, Lee, and Yun, p. 234, pl. 3, fig. 1.

non 1996 Larcopyle butschlii Dreyer (wrong spelling of the species name); Motoyama, pl. 3, fig. 3a-b (only).

? $1996 \quad$ Larcopyle butschlii Dreyer (wrong spelling of the species name); Motoyama, pl. 3, fig. 4 (only).

1997 Larcopyle buetschlii Dreyer; Bak, Lee, and Yun, pl. 1, figs. 8?, 9?, pl. 2, figs. 4?, 5.

1999 Larcopyle bütschlii Dreyer (wrong spelling of the species name according to ICZN Article 32.5.2.1); Sharma, Singh, and Rawal, pl. 3 , fig. 3.

2002 Larcopyle buetschlii Dreyer; Anma, Kawakami, and Yamamoto, fig. 12.13.
2002

Larcopyle bütschlii Dreyer (wrong spelling of the species name according to ICZN Article 32.5.2.1); Cortese and Abelmann, pl. 1, fig. 17.

non 2002 Larcopyle butschlii Dreyer (wrong spelling of the species name); Matsuoka, Shinzawa, Yoshida, Machidori, Kurita, and Todo, pl. 1, figs. 1-2, pl. 2, fig. 1.

non 2003 Larcopyle buetschlii Dreyer; Itaki, pl. 1, figs. 1, 3 (only).

aff. 2003 Larcopyle buetschlii Dreyer; Itaki, pl. 1, figs. 2, 4 (only).

non 2003 Larcopyle butschlii Dreyer (wrong spelling of the species name); Itaki and Ikehara, fig. 4.a, c. 
non 2003 Larcopyle butschlii Dreyer (wrong spelling of the species name); Okazaki, Takahashi, Yoshitani, Nakatsuka, Ikehara, and Wakatsuchi, pl. 1, fig. 25.

non 2003 Larcopyle buetschlii Dreyer; Sharma, and Ram, pl. 2, figs. 19-20.

non 2004 Larcopyle buetschlii Dreyer; Itaki, Ikehara, Motoyama, and Hasegawa, pl. 1, figs. 1-2, 4 (only).

aff. 2004 Larcopyle buetschlii Dreyer; Itaki, Ikehara, Motoyama, and Hasegawa, pl. 1, figs. 3, 5 (only).

? 2004 Larcopyle butschlii Dreyer (wrong spelling of the species name); Okazaki, Takahashi, Itaki, and Kawasaki, pl. 1, fig. 16.

non 2004 Larcopyle butschlii Dreyer (wrong spelling of the species name); Okazaki, Takahashi, Itaki, and Kawasaki, pl. 1, figs. 17-18.

non 2005 Larcopyle buetschlii Dreyer; Lazarus, Faust, and Popova-Goll, p. 106-108, pl. 1, figs. 1014.

2005 Larcopyle buetschlii Dreyer; Motoyama and Nishimura, fig. 10.1-3.

non 2005 Larcopyle butschlii Dreyer (wrong spelling of the species name); Okazaki, Takahashi, Onodera, and Honda, fig. 10.12.

? 2005 Larcopyle butschlii Dreyer (wrong spelling of the species name); Zapata and Olivares, p. 83, fig. 3.2.

non 2006 Larcopyle butschlii Dreyer (wrong spelling of the species name); Kurihara, Shimotani, and Matsuoka, pl. 2, fig. 8.

aff. 2006 Larcopyle buetschlii Dreyer; Motoyama and Nagamori, fig. 5.4 .

non 2007 Larcopyle butschlii Dreyer (wrong spelling of the species name); Ishitani and Takahashi, pl. 2, figs. a-c.

non 2008 Larcopyle buetschlii Dreyer; Itaki, Minoshima, and Kawahata, pl. 1, figs. 1819.

non 2008 Larcopyle butschlii Dreyer (wrong spelling of the species name); Tanaka and Takahashi, pl. 1, figs. 10-11.

2009 Larcopyle buetschlii Dreyer; Hatakeda and Bjørklund, pl. 1, figs. 1-3.

non 2009 Larcopyle buetschlii Dreyer; Itaki, p. 48, pl. 12, figs. 1-21.

non 2009 Larcopyle buetschlii Dreyer; Sono, Suzuki, Yoshimura, Kano, and Takeda, pl. 1, figs. 17a-19b.

non 2009 Larcopyle buetschlii Dreyer; Zhang, Chen, Xiang, Zhang, Liu, Huang, and Lu, pl. 1, fig. $\mathrm{L}$.

non 2011 Larcopyle buetschlii Dreyer; Kurihara and Matsuoka, figs. 3.1-3, 4.1-2. non 2012 Larcopyle buetschlii Dreyer; Ikenoue, Takahashi, and Tanaka, pl. 2, fig. 7.

non 2013 Larcopyle buetschlii Dreyer; HernándezAlmeida, Bjørklund, Sierro, Filippelli, Cacho, and Flores, pl. 2, figs. 7, 8.

2015a Larcopyle buetschlii Dreyer; Matsuzaki, Suzuki, and Nishi, p. 33, figs. 6.22, 6.26-28.

non 2015a Larcopyle buetschlii Dreyer; Matsuzaki, Suzuki, and Nishi, p. 33, figs. 6.21, 6.23-25.

2015b Larcopyle buetschlii Dreyer; Matsuzaki, Suzuki, Nishi, Hayashi, Gyawali, Takashima, and lkehara, fig. 7.16-17.

non 2016 Larcopyle buetschlii Dreyer; Matsuzaki, Itaki, and Kimoto, fig. 8.15.

Description. Test is ellipsoid in shape with a bore pylome and consists of a pylodiscid-type central combination, two or three pseudo-concentric shells, and outermost coverage shell with fine pores. The Lt-axis of the central combination is oblique or parallel to the longest axis (the Ug-axis) of the test. One or two spiral girdles develop from one side of the central combination and gradually rotate around the inner skeleton. The axes of the spiral girdles continuously rotate in three dimensions in Type 1 coordinates, but this rotation tends to be parallel to the previously developed girdle just below that girdle. Consequently, they seem to develop two or three pseudo-concentric shells from one view in Type 2 coordinates, whereas they resemble spirals from the other view in the same coordinates. The outer girdle is connected to the inner girdle with vertical pillar beams. Numerous pillar beams are present, but they rarely pierce through an outer girdle. Pores of these spiral girdles are large and polygonal to elliptical in shape. The pore sizes of these spiral girdles are largely related on the density of the pillar beams. The outermost coverage shell is ellipsoid in shape with numerous small pores that form a thick wall. The ratio of the short and long diameters of the outermost shell is ca. 0.6-0.7. No by-spines or radial spines are present on the surface of the outermost coverage shell. A bore pylome tends to develop on one side of the outermost coverage shell and is associated with a number of spinules. This pylome is closed in some fully mature forms, and no distinctive structure corresponding to a pylome has been detected inside the test. The outermost coverage shell is also connected with the internal spiral structures of numerous pillar beams.

Remarks. The Larcopyle buetschlii group has been used in several studies for a wide variety of Larcopyle species with spiral internal structures and ellipsoid appearances. The "L. buetschlii" specimens from the Sea of Japan generally have 
more tightly coiled inner structures, more robust outermost coverage shell, and radial spines or byspines across the outermost coverage shell (e.g., Itaki, 2009). These observations strongly suggest that the Larcopyle buetschlii from the Sea of Japan is morphologically independent from our Indian Larcopyle buetschlii. We examined the topotypic specimens from the H.M.S. Challenger Stations 261,266 , and 271 and found equivalent specimens to the type image in Dreyer (1889) in the Station 271 sample (Figure 17.7-12). We confirmed the same morphological characteristics between specimens from Station 271 and illustrated specimens of Larcopyle buetschlii buetschlii from the Indian Ocean. Larcopyle buetschlii buetschlii is different from Larcopyle buetschlii n. subsp. based on the former's major spiral girdles, the smoother surface of these spiral girdles, and the final thick coverage of fine pores if present. Lazarus et al. (2005) synonymized Larnacantha polyacantha Campbell and Clark, 1944, with $L$. buetschlii, but we separate the former from the synonym of the latter because the spiral patterns of each differ. The subspecific name "buetschlii" applies strictly to specimens that match the above definition. This subspecies is limited to warm, open regions of the Pacific, whereas the morphotype described by Itaki $(2009,2016)$ is limited to the Sea of Japan and, rarely, the Sea of Okhotsk and the boreal North Pacific.

Larcopyle buetschlii chenmuhongi n. subsp. Figure 20

\section{zoobank.org/9E29E697-BB2E-4F7D-B719-4E6A67C37344}

1977 Larcopyle butschlii Dreyer (wrong spelling of the species name); Kling, pl. 1, fig. 11.

1978 Litheliidae gen. et spp. indet. Riedel and Sanfilippo, pl. 3, figs. 17?, 20.

$1981 \quad$ Larcopyle butschlii Dreyer (wrong spelling of the species name); Takahashi and Honjo, p. 150 , pl. 5, fig. 15.

1985 Larcopyle buetschlii Dreyer; Boltovskoy and Jankilevich, pl. 3, fig. 14.

? 1986 Pyloniid group Mullineaux and WestbergSmith, pl. 2, fig. 2.

1991 Larcopyle butschlii Dreyer (wrong spelling of the species name); Takahashi, p. 91, pl. 22, fig. 2 (only).

2009 Larcopyle buetschlii Dreyer; Sono, Suzuki, Yoshimura, Kano, and Takeda, pl. 1, figs. 17a-19b.

2012 Larcopyle buetschlii Dreyer; HernándezAlmeida, Bjørklund, Sierro, Filippelli, Cacho, and Flores, pl. 2, fig. 8.

Etymology. In honor of Prof. Chen Muhong, a Chinese radiolarian specialist.
Holotype. Specimen in Figure 20.5-6 from the sample YDY05-01.

Paratype. Specimen in Figure 20.15-16 from the sample YDY05-01.

Description. Test is ellipsoid in shape with a bore pylome and consists of a pylodiscid-type central combination and one or two pseudo-concentric shells. The Lt-axis in Type 1 coordinates is parallel to the shortest axis of the test. The 1st pseudoconcentric shell has a flat, triangular form in Sgview in Type 1 coordinates. Two large gates are visible in the 1st pseudo-concentric shell in Sgview in Type 1 coordinates. Subsequent girdles develop along the Lt-axis from both ends of the 1st pseudo-concentric shell, and these girdles form the 2nd pseudo-concentric shell or the outermost coverage shell with subsequent girdles. The subsequent girdles are difficult to recognize as independent girdles or pseudo-concentric shells. Caps may develop at the apex and pylomate ends of the test in fully mature forms. The outermost coverage shell is fragile, and pores on the surface of the test at any ontogenetic stages are irregular in shape and size.

Remarks. This subspecies has also been included in the Larcopyle buetschlii group. This subspecies is differentiated from Larcopyle buetschlii buetschlii Dreyer, 1889, based on the presence of two large gates in the Sg-view in Type 1 coordinates, larger pores on each girdle, and the fragile outermost coverage shell. This species is easily distinguished from Larcopyle cervicornis (Haeckel, 1887) because the latter has a more elongated central part with two gates, more coarsely latticed girdles, a looser spiral structure, and no outermost coverage shell.

Dimensions. Based on the holotype specimen. The width of the central combination (S1a): 18.1 $\mu \mathrm{m}$; The length of the S1a-girdle: $13.3 \mu \mathrm{m}$; The height of the 1st pseudo-concentric shell: $44.6 \mu \mathrm{m}$; The length and width of the outermost coverage shell: $100.7 \mu \mathrm{m}$ and $65.5 \mu \mathrm{m}$. The length ratio to the width of the outermost coverage shell: ca. 1.5.

\section{Larcopyle buetschlii orion n. subsp.} Figure 21

zoobank.org/2AAB8F10-A6CB-4ABC-8954-CA404AEB86AA

? 1978 Prunopyle or Larcopyle indet. Riedel and Sanfilippo, pl. 2, fig. 16 (only).

Etymology. The Latin masculine noun "Orion" (onis), a name of one of the Giants of Greek mythology.

Holotype. Specimen in Figure 21.15-16 from the sample YDY05-01. 

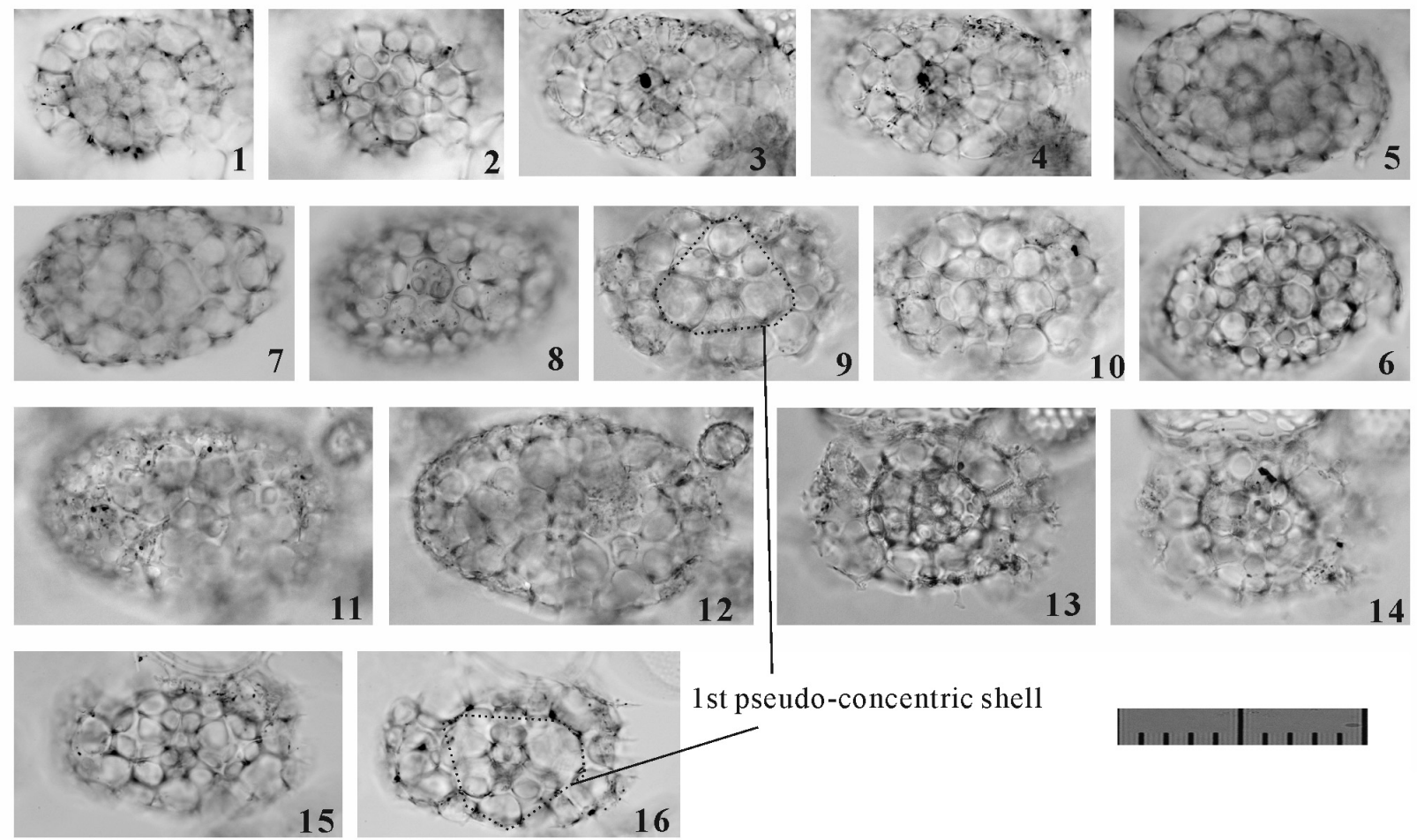

FIGURE 20. Photographs of the encountered morphotypes of Larcopyle buetschlii chenmuhongi n. subsp. All are Frview at Type 2. Scale bar equals $0.1 \mathrm{~mm}$. All specimens are from YDY05-01.

Paratype. Specimen in Figure 21.11-12 from the sample YDY05-01.

Description. Test is flat and ellipsoid in shape, with a pylodiscid-type central combination, two or three large pseudo-concentric shells, and an outermost coverage shell with coarse pores. The Lt-axis in Type 1 coordinates is nearly parallel to the shortest axis (Ug-axis in Type 2 coordinates) of the test. The 1st pseudo-concentric shell appears as a rounded square in Lt-view and as an elongated oblong form in Sg- and Pl-views. The 2nd pseudoconcentric shell develops along the Lt-axis from both ends of the 1st pseudo-concentric shell in Type 1 coordinates. Pillar beams extend from both ends of the 1st pseudo-concentric shell to connect directly with the 2 nd pseudo-concentric shell. The twin gates inside the 2nd pseudo-concentric shell are visible from the lateral side of the test. The 3rd pseudo-concentric shell develops outside of the 2nd pseudo-concentric shell, which is connected with the 3 rd by numerous pillar beams. At least four fine, straight rods extend from each corner of the 2nd pseudo-concentric shell. These pillar beams further elongate outside of the 3rd pseudoconcentric shell, and have a spiny appearance. The outermost coverage shell comprises thin pore frames and rough surfaces with variable sizes and shapes of pores. Short radial spines or by-spines emerge from some pillar beams from the 2nd pseudo-concentric shell. A pylome is not present.

Remarks. Larcopyle buetschlii orion n. subsp. is primarily characterized by its large test (ca. $200 \mu \mathrm{m}$ in the longest axis (Ug-axis) in Type 2 coordinates, 1.5-2.0 times larger than other Larcopyle buetschlii subspecies. The type specimen of Larcopyle buetschlii buetschlii is as large as this new subspecies, nearly $200 \mu \mathrm{m}$ in the longest axis (see the original description of Dreyer, 1889). Larcopyle buetschlii orion $\mathrm{n}$. subsp. is distinguishable from large $L$. buetschlii buetschlii based on the latter's very small 1st pseudo-concentric shell, tightly revolved girdles, and its thick, robust outermost coverage shell with fine pores and a pylome. Larcopyle buetschlii orion n. subsp. differs from Larcopyle cervicornis (Haeckel, 1887) based on the latter's more laterally elongated 1st pseudo-concentric shell and rougher pores, and from Larcopyle buetschlii chenmuhongi n. subsp, based on the latter's more tightly coiled girdles and smaller shell.

Dimensions. Based on the holotype specimen. The width of the central combination (S1a): ca. $16.3 \mu \mathrm{m}$; The length and width of the 1st pseudoconcentric shell: $66.8 \mu \mathrm{m}$ and $57.1 \mu \mathrm{m}$; The length and width of the 2 nd pseudo-concentric shell: 

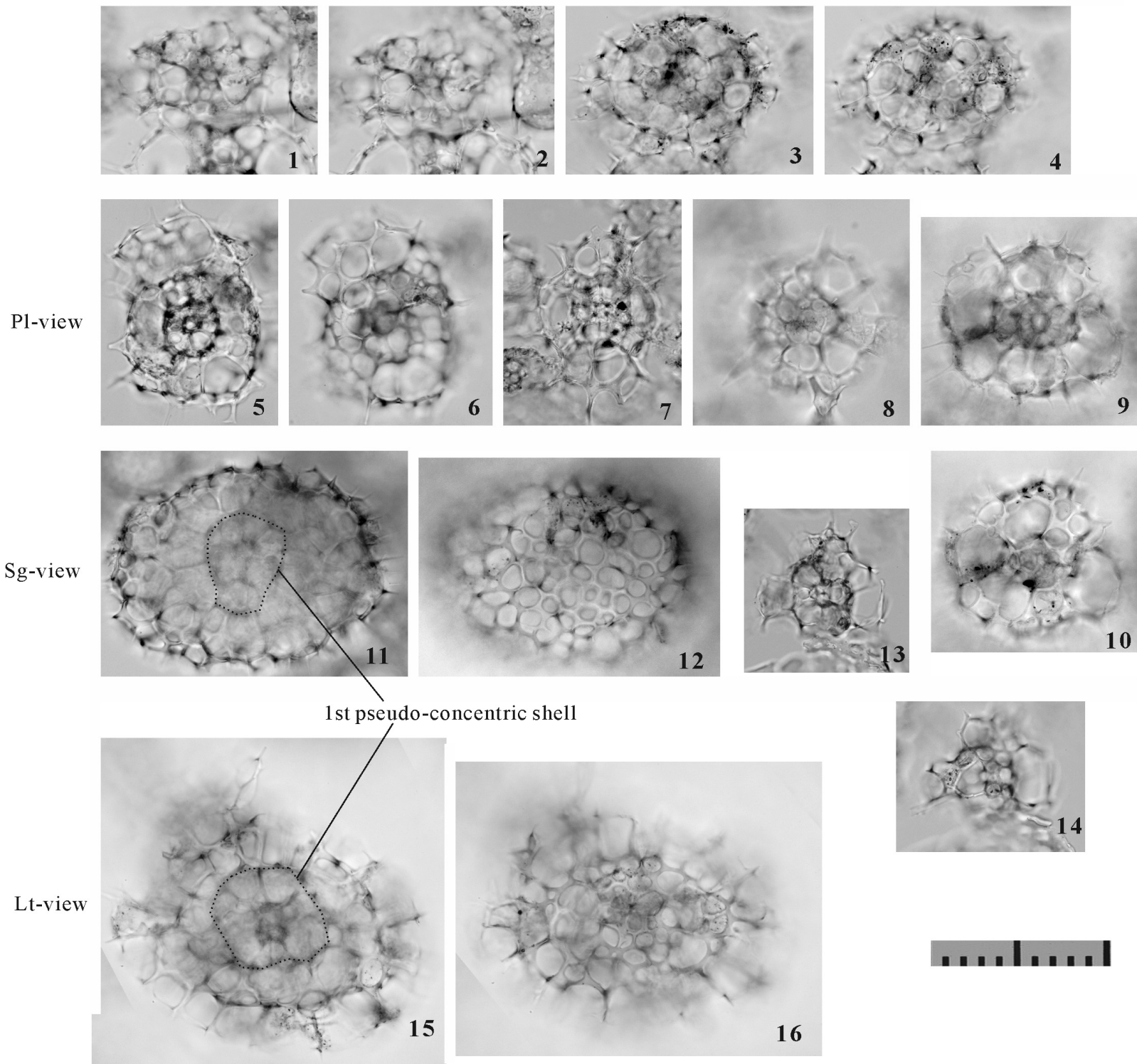

10

FIGURE 21. Photographs of the encountered morphotypes of Larcopyle buetschlii orion $\mathrm{n}$. subsp. All are Fr-view at Type 2. Scale bar equals $0.1 \mathrm{~mm}$. All specimens are from YDY05-01.

$116.2 \mu \mathrm{m}$ and $103.3 \mu \mathrm{m}$. The length and width of the outermost coverage shell: $170.4 \mu \mathrm{m}$ and 137.3 $\mu \mathrm{m}$. The ratio of length to width of the outermost coverage shell: ca. 1.2.

\section{Larcopyle molle n. sp. \\ Figure 18.7-12}

\section{zoobank.org/85A0F286-30E4-4F44-A18D-9F4585A1ED53}

Etymology. The Latin adjective "mollis" (-ie, -e), meaning gentle.

Holotype. Specimen in Figure 18.11-12 from the sample YDY05-01.
Paratype. Specimen in Figure 18.9-10 from the sample YDY05-01.

Description. Test is ellipsoid to slender ellipsoid in shape and consists of a pylodiscid-type central combination, one or two pseudo-concentric shells, and an outermost coverage shell. The central combination is obliquely oriented to the shorter axis of the test. The 1st pseudo-concentric shell is oblong in shape (the ratio of the longest axis (Ug-axis in Type 2 coordinates) to the shortest axis is 1.3-1.5) with large pores (3.6-7.8 $\mu \mathrm{m}$ in diameter). Large spaces exist between the central combination and the 1st pseudo-concentric shell, and these two 
parts are connected with two beams parallel to the Lt-axis direction, at least two apical rods, and at least three basal rods. The outermost coverage shell has a relatively rough surface. Space between the 1st pseudo-concentric shell and the outermost coverage shell is present throughout. A bore pylome is present on one side of the outermost coverage shell.

Remarks. Larcopyle molle n. sp. differs from both Larcopyle variabile (Dreyer, 1889) and Larcopyle eccentricanoides $\mathrm{n}$. sp. in that the latter two species have irregular contact between the outermost coverage shell and the 2nd pseudo-concentric shell and narrow space between the central combination and the 1st pseudo-concentric shell.

Dimensions. Based on the holotype specimen. The width of the central combination (S1a): 14.3 $\mu \mathrm{m}$; The length of the S1a-girdle: $15.3 \mu \mathrm{m}$; The length of the 1st pseudo-concentric shell: $59.3 \mu \mathrm{m}$; The length and width of the outermost coverage shell: $97.8 \mu \mathrm{m}$ and $55.3 \mu \mathrm{m}$. The length ratio to the width of the outermost coverage shell: ca. 1.8.

Larcopyle eccentricanoides $\mathrm{n}$. sp. Figure 18.13-18

zoobank.org/B6634317-B65C-4542-8745-7F8F95946E2F

cf. 1987 Sponguras? sp. (wrong spelling of the genus name); Akers, Marolt, and Navarette, pl. 1, fig. 9.

Etymology. Similar to Larcopyle eccentrica.

Holotype. Specimen in Figure 18.13-14 from the sample YDY05-01.

Paratype. Specimen in Figure 18.15-16 from the sample YDY05-01.

Description. Test is spindle-shaped to ellipsoid and consists of a pylodiscid-type central combination, two ellipsoid pseudo-concentric shells, and an outermost coverage shell with a slender bore pylome. The central combination is spherical in shape. The 1st pseudo-concentric shell appears rectangular in shape from some directions but spherical from other directions. The relationship between the central combination and the remaining pseudo-concentric shell is unknown. The 2nd pseudo-concentric shell is also rectangular in shape. The longest axis of the 1st pseudo-concentric shell is parallel to that of the 2nd pseudo-concentric shell. In contrast, the longest axis of the outermost shell is variably oriented in the direction of the 2nd pseudo-concentric shell. The stage of development of the outermost coverage shell is also variable from a complete ellipsoid to spindlelike coverage to incomplete conditions at the joint with the 2nd pseudo-concentric shell. Because of these irregular orientations and developmental conditions of the outermost coverage shell, the space between the 2nd pseudo-concentric shell and the outermost coverage shell is different around the 2nd pseudo-concentric shell. The pore frames of the 2nd pseudo-concentric shell are robust with relatively large pores (ca. $5 \mu \mathrm{m}$ in diameter).

Remarks. Larcopyle eccentricanoides $\mathrm{n}$. $\mathrm{sp}$. is similar to Larcopyle eccentrica Lazarus, Faust and Popova-Goll, 2005, with a rectangular 2nd pseudoconcentric shell and a slender bore pylome. The former is distinguishable from the latter in that the latter has more pores in former's thick-walled outermost coverage shell, as well as sufficient space between the outermost coverage shell and the preceding pseudo-concentric shell. Larcopyle eccentricanoides $\mathrm{n}$. $\mathrm{sp}$. is distinguishable from other Larcopyle species based on the former's presence of the quadrangular 2nd pseudo-concentric shell. The direction of the outermost coverage shell is less important for determining the species name.

Dimensions. Based on the holotype specimen. The length and width of the 1st pseudo-concentric shell: $24.4 \mu \mathrm{m}$ and $17.1 \mu \mathrm{m}$; The length and width of the 2nd pseudo-concentric shell: $42.0 \mu \mathrm{m}$ and $35.1 \mu \mathrm{m}$. The length and width of the outermost coverage shell: $73.9 \mu \mathrm{m}$ and $45.8 \mu \mathrm{m}$. The ratio of length to width of the outermost coverage shell: 1.6.

\section{Larcopyle pulchella $\mathrm{n} . \mathrm{sp}$.}

Figure 18.19-22

\section{zoobank.org/E6AD5779-03F0-4709-9EB2-235B05CBC4A0}

Etymology. The Latin adjective "pulchellus" (-a, um), meaning pretty.

Holotype. Specimen in Figure 18.19-20 from the sample YDY05-01.

Paratype. Specimen in Figure 18.21-22 from the sample YDY05-01.

Description. Test is flat and ellipsoid in shape and consists of a pylodiscid-type central combination, one ellipsoid pseudo-concentric shell, and an outermost coverage shell with a wide bore pylome. Additional caps may develop at the apex and pylomate ends in mature forms. The central combination appears spherical or rectangular in shape depending on the orientation of observation. The 1st pseudo-concentric shell appears rectangularellipsoid in shape. The 1st pseudo-concentric shell is connected with the central combination by at least eight rods from each edge of the central combination. No pylomate structure exists in the 1st pseudo-concentric shell. The longest axis of the 1 st pseudo-concentric shell is parallel to that of the central combination. The outermost shell is latticed 
and is also rectangular-ellipsoid in shape; its longest axis is parallel to the longest axis of the 1st pseudo-concentric shell. A bore pylome is present during the ontogenetic stage with a thin-walled outermost shell; this pylome is enclosed in the thickwalled ontogenetic stage. The sizes of the pores of the 1stpseudo-concentric shell and the outermost shell are similar, ranging from 12 to $18 \mu \mathrm{m}$ in diameter.

Remarks. Larcopyle pulchella n. sp. is characterized by a rectangular-ellipsoid 1st pseudo-concentric shell. The developmental stage of the outermost shell varies. This new species differs from "Prunopyle" longiseta (Dreyer, 1890) in that the latter has a more spherical outermost coverage shell and a larger bore pylome. This new species is different from Larcopyle peregrinator Lazarus, Faust, and Popova-Goll, 2005, in that the latter has a more robust outermost coverage shell with deeply depressed pores and numerous spinules around the mouth of the bore pylome.

Dimensions. Based on the holotype specimen. The length and width of the 1st pseudo-concentric shell: $42.5 \mu \mathrm{m}$ and $31.9 \mu \mathrm{m}$; The length and width of the outermost coverage shell: $74.3 \mu \mathrm{m}$ and 49.7 $\mu \mathrm{m}$. The ratio of length to width of the outermost coverage shell: ca. 1.5.

Genus SPHAEROPYLOLENA n. gen. zoobank.org/F9753C4-FFFD-412B-AA11-5819E45DB6EB

Type species. Sphaeropylolena laxa $\mathrm{n}$. gen. et $\mathrm{n}$. sp.

Etymology. Latin feminine noun "sphaera" (-ae) and the genus name Pylolena, meaning spherical pylodiscid genera. Grammatical feminine noun.

Description. Test consists of a triangular 1st pseudo-concentric shell with a S1a (microsphere), an inflated triangular 2nd pseudo-concentric shell, and surrounding spherical pseudo-concentric shells, with more than eight (likely up to 12) strong radial beams. The architecture of the first two triangular pseudo-concentric shells is the same as that of the genus Pylodiscus. The 3rd pseudo-concentric shell has rounded corners. Its shape is variable between ellipsoid, inflated pentagonal, and inflated hexagonal shapes, depending on the orientation of the test. The 3rd pseudo-concentric shell comprises six to eight girdles. A joint with three or four girdles forms on a flat side of the 2nd pseudo-concentric shell. The tunnel of each gate is oriented radially from the center of the test. Similar sets of girdles develop on the opposite flat side of the 2nd pseudo-concentric shell. These two sets of girdles from both flat sides are connected by the opposite sides of other girdles with visible apertures. These girdles resemble circular bands or several jointed girdles and will then form the 3rd pseudo-concentric shell. In some case, girdles of the 3rd pseudoconcentric shell are spirally turned to form different shapes, similar to the 2nd pseudo-concentric shell. The 3rd pseudo-concentric shell possesses several apertures relevant to gates, but the orientations of these gates are irregular relative to the encircling direction of each girdle. Radial spines may or may not be present; if present, several spines emerge from the edge of the girdles of the 2nd pseudo-concentric shell, and two more spines connect to the girdles of the 2 nd pseudo-concentric shell. Pores are circular to subcircular in the central combination and subcircular to elliptical in the 1st pseudo-concentric shell.

Remarks. The overall appearance of Sphaeropylolena is similar to that of Pentapylonium Dumitrica, 1991a (Dactyliosphaeridae, Pylonioidea; type species Pentapylonium implicatum Dumitrica, 1991a), but the internal structure is different. The genus Sphaeropylolena n. gen. is similar to the genus Discozonium Haeckel, 1887, but the original description of the latter described a "pylodiscid with Triopyle-shaped medullary shell and Pylodiscusshaped cortical shell, which is surrounded by an equatorial chambered girdle" (Haeckel, 1887, p. 571). Sphaeropylolena $\mathrm{n}$. gen. does not have an "equatorial chambered girdle"; it has a Pylodiscustype central combination and two pseudo-concentric shells. Therefore, juvenile forms of these two genera may not be differentiable from Pylodiscus, although Sphaeropylolena n. gen. with a 3rd pseudo-concentric shell is easily distinguished from Pylodiscus based on the former's spherical appearance. This new genus also includes "Streblacantha" circumtexta (Jørgensen, 1899), based on the photographs of its lectotype and paralectotypes (Dolven et al., 2014, plate 3, figures 1a-5b). This species was first described as a member of the genus Sorolarcus Haeckel, 1887, and later moved to Streblacantha Haeckel, 1887, by Jørgensen (1905). The lectotype and paralectotype photographs of this species from Dolven et al. (2014) show slightly oblique Sg-views in plate 3 and figures $1 \mathrm{a}$ and $4 \mathrm{a}$, oblique basal area from the PIview in plate 3 and figure 3 , and the oblique apical area from the $\mathrm{Pl}$-view in plate 3 and figure 5a. Taking their orientations into account, the skeletal structures of these type specimens of "Streblacantha" circumtexta show pylodiscid internal structure and several spirally developed girdles. Plate 3 and figure 4b of Dolven et al. (2014) show the typical three apertures of the 1st pseudo-concentric shells 

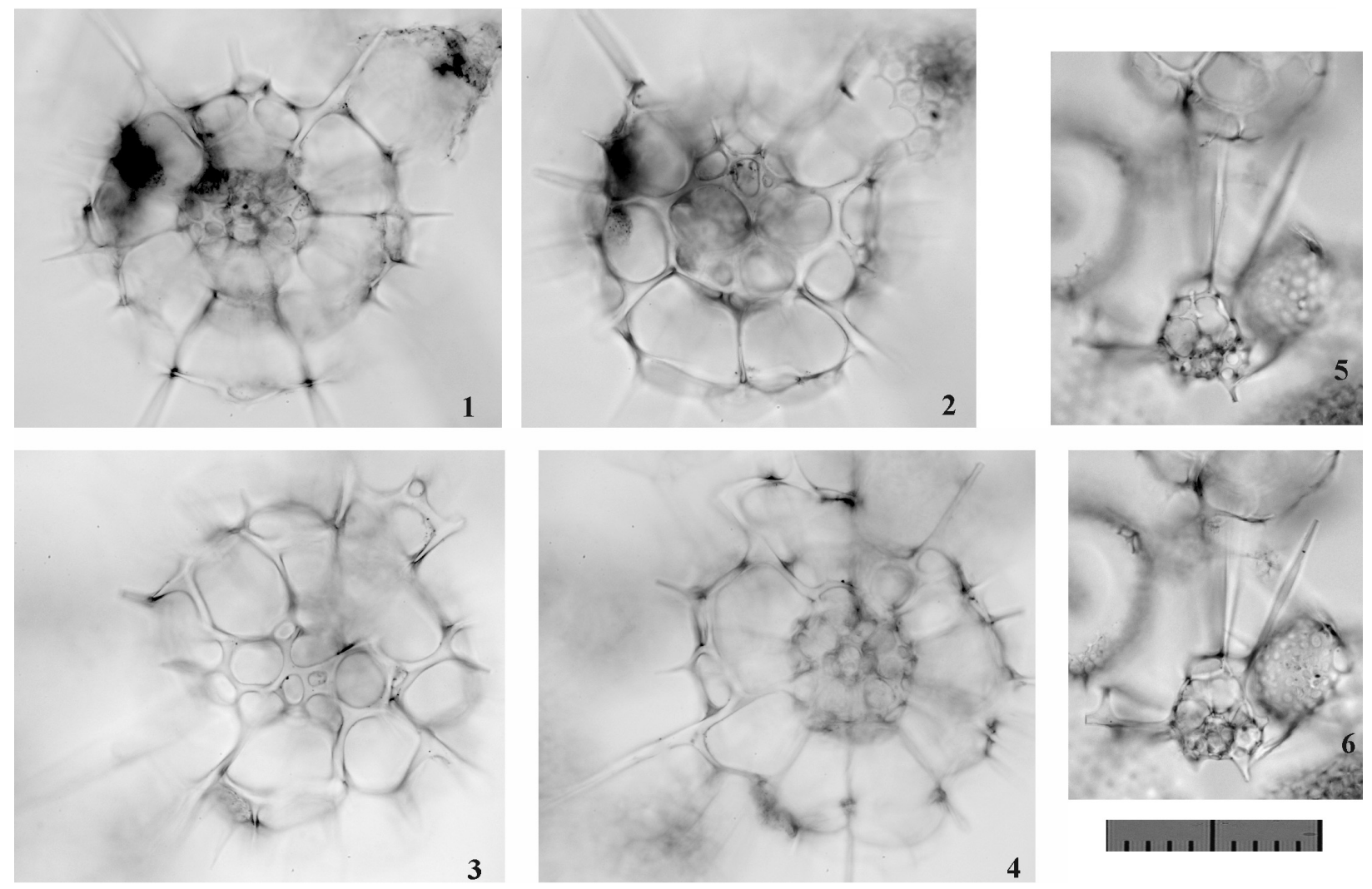

FIGURE 22. Photographs of the encountered morphotypes of Sphaeropylolena laxa n. sp. All are Fr-view at Type 2. Scale bar equals $0.1 \mathrm{~mm}$. All specimens are from YDY05-01.

of Sphaeropylolena n. gen. Although Jørgensen (1905) documented that a specimen with "a single central chamber" would "not belong to the genus Sorolarcus", "Streblacantha" circumtexta belongs to the family Pyloniidae. The type species of Streblacantha, Streblacantha siderolina Haeckel, 1887, appears to have a spherical S1a without any girdles, and thus "Streblacantha" circumtexta does not belong to Streblacantha. The type species of Sorolarcus, Sorolarcus larnacillifer Haeckel, 1887, appears to have the typical pyloniid central structure, but has spirally arranged chambers, and thus "Streblacantha" circumtextum does not belong to Sorolarcus.

\section{Sphaeropylolena laxa $\mathrm{n} . \mathrm{sp}$.}

Figure 22

\section{zoobank.org/4901699A-6BE3-4465-8AA3-1796B6E8EBE7}

1982

Larcoids gen. et sp. indet. Nakaseko and Nishimura, pl. 27, fig. 5.

1995 Phorticium circumtextum (Jørgensen); van de Paverd, p. 198, pl. 59, fig. 2.

Etymology. The Latin adjective "laxus" (-a, -um), meaning loose.
Holotype. Specimen in Figure 22.3-4 from the sample YDY05-01.

Paratype. Specimen in Figure 22.1-2 from the sample YDY05-01.

Description. The aperture of the 1st pseudo-concentric shell is closed or resembles a normal latticed pore frame. More than eight (likely 12) radial spines extend from both sides of the central combination, and extend from the boundaries between the three girdles with visible longitudinal sides on the Sg-view, as well as from the remaining three girdles. These radial spines are twice as long as the width of the 1st pseudo-concentric shell. The 2nd pseudo-concentric shell is composed of several girdles (the exact number of girdles is unknown). Two sets of girdles develop from both lateral sides of the 1st pseudo-concentric shell. These girdles attach to larger girdles. The 2nd pseudo-concentric shell is twice to three times larger than the 1st pseudo-concentric shell and has various shapes, such as a rounded triangle, pentagon, or a hexagonal sphere, when viewed from different orientations. Pores in the 2nd pseudoconcentric shell are polygonal to quadrangular in shape. Pores of the central combination are 5-10 

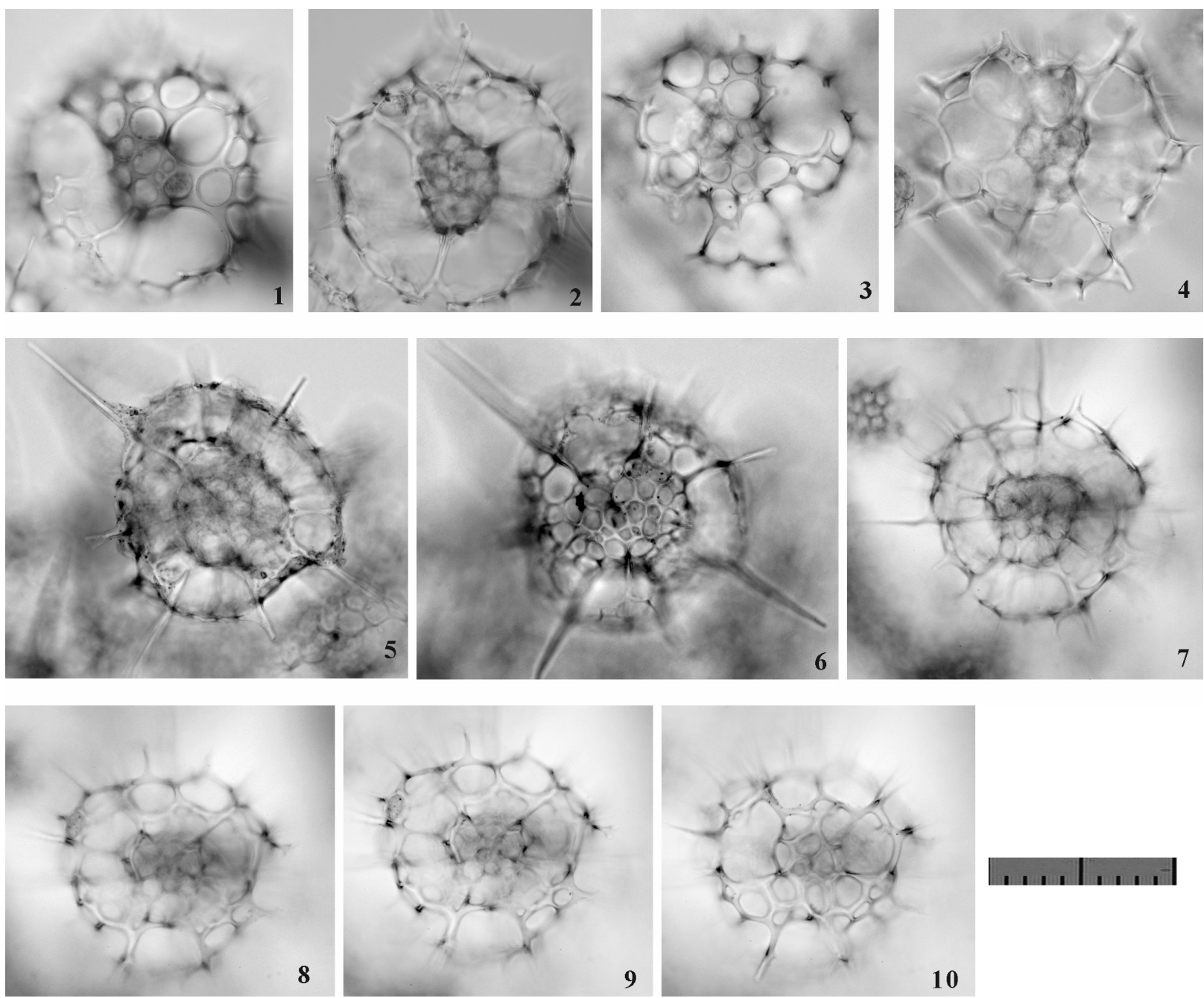

FIGURE 23. Photographs of the encountered morphotypes of Sphaeropylolena tenellispinosa n. sp. All are Fr-view at Type 2. Scale bar equals $0.1 \mathrm{~mm}$. All specimens are from YDY05-01.

$\mu \mathrm{m}$ in diameter, those of the 1st pseudo-concentric shell are $8-15 \mu \mathrm{m}$, and those of the 2nd pseudoconcentric shell are $25-50 \mu \mathrm{m}$. The larger pores of the 2nd pseudo-concentric shell are partially derived from apertures and tunnels of gates.

Remarks. Sphaeropylolena laxa n. sp. is easily distinguished from Sphaeropylolena circumtexta (Jørgensen, 1899) and Sphaeropylolena tenellispinosa $\mathrm{n}$. sp. based on its loosely spiraled girdles and the larger pores of the 2nd pseudo-concentric shell, as well as its long, robust radial spines.

Dimensions. Based on the holotype specimen. The width of the 1st pseudo-concentric shell: 55.8 $\mu \mathrm{m}$; The width of the 2nd pseudo-concentric shell: $142.1 \mu \mathrm{m}$. The width ratio of the the 2 nd pseudoconcentric shell to the 1st pseudo-concentric shell: ca. 2.5. Diameter of pores: $5-10 \mu \mathrm{m}$ (the central combination), 8-15 $\mu \mathrm{m}$ (1st pseudo-concentric shell), and 25-50 $\mu \mathrm{m}$ (2nd pseudo-concentric shell).

Sphaeropylolena tenellispinosa n. sp. Figure 23

zoobank.org/DDE29FB4-665D-4088-94BC-056C12E3200D

1992 Phorticium spp. Sugiyama, Nobuhara, and Inoue, pl. 1, fig. 4 (only).

1999 Phorticium pylonium Haeckel group; Molina-Cruz, Welling, and CaudilloBohorquez, pl. 1, figs. 6-7.

2009 Streblacantha circumtexta Jørgensen; Zhang, Chen, Xiang, Zhang, Liu, Huang, and Lu, pl. 1, fig. 2.

2013 Streblacantha cf. circumtexta Jørgensen; Suzuki, Ogawa, Ogane, and Tuji, p. 63-74, figs. 4.1-9, 5.1-21, 6.4, 7.1. 
2014d Pylodiscus triangularis Haeckel; Matsuzaki, Nishi, Suzuki, Takashima, Kawate, and Sakai, pl. 2, fig. 5 .

Etymology. The Latin adjective "tenellus" (-a, -um) and "spinosus" (-a, -um), meaning having fragile spines.

Holotype. Specimen in Figure 23.7-10 from the sample YDY05-01.

Paratype. Specimen in Figure 23.5-6 from the sample YDY05-01.

Description. Three girdles join directly on the Sgsides of the 1st pseudo-concentric shell in Type 1 coordinates. Because of this architecture, three apertures are present at the corner of the 2nd pseudo-concentric shell, which is connected to the 1st pseudo-concentric shell by several beams. Approximately eight beams emerge from each of the flat sides of the 1st pseudo-concentric shell, and additional beams extend from the boundary of the girdle with a longitudinal side visible from the Sg-view and a transverse side visible from the Ltview. These beams from the 1st pseudo-concentric shell pierce through the 2nd pseudo-concentric shell to form radial spines. Partial girdles are developed between these beams in some specimens. One apical and two sagittal rods extend from the central combination to pierce through the 2nd pseudo-concentric shell as radial spines. Further radial spines arise radially from the 2 nd pseudoconcentric shell. All of these spines are cylindrical and relatively thin. However, the radial spines from the central combination tend to be longer than the radial spines from the 1 st pseudo-concentric shell, and the latter is longer than those from the 2nd pseudo-concentric shell. The 2 nd pseudo-concentric shell is twice as large as the 1st pseudo-concentric shell. The pores are elliptical to polygonal in shape in the 2nd pseudo-concentric shell. Pores of the 1st pseudo-concentric shell are 7-11 $\mu \mathrm{m}$ in diameter, and those of the 2 nd pseudo-concentric shell are $10-23 \mu \mathrm{m}$ in diameter.

Remarks. Sphaeropylolena tenellispinosa n. sp. is easily distinguished from Sphaeropylolena laxa $\mathrm{n}$. $\mathrm{sp}$. based on its more tightly concentric 1st and 2nd pseudo-concentric shells and its shorter and more fragile radial spines. Although $S$. tenellispinosa $\mathrm{n}$. sp. is characterized by an inflated triangular 2nd pseudo-concentric shell, it is difficult apply for identifying the species because its appearance is variable in different orientations. Sphaeropylolena tenellispinosa n. sp. differs from Sphaeropylolena circumtexta (Jørgensen, 1899) in that the former's radial spines are more robust and its pseudo-concentric shells longer and more tightly concentric.
Dimensions. Based on the holotype specimen. The height of the 1st pseudo-concentric shell: 47.8 $\mu \mathrm{m}$; The height of the 2nd pseudo-concentric shell: $105.6 \mu \mathrm{m}$. The height ratio of the the 2 nd pseudoconcentric shell to the 1st pseudo-concentric shell: ca. 2.2. Diameter of pores: 7-11 $\mu \mathrm{m}$ (1st pseudoconcentric shell), and 10-23 $\mu \mathrm{m}$ (2nd pseudo-concentric shell).

\section{Subsuperfamily LARNACILLIDAE Haeckel, 1884 (non 1887) \\ Family LARNACILLIDAE Haeckel, 1884 (non 1887) sensu emend. Dumitrica, 1989}

Remarks. In contrast to the Pyloniidae, the Larnacillidae lack an S1a-girdle in their central combinations. The detailed frame structure of this microsphere is shown in Dumitrica (1989, figure 5.A-F). The Larnacillidae have girdles or cupolas on both sides of the S1a (microsphere). A pillar beam always extends from both sides of S1a along the Lt-axis in Type 1 coordinates. The Lt-axis is defined as the longest axis of the G1 girdle/cupola that attaches directly to $\mathrm{S} 1 \mathrm{a}$. The $\mathrm{Pl}$-axis is orthogonal to the Lt-axis and passes through the G2 girdle/cupola. In many cases, identical girdles or cupolas are placed on opposite sides and arranged to be mutually perpendicular to each other. A set of four (or six) cupolas/girdles makes a pseudo-concentric shell.

\section{Subfamily LARNACILLINAE Haeckel, 1887 sensu De Wever et al., 2001 \\ Genus PHORTICIUM Haeckel, 1887 sensu emend.}

*1887 Phorticium Haeckel, p. 709.

$1954 \quad$ Phorticium Haeckel; Campbell, p. D100.

Type species. Phorticium (Phortopyle) pylonium Haeckel, 1887 (SD by Campbell, 1954).

Description. Test is rounded, flat, and quadrangular in shape and consists of a central combination with one or two pseudo-concentric shells. The central combination is ellipsoid in shape and comprises an S1a with a twin girdle that is designated the G1 girdle. Each of these twin girdles has a circular to ellipsoid aperture. The Lt-, PI-, and Sgaxes are clearly determined based on their definitions. The shape of the 1st pseudo-concentric shell is similar to that of the central combination. The 1st pseudo-concentric shell is fully latticed or has twin opposite gates. The gates open on both sides of the 1st pseudo-concentric shell along the Ug-axis direction. Polar beams may or may not be present along the Ug-axis from one or both sides of the 1st pseudo-concentric shell. The 1st and 2nd pseudoconcentric shells are connected with numerous 

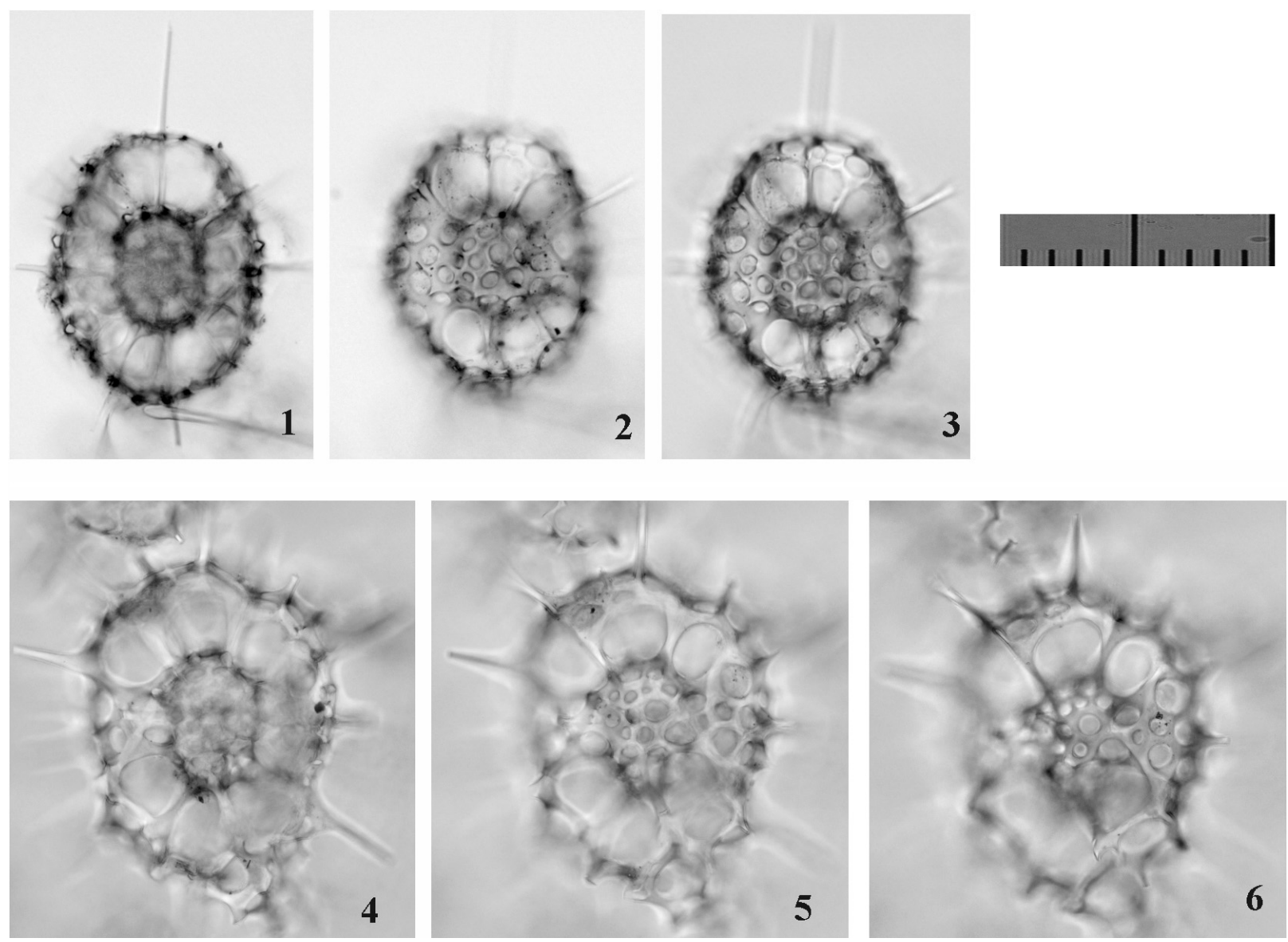

FIGURE 24. Photographs of the encountered morphotypes of Phorticium multispinum Popofsky, 1912 sensu emend. (1-3) and Phorticium itakii n. sp. (4-6). All are PI-view at Type 1, Fr-view at Type 2. Scale bar equala $0.1 \mathrm{~mm}$. All specimens are from YDY05-01.

thick pillar beams on both sides of the shells. Pillar beams are sparse in the gates between adjacent pseudo-concentric shells.

Remarks. A good reference for the internal structure of Phorticium is Sugiyama et al. (1992, plate 10, figures 1-9). Phorticium is characterized by gates between each pseudo-concentric shell oriented in nearly the same direction. Phorticium and Tetrapyle can be differentiated based on the presence or absence of the S1a-girdle, but Phorticium also tends to have numerous pillar beams between pseudo-concentric shells. This criterion is applicable for these two genera.

Phorticium multispinum Popofsky, 1912 sensu emend.

Figure 24.1-3

1912 Phorticium multispinum Popofsky, p. 153154, text-fig. 76.

1980 Octopyle octopyle Haeckel; Boltovskoy and Riedel, pl. 4, fig. 9.
Description. Test is elliptical to rounded-rectangular in shape (length ratio of the longest axis to the middle axis: ca. 1.3) and consists of a central combination, a rounded rectangular 1st pseudo-concentric shell, a 2nd pseudo-concentric shell with two gates, four long spines that are orthogonally arranged relative to each other on the Sq-plane, three to six pillar beams visible from the aperture of the 2nd pseudo-concentric shell, and numerous radial spines distributed throughout the 2nd pseudo-concentric shell. The 1st and 2nd pseudoconcentric shells are arranged in the same orientation. The 1st pseudo-concentric shell appears to be completely latticed. The 2nd pseudo-concentric shell consists of a subrounded twin girdle along the Lt-axis, and is directly connected with the 1st pseudo-concentric shell on both sagittal sides of the center. Pillar beams are present between the 1st and 2nd pseudo-concentric shells. Less than eight pillar beams are present between the 1st and 2nd pseudo-concentric shells in the direction of the Lt-axis. Most of these pillar beams pierce through 
the 2nd pseudo-concentric shell to form fine cylindrical radial spines. Two lateral spines, one apical spine and one basal spine, extend from the central combination fully mature. Pores of the 2nd pseudoconcentric shell are subcircular to elliptical in shape. Four or five pores are aligned along the Ltaxis on the joint between the 1st and 2nd pseudoconcentric shells. Eight to 10 pores are aligned along the $\mathrm{Pl}$-axis on the 2nd pseudo-concentric shell. The size ratio of the 2 nd pseudo-concentric shell to the 1 st pseudo-concentric shell is 2.2 along the Lt-axis and 2.3 along the Pl-axis.

Remarks. Phorticium multispinum Popofsky, 1912, is similar to Phorticium rotundospinosum (Tan, 1993), but the former differs from the latter in the former's absence of many pillar beams between the 1st and 2nd pseudo-concentric shells and of radially distributed radial spines around the 2 nd pseudo-concentric shell. The juvenile form of Phorticium multispinum without longer lateral spines is similar to Phorticium scitulum n. sp., but the former is distinguishable from the latter based on the former's greater numbers of pillar beams between the 1st and 2nd pseudo-concentric shells and former's larger size.

Phorticium polycladum Tan and Tchang, 1976

Figure 25

1976 Phorticium polycladum Tan and Tchang, p. 267, text-fig. 39a-b.

1980 Pylospira octopyle Haeckel; Boltovskoy and Riedel, pl. 4, fig. 7.

non 1983 Phorticium polycladum Zhiyuan et Tso-run (author's names are wrong); Srinivasan, Lombari, and Dave, p. 11, pl. 2, figs. 9.

non 1984 Phorticium polycladum Tan and Tchang; Nigrini and Lombari, p. S83-84, pl. 12, fig. $1 \mathrm{a}-\mathrm{b}$.

non 1987 Phorticium polycladum Tan and Tchang; Akers, Marolt, and Navarette, p. 16, pl. 3, figs. 9,11 .

non 1988 Phorticium polycladum Tan and Tchang; Sharma and Sharma, pl. 2, fig. 9.

non 1992 Phorticium polycladum Tan and Tchang; Gupta and Srinivasan, pl. 2, fig. 15.

non 1993 Phorticium polycladum Tan and Tchang; Sharma and Singh, pl. 2, fig. 20.

1995 Pylonidae gen. et sp. indet. van de Paverd, pl. 58, fig. 11 (only).

1996 Phorticium polycladum Tan and Tchang; Chen and Tan, p. 199-200, pl. 23, figs. 1213.

non 1999 Phorticium polycladum Tan and Tchang; Sharma, Singh, and Rawal, pl. 3, fig. 7.
1999 Phorticium polycladum Tan and Tchang; Tan and Chen, p. 255, text-fig. 5.168.

non 2003 Phorticium polycladum Tan and Tchang; Sharma and Ram, pl. 3, figs. 16-17.

2008 Phorticium polycladum Tan and Tchang; Kamikuri, Motoyama, and Nishimura, pl. 2, fig. 15.

2009 Phorticium polycladum Tan and Tchang; Itaki, p. 47, pl. 11, fig. 4.

2013 Phorticium clevei (Jørgensen); HernándezAlmeida, Bjørklund, Sierro, Filippelli, Cacho, and Flores, pl. 3, fig. 2 (only).

2014a Phorticium pylonium Haeckel; Matsuzaki, Nishi, Hayashi, Suzuki, Ikehara, Gyawali, Tanaka, and Takashima, fig. 2.9.

2014c Phorticium polycladum Tan and Tchang; Matsuzaki, Nishi, Suzuki, Kawate, Takashima, and Sakai, pl. 1, fig. 20.

2014d Phorticium polycladum Tan and Tchang; Matsuzaki, Nishi, Suzuki, Takashima, Kawate, and Sakai, pl. 2, fig. 3.

non 2015a Phorticium polycladum Tan and Tchang; Matsuzaki, Suzuki, and Nishi, p. 32, fig. 6.13-14.

2015b Phorticium polycladum Tan and Tchang; Matsuzaki, Suzuki, Nishi, Hayashi, Gyawali, Takashima, and lkehara, fig. 7.13-14.

Description. The test is large and ellipsoid in shape (the length ratio of the Ug-axis to the Pr-axis in Type 2 coordinates: ca. 1.1-1.2) in Sg-view, and it consists of an elongate central combination, a rounded rectangular 1st pseudo-concentric shell, a large 2nd pseudo-concentric shell with two large apertures in one side of the test in Sg-view, numerous pillar beams between the central combination and 1st pseudo-concentric shell and between the 1st and 2nd pseudo-concentric shells, and numerous radial spines. An incomplete 3rd pseudo-concentric shell develops in the fully mature form. The 1st and 2nd pseudo-concentric shells are arranged in a common orientation. The 1st pseudo-concentric shell has two gates in the juvenile form in the absence of the 2nd pseudo-concentric shell, and it is completely latticed in the mature form with a partial 2nd pseudo-concentric shell. Many pillar beams are present between the central combination and the 1st pseudo-concentric shell, and between the 1st and 2nd pseudo-concentric shells. Some pillar beams from the 1st pseudo-concentric shell pierce through the 2nd pseudo-concentric shell to form cylindrical radial spines. The spines between the adjacent girdles of each pseudo-concentric shell tend to be longer than other radial spines. Pores are subcircular and small (5-8 $\mu \mathrm{m}$ in diameter) on the 1 st pseudo-concentric shell, polygonal and 

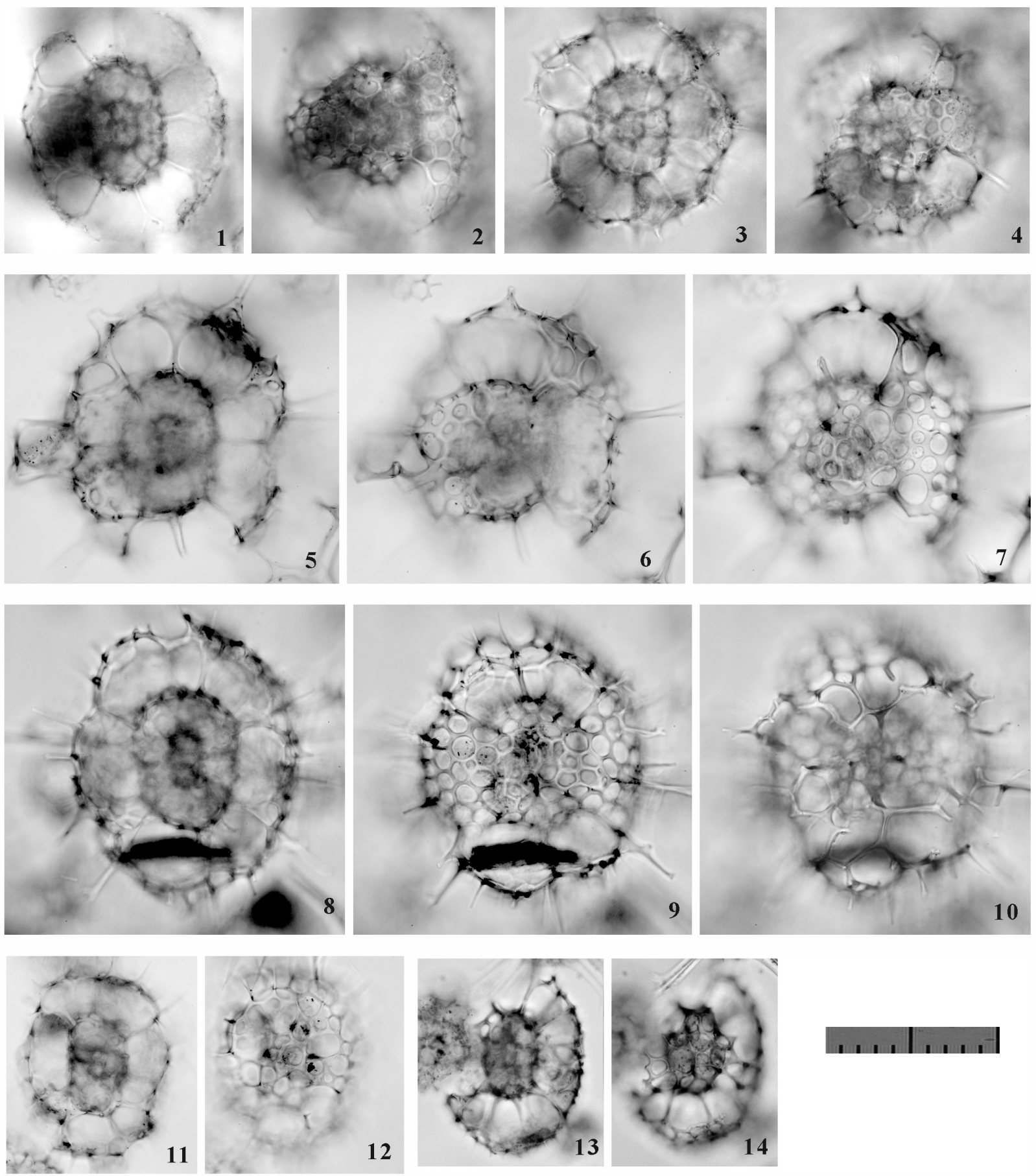

FIGURE 25. Photographs of the encountered morphotypes of Phorticium polycladum Tan and Tchang, 1976. 1-10, Sg-view at Type 1; 11-14, PI-view at Type 1. Scale bar equals $0.1 \mathrm{~mm}$. All specimens are from YDY05-01.

moderate in size (8-16 $\mu \mathrm{m}$ in diameter) on the $2 \mathrm{nd}$ pseudo-concentric shell, and polygonal and large (16-35 $\mu \mathrm{m}$ in diameter) on the 3rd pseudo-concentric shell. Four or five pores are aligned along the Lt-axis at the joint between the 1st and 2nd pseudo-concentric shells, and 10 to 14 pores are aligned along the $\mathrm{Pl}$-axis on the 2nd pseudo-concentric shell. The pore frames of the 1st and 2nd pseudo-concentric shells are very thin. The size ratio of the 2nd pseudo-concentric shell to the 1st pseudo-concentric shell is $1.8-2.0$ along the Ltaxis and 1.9-2.3 along the PI-axis. 
Remarks. Phorticium polycladum Tan and Tchang, 1976 , is characterized by its large 1st and 2nd pseudo-concentric shells, the large size ratio between the 2nd pseudo-concentric shell to the 1st pseudo-concentric shell, and its many radial spines. Nigrini and Lombari (1984) included a morphotype with a smaller size ratio of the 2 nd pseudo-concentric shell to the 1st pseudo-concentric shell (1.7 along the longer axis of the test and 1.8 along the middle axis of the test, as shown in plate 12 , figure $1 \mathrm{a}$ and $1 \mathrm{~b}$ ) and a higher number of pores on the 2nd pseudo-concentric shell (7-8 pores and 14 pores are visible along the Fr-axis and the Pr-axis, respectively), but this smaller morphotype is inferred to be a different species because no intermediate forms were detected in our samples. Phorticium polycladum is distinguishable from Phorticium pylonium Haeckel, 1887, because the former has larger pores on the 2nd pseudo-concentric shell, robust pillar beams between the 1st and 2nd pseudo-concentric shell, and robust radial spines.

Phorticium itakii n. sp.

Figure 24.4-6

zoobank.org/CF919390-DE41-429D-AADB-666B55AAFB07

2008 Phorticium pylonium Haeckel; Itaki, Minoshima, and Kawahata, pl. 2, figs. 1516.

Etymology. Takuya Itaki who illustrated a typical specimen in his paper.

Holotype. Specimen in Figure 24.4-6 from the sample YDY05-01.

Description. The test is sub-rectangular in shape (the length ratio of the Fr-axis to the Pr-axis: ca. 1.3-1.4) in Sg-view, and consists of an elongate central combination, an elliptical 1st pseudo-concentric shell, a 2nd pseudo-concentric shell with two large apertures in one side of the test in the Sg-view, and numerous robust radial spines. The 1st pseudo-concentric shell is completely latticed in its fully mature form. The 2nd pseudo-concentric shell is roughly sub-rectangular in shape with a rough surface. Three to six pillar beams extend from both ends of the 1st pseudo-concentric shell in the Lt-axis direction in Type 1 coordinates, and these beams connect to the 2 nd pseudo-concentric shell. Some of these pillar beams pierce through the 2nd pseudo-concentric shell to form robust, cylindrical radial spines. Pores are subcircular and small (4-7 $\mu \mathrm{m}$ in diameter) on the 1st pseudo-concentric shell, and polygonal and moderate in size (10-14 $\mu \mathrm{m}$ in diameter) on the 2nd pseudo-concentric shell. Four or five pores are aligned along the Lt-axis at the joint between the 1st and 2nd pseudo-concentric shells, and eight to 12 pores are aligned along the $\mathrm{Pl}$-axis on the 2 nd pseudo-concentric shell. Pore frames of the 1st and 2nd pseudo-concentric shells are thin. The size ratio of the 2nd pseudo-concentric shell to the 1st pseudoconcentric shell is ca. 2.4 along the Lt-axis and 2.8 along the $\mathrm{Pl}$-axis.

Remarks. Phorticium itakii n. sp. is characterized by robust radial spines, three to six pillar beams visible through the gates of the 2nd pseudo-concentric shell, and a sub-rectangular 2 nd pseudoconcentric shell with larger pores. Phorticium itakii $\mathrm{n}$. sp. is easily confused with Phorticium pylonium Haeckel, 1887; however, P. itakii n. sp. differs from $P$. pylonium in former's more robust spines between the central combination and 1st pseudoconcentric shell. Phorticium itakii n. sp. differs from Phorticium clevei (Jørgensen, 1899) in that the former typically has a quadrangular 2nd pseudo-concentric shell and a larger size ratio between the 2nd pseudo-concentric shell and the 1st pseudoconcentric shell. Phorticium itakii n. sp. is distinguishable from Phorticium polycladum Tan and Tchang, 1976 based on the latter's more rounded elliptical 2nd pseudo-concentric shell. The size ratio of the 2 nd pseudo-concentric shell to the $1 \mathrm{st}$ pseudo-concentric shell is also different between these two species. It was measured as ca. 2.4 along the Lt-axis and 2.8 along the Pl-axis for Phorticium itakii n. sp. and as $1.8-2.0$ along the Ltaxis and 1.9-2.3 along the PI-axis for Phorticium polycladum.

Dimensions. Based on the holotype specimen. The length along the Lt-axis: $111.1 \mu \mathrm{m}$ (2nd pseudo-concentric shell), $46.4 \mu \mathrm{m}$ (1st pseudoconcentric shell); The length along the Pl-axis: 88.1 $\mu \mathrm{m}$ (2nd pseudo-concentric shell), $31.6 \mu \mathrm{m}$ (1st pseudo-concentric shell); The size ratio of the 2nd pseudo-concentric shell to the 1st pseudo-concentric shell: ca. 2.4 along the Lt-axis and ca. 2.8 along the $\mathrm{Pl}$-axis. The length ratio of the $\mathrm{Fr}$-axis to the $\mathrm{Pr}$ axis in Sg-view: ca. 1.3-1.4; Diameter of pores on the 1st pseudo-concentric shell: 4-7 $\mu \mathrm{m}$; Diameter of pores on the 2nd pseudo-concentric shell: 10$14 \mu \mathrm{m}$.

\section{Phorticium scitulum n. sp.} Figure 26

zoobank.org/0B55A012-2DB2-4635-9BAB-485D695A4F12

Etymology. The Latin adjective "scitulus" (-a, -um), meaning good looking.

Holotype. Specimen in Figure 26.6-7 from the sample YDY05-01.

Paratype. Specimen in Figure 26.16-17 from the sample YDY05-01. 

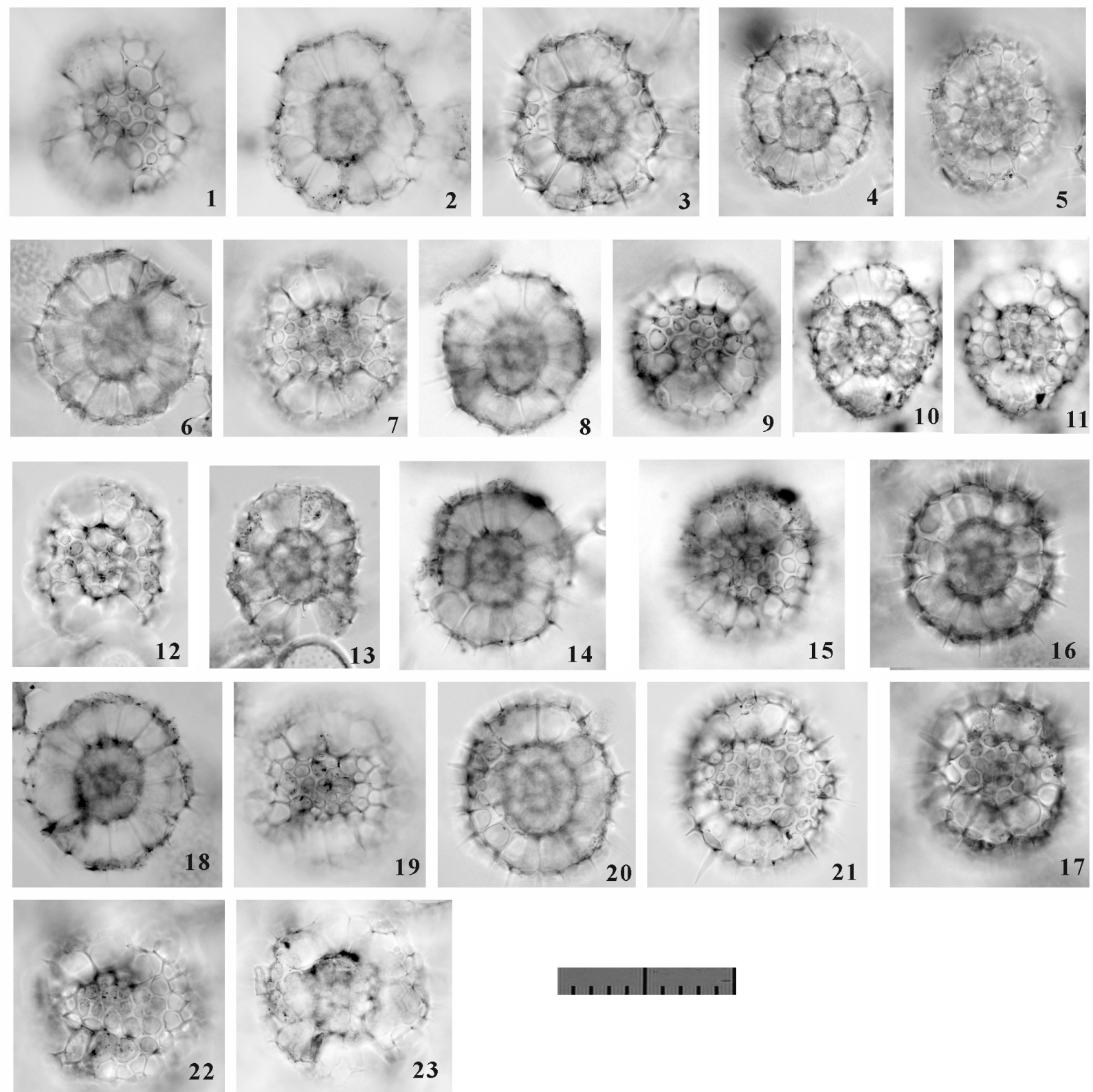

23

FIGURE 26. Photographs of the encountered morphotypes of Phorticium scitulum n. sp. 1-23, Sg-view at Type 1. Scale bar equals $0.1 \mathrm{~mm}$. All specimens are from YDY05-01.

Description. The test is circular to sub-circular in shape (the length ratio of the longest axis to the middle axis: ca. 1.0-1.2) from the Sg-view, and it consists of an oblong central combination, an elliptical 1st pseudo-concentric shell, a circular to subcircular 2nd pseudo-concentric shell with a large aperture on both sides of the test in Sg-view, numerous pillar beams between the central combination and 1st pseudo-concentric shell and between the 1st and 2nd pseudo-concentric shells, and numerous short radial spines. The 1 st and 2 nd pseudo-concentric shells are arranged in the same orientation. The 1st pseudo-concentric shell has two gates in its juvenile form without the 2nd pseudo-concentric shell, and is completely latticed in its grown form with a partial 2 nd pseudo-concentric shell. The ratio of the width of the 2 nd pseudoconcentric shell along the Lt-axis to that along its $\mathrm{Pl}$-axis is smaller than this ratio for the 1st pseudoconcentric shell. Many pillar beams are present between the 1st and 2nd pseudo-concentric shells. Some pillar beams from the 1st pseudo-concentric 
shell pierce through the 2 nd to form short, cylindrical radial spines. Pores are subcircular and small (5-8 $\mu \mathrm{m}$ in diameter) on the 1st pseudo-concentric shell, and subcircular to polygonal in shape and moderate in size (8-13 $\mu \mathrm{m}$ in diameter) on the 2 nd pseudo-concentric shell. Six or eight pores are aligned along the Lt-axis on the joint part between the 1st and 2nd pseudo-concentric shells, and 10 to 12 pores are aligned along the $\mathrm{Pl}$-axis on the 2nd pseudo-concentric shell. Pore frames of the 1st and 2nd pseudo-concentric shells are very thin. The size ratio of the 2 nd to the 1 st pseudo-concentric shell is 1.9-2.6 along the Lt-axis and 1.9-2.5 along the $\mathrm{Pl}$-axis.

Remarks. Phorticium scitulum n. sp. differs from Phorticium polycladum Tan and Tchang, 1976 in that the latter has a larger and more elongate test, a larger size ratio between the 2nd pseudo-concentric shell and the 1st pseudo-concentric shell, a lower number of pillar beams between the 1st and 2nd pseudo-concentric shells, larger pores on the 2nd pseudo-concentric shell, and more developed radial spines. Phorticium scitulum n. sp. is distinguishable from Phorticium multispinum Popofsky, 1912, based on its four major radial spines that arise from the apical, basal and both lateral sides of the central combination.

Dimensions. Based on the holotype specimen. The length along the Lt-axis: $95.0 \mu \mathrm{m}$ (2nd pseudoconcentric shell), $42.9 \mu \mathrm{m}$ (1st pseudo-concentric shell); The length along the Pl-axis: $89.1 \mu \mathrm{m}$ (2nd pseudo-concentric shell), $36.9 \mu \mathrm{m}$ (1st pseudoconcentric shell); The size ratio of the 2 nd pseudoconcentric shell to the 1st pseudo-concentric shell: ca. 2.2 along the Lt-axis and ca. 2.4 along the PIaxis. Diameter of pores on the 1st pseudo-concentric shell: ca. 5-8 $\mu \mathrm{m}$; Diamter of pores on the 2nd pseudo-concentric shell: ca. 8-13 $\mu \mathrm{m}$.

\section{Genus SPHAEROLARNACILLIUM n. gen.} zoobank.org/5545813D-C45D-4204-985E-D317AE437220

Type species. Sphaerolarnacillium cochleatum $n$. gen. et n. sp.

Etymology. Derived from a spherical genus belonging to the family Larnacillidae. The grammatical neuter.

Description. Test consists of a larnacillid central combination and several spherical pseudo-concentric shells. Radial spines may be present or absent. The larnacillid central combination comprises a heteropolar S1a (microsphere) with a 1st twin girdle that develops on both sides of the S1a along the Lt-axis. A rod extends from each side of the S1a along the Lt-axis. The 1st pseudo-concentric shell has two gates with apertures visible in the Sg- view. The 2 nd and subsequent pseudo-concentric shells are composed of spirally turned girdles or resemble spherical lattice shells with several apertures. These apertures are relevant to pyloniid gates (Table 1). These pseudo-concentric shells are connected to each other by several pillar beams. Radial spines, if present, arise from pseudo-concentric shells. Gates of this genus cannot be attributed to a relationship with the girdle; these gates are thus named "para-gates." Paragates occasionally close with normal latticed pore frames when a later pseudo-concentric shell develops.

Remarks. Morphotypes with spiral structures have been ascribed to the genera Lithelius (Litheliidae, Lithelioidea), Larcopyle (Pyloniidae, Pylonioidea), Sphaeropylolena n. gen. (Pyloniidae, Pylonioidea), and this genus. Lithelius differs from Sphaerolarnacillium $\mathrm{n}$. gen. based on the presence of a spherical actinommid microsphere. Larcopyle has a small pyloniid central combination and an ellipsoid test, and Sphaeropylolena n. gen. has a pylodiscid central structure. This genus should be carefully differentiated from Sphaeropylolena $\mathrm{n}$. gen. by examining ontogenetic growth series as well as differently oriented specimens in slides because the internal structure appears to have a triangular pattern in obliquely oriented Sphaerolarnacillium specimens. Sphaerolarnacillium $\mathrm{n}$. gen. differs from Larnacalpis Haeckel, 1887 (type species: Larnacalpis lentellipsis Haeckel, 1887, designated by Frizzell and Middour, 1951), based on the latter's presence of a completely closed 2nd pseudo-concentric shell and the absence of subsequent girdles.

\section{Sphaerolarnacillium cochleatum n. sp.}

Figure 27

zoobank.org/223A8085-9F66-4938-8C22-37978D99A62B

1978 Trizonium sp. McMillen and Casey, pl. 3, fig. 1.

1987 Tholospira cervicornis Haeckel group; Dworetzky and Morley, pl. 2, fig. 3.

1991 Tholospira cervicornis Haeckel group; Takahashi, p. 91, figs. 7-9 (only).

1995 Pylonidae gen. et sp. indet. van de Paverd, pl. 58, fig. 7.

1995 Phorticium? sp. van de Paverd, pl. 59, figs. $1,7$.

Etymology. Latin adjective "cochleatus" (-a, -um), meaning spiral/screw formed.

Holotype. Specimen in Figure 27.12-14 from the sample YDY05-01.

Paratype. Specimen in Figure 27.9-10 from the sample YDY05-01. 

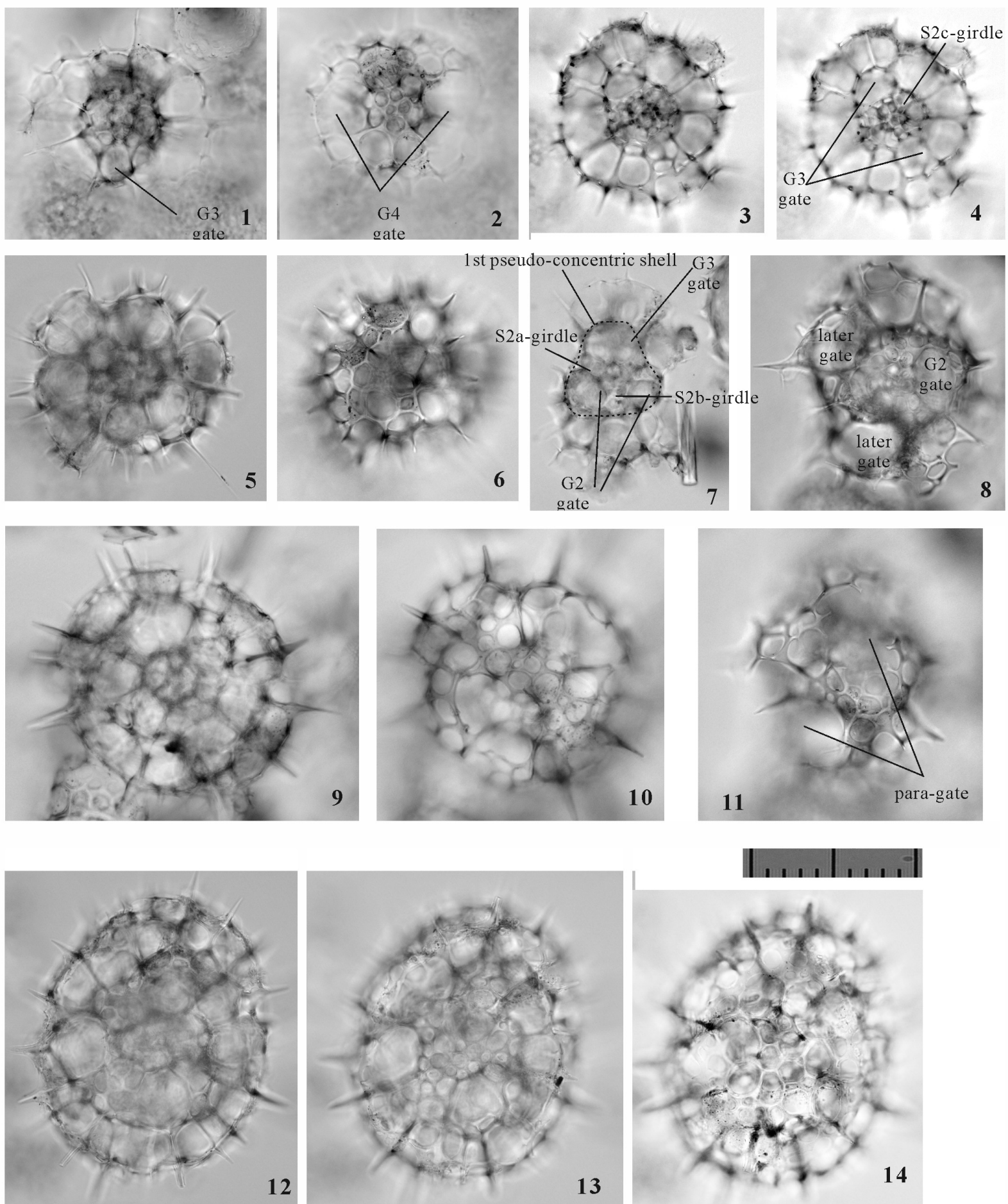

FIGURE 27. Photographs of the encountered morphotypes of Sphaerolarnacillium cochleatum gen. et $\mathrm{n}$. $\mathrm{sp}$. All are Fr-view at Type 2. Scale bar equals $0.1 \mathrm{~mm}$. All specimens are from YDY05-01. 
Description. Test shows a highly spiraled spherical to oval shape with numerous short radial spines and consists of a larnacillid central combination, two pseudo-concentric shells with spiral girdles, and incompletely developed girdles. Cylindrical radial spines are radially distributed during any ontogenetic stage of the test except in specimens with only the larnacillid central combination. Wellregulated girdles are coiled along either the Lt-, Sg, or Pl-axis. The 1st pseudo-concentric shell consists of S2a-, S2b-, and S2c-girdles and appears triangular. This triangular shadow is formed by a combination of the other side of the twin S2b-girdle and both sides of the twin S2a-girdles. In addition, one side of the twin S2a-girdle is generally fragile and coarsely framed. The S2c-girdle develops vertically to the orientation of the S2b-girdles and they turned irregularly to form a spherical appearance. The S2c-girdles and subsequent girdles join at similar diameter levels of the test to form the 1st pseudo-concentric shell. The pseudo-concentric shell has gates or openings related to the spiral girdles. The 1st pseudo-concentric shell includes G2 gates and G3 gates. There "para-gates" are present in the outmost cap-like twin girdles. Fine, cylindrical radial spines emerge from the larnacillid central combination, which consists of the larnacillid central combination. The 2nd pseudo-concentric shell is composed of spiral girdles. Radial spines that arise from the larnacillid central combination become pillar beams beneath the 2 nd pseudo-concentric shell because these radial spines do not pierce through the 2nd pseudo-concentric shell. Instead, new pillar beams arise from the 1st pseudo-concentric shell and extend outward from the 2nd pseudo-concentric shell to form cylindrical radial spines. Because the 1st pseudo-concentric shell is composed of spiral girdles, several paragates are present, and these spiral girdles have an overall irregular appearance. Pores on the larnacillid central combination are sub-circular and small. Those on the 1st pseudo-concentric shell arelarger than those on the inner shell, and smaller than those on the outer shell. Those on the 2nd pseudoconcentric shell are large and polygonal with very thin pore frames.

Remarks. Sphaerolarnacillium cochleatum is distinguished from Sphaerolarnacillium exactum $\mathrm{n}$. $\mathrm{sp}$. in that the latter has more regular pseudo-concentric shells and an overall flattened appearance. Furthermore, Sphaerolarnacillium cochleatum has gates in its pseudo-concentric shells, but there are no gates in the pseudo-concentric shells of Sphaerolarnacillium exactum. Sphaerolarnacillium cochleatum can be differentiated from Sphaerolarnacillium tanzhiyuani $\mathrm{n}$. $\mathrm{sp}$. based on the former's larger size and more elliptical shape.

Dimensions. Based on the holotype specimen. The height of the 1st pseudo-concentric shell: ca. 93-98 $\mu \mathrm{m}$; The length and width of the 2nd pseudo-concentric shell: $166.5 \mu \mathrm{m}$ and $133.7 \mu \mathrm{m}$. The ratio of length to width of the 2 nd pseudo-concentric shell: ca. 1.2.

\section{Sphaerolarnacillium exactum n. sp. Figure 28}

zoobank.org/AF5B32CE-D9BD-4C19-99B7-ECA749124FA9

1979

Pylospira octopyle Haeckel? Nigrini and Moore, p. S139-140, pl. 17, fig. 6c (only).

Etymology. Latin adjective "exactus" (-a, -um), meaning accurate.

Holotype. Specimen in Figure 28.6-8 from the sample YDY05-01.

Paratype. Specimen in Figure 28.3-5 from the sample YDY05-01.

Description. Test is flattened and ellipsoid in shape with several short radial spines and consists of a larnacillid central combination, two complete pseudo-concentric shells, and twin cap-like pseudo-concentric shells. Cylindrical radial spines are radially distributed at any ontogenetic stage of the test. Well-regulated girdles are coiled along either the Lt-, Sg-, or Pl-axis. The complete larnacillid central combination appears flattened and ellipsoid in shape. The 1st and 2nd pseudo-concentric shells have no gates. The Ug-axis of the test in Type 2 coordinates is parallel to the Lt-axis in Type 1 coordinates, whereas the Pr-axis of the test in Type 2 coordinates is oriented parallel to the $\mathrm{Pl}$-axis. The 2nd pseudo-concentric shell also has a flattened ellipsoid shape, but it shows a more circular outline than the larnacillid central combination. The 2nd pseudo-concentric shell is connected with the 1st pseudo-concentric shell by several pillar beams. Some of these pillar beams are derived from the Sg-rods and extend along the boundary between the S2a- and S2b-girdles. In a fully mature specimen, narrow cap-like girdles develop on both sides of the 2nd pseudo-concentric shell along the Lt-axis. No gates are present in these outermost cap-like twin girdles. Pores on the 1st pseudo-concentric shell are sub-circular to rounded polygonal in shape and small in size. Those on the 2nd pseudo-concentric shell are large and polygonal with very thin pore frames.

Remarks. Sphaerolarnacillium exactum n. sp. is easily distinguished from any other Sphaerolarnacillium species based on its more regularly formed pseudo-concentric shells and overall flattened 

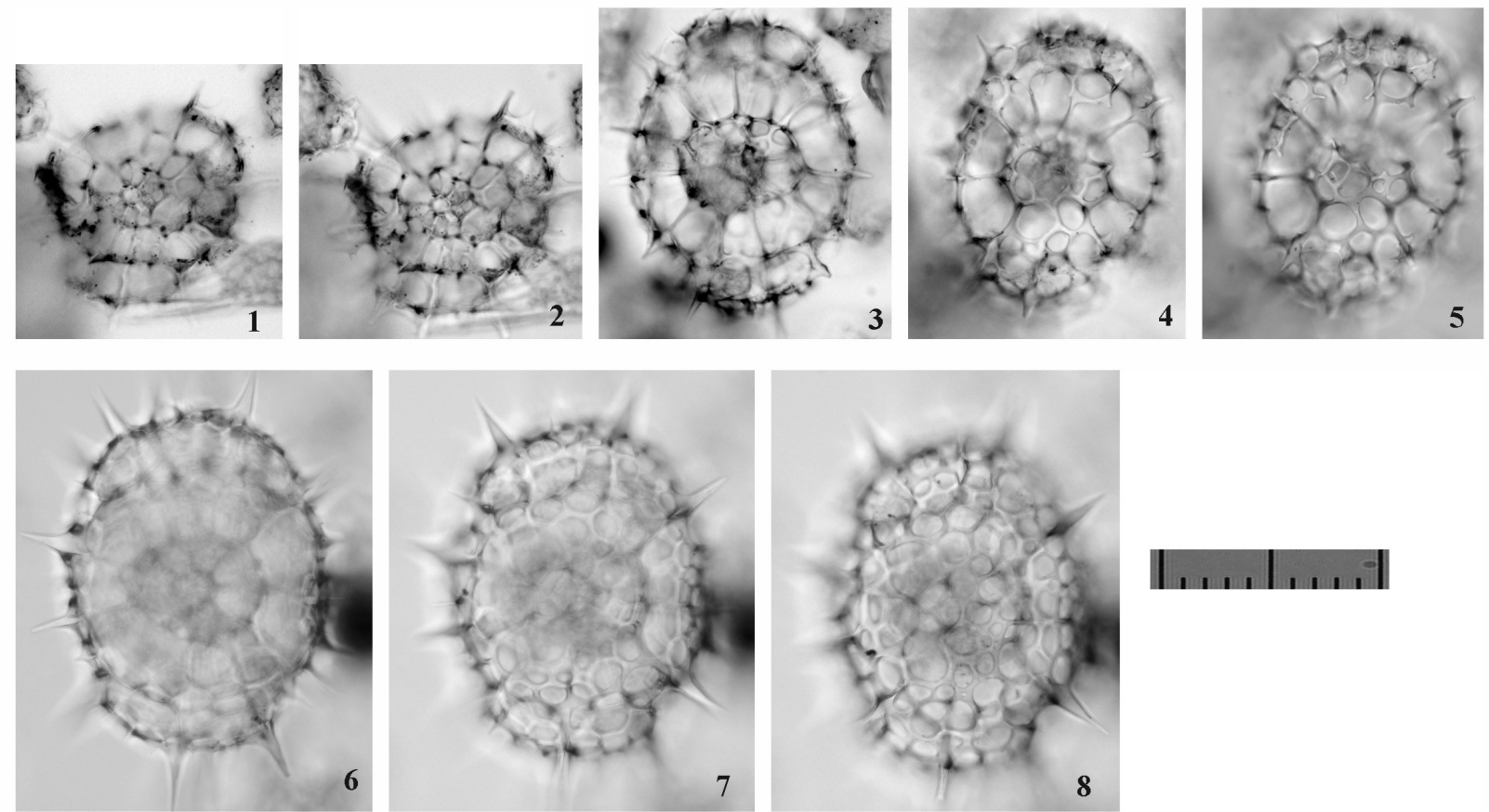

FIGURE 28. Photographs of the encountered morphotypes of Sphaerolarnacillium exactum $\mathrm{n}$. sp. All are Fr-view at Type 2. Scale bar equala $0.1 \mathrm{~mm}$. All specimens are from YDY05-01.

appearance. Sphaerolarnacillium exactum n. sp. has no gates in the pseudo-concentric shells. However, Sphaerolarnacillium cochleatum and Sphaerolarnacillium tanzhiyuani both have gates or openings related to the spiral girdles.

Dimensions. Based on the holotype specimen. The length and width of the 1st pseudo-concentric shell: $61.3 \mu \mathrm{m}$ and $45.9 \mu \mathrm{m}$; The length and width of the 2nd pseudo-concentric shell: $111.0 \mu \mathrm{m}$ and $107.2 \mu \mathrm{m}$. The height of the cap-like pseudo-concentric shell: $23 \mu \mathrm{m}$. The size ratio of the $2 \mathrm{nd}$ pseudo-concentric shell to the 1st pseudo-concentric shell: ca. 1.8 in length and ca. 2.3 in width.

Sphaerolarnacillium tanzhiyuani $\mathrm{n}$. sp.

Figure 29

\section{zoobank.org/2C1CA41A-F0DD-4133-8401-D00E0BBDC498}

1976 Lithelius? sp. Tan and Tchang, p. 264, textfig. 35.

1984b Tholospira sp. Nishimura and Yamauchi, pl. 16, fig. 13.

1985 Streblacantha circumtexta Jørgensen? Boltovskoy and Jankilevich, pl. 3, fig. 20.

1992 Phorticium spp. Sugiyama, Nobuhara, and Inoue, pl. 1, figs. 2-3, 5 (only).

cf. 1995 Phorticium octopyle (Haeckel); van de Paverd, p. 197-198, pl. 57, figs. 6-8 (only).
1995 Phorticium indet. van de Paverd, pl. 58, fig. 2.

1995 Pylonidae gen. et $\mathrm{sp}$. indet. van de Paverd, pl. 58, figs. 3, 6, 8?, 10.

1995 Pylonids gen. et sp. indet. van de Paverd, pl. 59, figs. 3-5.

cf. 2009 Hexapyle sp. Matsuoka, fig. 3.19.

Etymology. In honor of Prof. Tan Zhiyuan, a Chinese radiolarian specialist.

Holotype. Specimen in Figure 29.4-6 from the sample YDY05-01.

Paratype. Specimen in Figure 29.11-13 from the sample YDY05-01.

Description. Test is spherical to oblong-spherical in shape and consists of a larnacillid central combination, one complete pseudo-concentric shell, and several long, thin radial spines. Well-regulated girdles are coiled along one of the Lt-, Sg-, or Pl-axes. The complete larnacillid central combination appears flattened and quadrangular with rounded corners. The 1st pseudo-concentric shell also appears spherical to oblong-spherical in shape, with a more circular outline than the larnacillid central combination. Gates are present on both Sgsides of the 1st pseudo-concentric shell, and these gates are closed with a normal pore frame in fully mature specimens. The 1st pseudo-concentric shell is connected to the larnacillid central combi- 

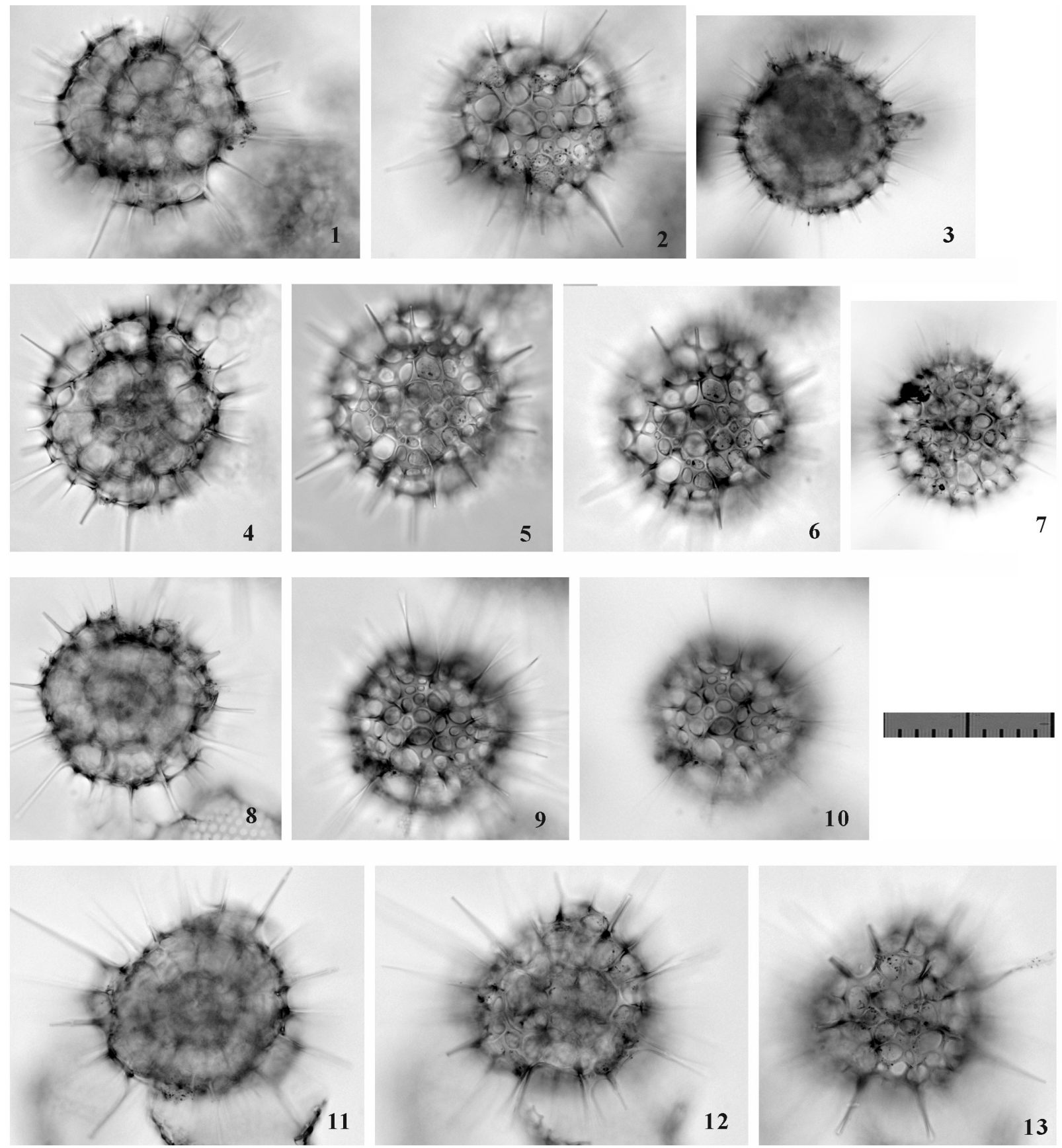

FIGURE 29. Photographs of the encountered morphotypes of Sphaerolarnacillium tanzhiyuani n. sp. All are Fr-view at Type 2. Scale bar equals $0.1 \mathrm{~mm}$. All specimens are from YDY05-01.

nation by several pillar beams, and almost all of these pillar beams pierce through the 1st pseudoconcentric shell to become cylindrical radial spines. Radial spines are the same length as half of the diameter of the 1st pseudo-concentric shell.

Remarks. Sphaerolarnacillium tanzhiyuani n. sp. is easily distinguished from all other Sphaerolarnacillium species because of its smaller size and more rounded shape. In contrast to the Sphaerolarnacillium cochleatum, Sphaerolarnacillium tanzhiyuani has more thorns.

Dimensions. Based on the holotype specimen. The length and width of the outer concentric shell: $110.2 \mu \mathrm{m}$ and $99.0 \mu \mathrm{m}$; The ratio of length to width of the outer concentric shell: ca. 1.1. The length of radial spines: ca. 12.5-35.7 $\mu \mathrm{m}$. 


\section{Genus QIURIPYLOLENA n. gen.}

zoobank.org/B2E344A6-1D9B-4EF5-9F48-80974787902B

Type species. Qiuripylolena pompon n. sp. Etymology. The Latinized female noun, derived from a Chinese word "qiu", meaning a ball and the member of the Pyloniidae.

Description. Test consists of a larnacillid central combination, and one or more pseudo-concentric shell/s. The central combination comprises an S1a (microsphere) and G2 girdles/cupolas on the Ltsides of the S1a. The shape of the pseudo-concentric shell appears variable with spherical, rounded quadrangular, elliptical, rounded triangular, and rounded pentagonal shapes at different orientations. In the pseudo-concentric shell, two girdles, and two apertures are visible from the Pl-view of the central combination, and an empty space with a rod is observable in the Sg-view in Type 1 coordinates. Pseudo-concentric shells outside the 1st pseudo-concentric shell are spherical to elliptical in shape and have two gates in juvenile forms. These gates close with normal latticed structures in more mature forms. Incompletely developed shells consist of twin latticed bands positioned on opposite sides of the test. Each pseudo-concentric shell is connected to the others by numerous pillar beams. Radial spines, if present, come from pillar beams beneath the outermost shell.

Remarks. The genus Qiuripylolena n. gen. is characterized by a larnacillid central combination, a larnacillid 1st pseudo-concentric shell, and a completely latticed cortical shell. Qiuripylolena $\mathrm{n}$. gen. is similar to spherical species of Tholomura Haeckel, 1887 (type species: Tholoma [Tholomura] metallasson Haeckel, 1887), but the former is different from the latter in that it has sutures between its cupolas/girdles. Qiuripylolena n. gen. is distinguishable from Sphaerolarnacillium n. gen. and Sphaeropylolena n. gen. based on the former's absence of a spiraled outer skeleton. Qiuripylolena n. gen. is easily distinguished from spherical species of Larcopyle Dreyer, 1899, in that the latter has spiral girdles.

\section{Qiuripylolena chikuchik n. sp.}

Figure 30.1-10

zoobank.org/9AAEAF52-F1F3-447B-970D-D7F9DC70862E

Etymology. The Latinized neuter noun from a Japanese word "chikuchiku", meaning spiny.

Holotype. Specimen in Figure 30.9-10 from the sample YDY05-01.

Paratype. Specimen in Figure 30.3-4 from the sample YDY05-01.
Description. Test is elliptical to spherical in shape and consists of a central combination, a pseudoconcentric shell, and a complete concentric shell. The side of the pseudo-concentric shell is close to the central combination and the other side stands wide apart from the central combination. Pore frames of the concentric shell are robust; the pores are polygonal in shape and large in size. Many fine spines are radially distributed over the concentric shell.

Remarks. Qiuripylolena chikuchik n. sp. is similar to Qiuripylolena pompon n. sp. in that the latter has a pseudo-concentric shell and a concentric shell. However, the latter taxon generally has a more spherical concentric shell with pores that appear to be smaller. And the size of the 1st pseudo-concentric shell of Qiuripylolena pompon n. sp. is larger than that of Qiuripylolena chikuchik n. sp. Qiuripylolena chikuchik $\mathrm{n}$. $\mathrm{sp}$. is easily distinguished from Qiuripylolena? multiconcentrica $\mathrm{n}$. sp. based on the former's absence of an elliptical pseudo-concentric shell and the former's presence of larger 1st pseudo-concentric shell and more width chamber.

Dimensions. Based on the holotype specimen. The length and width of the outer concentric shell: $103.6 \mu \mathrm{m}$ and $88.1 \mu \mathrm{m}$; The ratio of length to width of the outer concentric shell: ca. 1.2. The space width between the outer concentric shell and the 1st pseudo-concentric shell: $28.6 \mu \mathrm{m}$; The space width between the 1st pseudo-concentric shell and the central combination: $13.9 \mu \mathrm{m}$.

\section{Qiuripylolena pompon n. sp.}

Figure 30.11-22

zoobank.org/9B1C60D2-81AB-4217-B48C-CA3BC37658E3

Etymology. The Latinized neuter noun from an English word, "pompon."

Holotype. Specimen in Figure 30.19-20 from the sample YDY05-01.

Paratype. Specimen in Figure 30.13-14 from the sample YDY05-01.

Description. Test is spherical in shape and consists of a larnacillid central combination, a pseudoconcentric shell, and a spherical to ellipsoid complete concentric shell. The side of the pseudo-concentric shell is close or attached to the next concentric shell. This spherical to ellipsoid complete pseudo-concentric shell has weak depressions on both Lt-axis sides of the central combination, whereas the Pl-axis sides of the central combination have weak prominences. Pore frames of the pseudo-concentric shell are robust, the pores are polygonal in shape, and the size of pores is variable. Fine spines are radially distributed over the outermost pseudo-concentric shell. 

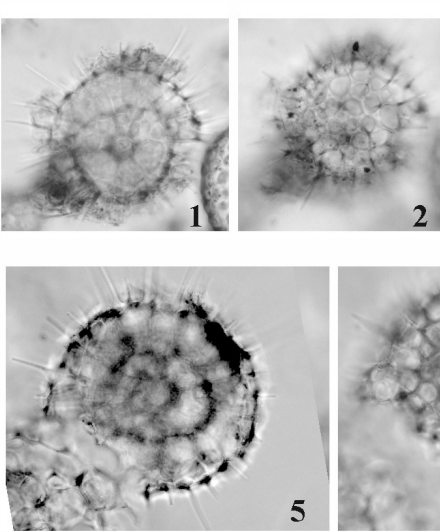

5

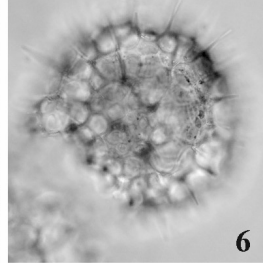

6
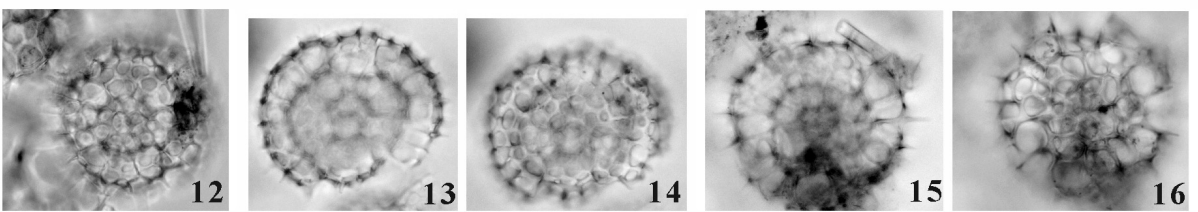
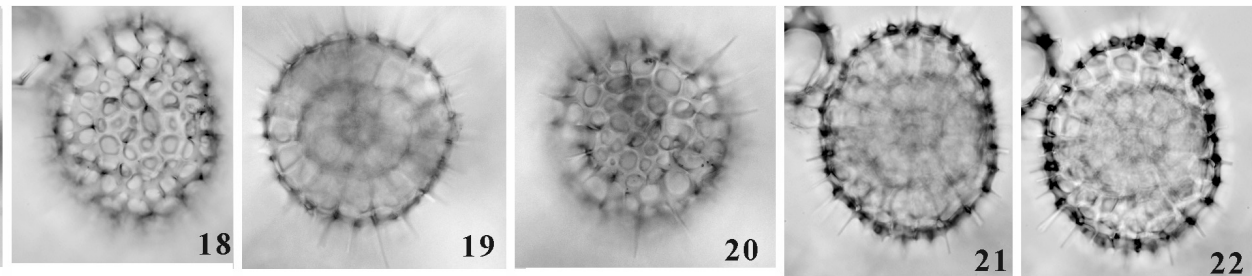
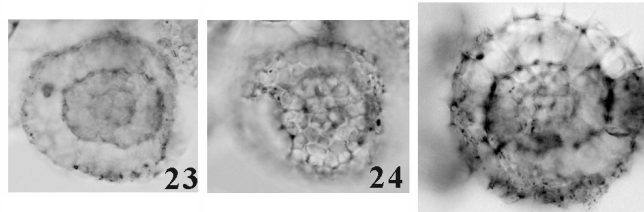
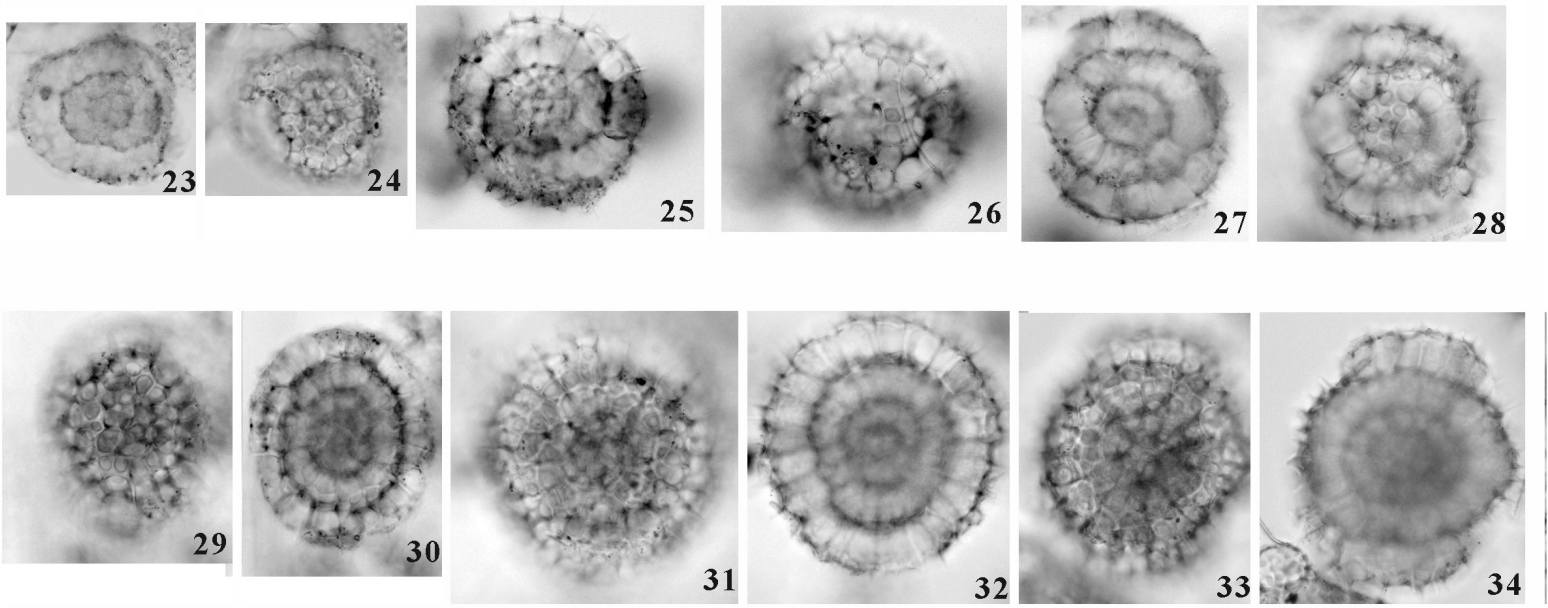

FIGURE 30. Photographs of the encountered morphotypes of Qiuripylolena. 1-10, Qiuripylolena chikuchik n. sp.; 1122, Qiuripylolena pompon n. sp.; 23-34, Qiuripylolena? multiconcentica n. sp. All are Sg-view at Type 1. Scale bar equals $0.1 \mathrm{~mm}$. All specimens are from YDY05-01.

Remarks. Qiuripylolena pompon n. sp. differs from Qiuripylolena chikuchik n. sp. in that the latter has a more loosely concentric structure, a more rounded quadrangular concentric shell, and a greater number of radial spines. Qiuripylolena pompon n. sp. is easily distinguished from Qiuripylolena? multiconcentrica $\mathrm{n}$. $\mathrm{sp}$. based on the for- mer's presence of larger 1st pseudo-concentric shell.

Dimensions. Based on the holotype specimen. The length and width of the outer concentric shell: $81.1 \mu \mathrm{m}$ and $78.6 \mu \mathrm{m}$; The ratio of length to width of the outer concentric shell: ca. 1.0. The length space between the outer concentric shell and the 
1st pseudo-concentric shell: $12.1 \mu \mathrm{m}$; The length space between the 1st pseudo-concentric shell and the central combination: $14.5 \mu \mathrm{m}$.

Qiuripylolena? multiconcentrica n. sp. Figure 30.23-34

zoobank.org/90991B16-59B8-4FC7-AFDE-6E0092B4DE39

1976 Lithelius spp. aff. alveolina Haeckel; Renz, p. 91-92, pl. 1, fig. 17.

cf. 1985 Tholospira cervicornis Haeckel; Boltovskoy and Jankilevich, pl. 3, fig. 21.

1995 Pylonidae gen. et sp. van de Paverd, pl. 58, fig. 4.

Etymology. The Latin prefix "multi-"and adjective "concentricus" (-a, -um), meaning many concentric shells.

Holotype. Specimen in Figure 30.31-32 from the sample YDY05-01.

Paratype. Specimen in Figure 30.33-34 from the sample YDY05-01.

Description. Test is elliptical in shape and consists of a probable larnacillid central combination, an elliptical to distorted pseudo-concentric shell, and two or three ellipsoid complete pseudo-concentric shells. Pore frames of the pseudo-concentric shells are robust; the pores are circular to sub-circular in shape and moderate in size. The size ratio is nearly the same between the 1st and 2nd pseudoconcentric shells, and the size ratio of the 3rd concentric shell to the 2 nd concentric shell yields a smaller value (1.5-1.6). Pseudo-concentric shells are connected to each other by numerous pillar beams. These beams pierce through the outermost pseudo-concentric shell to form short spines that are similar to by-spines.

Remarks. The 1st pseudo-concentric shell of Qiuripylolena? multiconcentrica $\mathrm{n}$. $\mathrm{sp}$. is more ellipsoid that Qiuripylolena chikuchik n. sp., and smaller than that of Qiuripylolena pompon n. sp. Qiuripylolena? multiconcentrica n. sp. generally has more concentric shells than Qiuripylolena chikuchik n. $\mathrm{sp}$. and Qiuripylolena pompon n. sp. Qiuripylolena chikuchik n. sp. and Qiuripylolena pompon n. sp. have a wider chamber than Qiuripylolena? multiconcentrica $\mathrm{n}$. $\mathrm{sp}$.

Dimensions. Based on the holotype specimen. The length and width of the 3rd pseudo-concentric shell: $109.5 \mu \mathrm{m}$ and $100.0 \mu \mathrm{m}$; The ratio of length to width of the 3rd pseudo-concentric shell: ca. 1.1. The size ratio of the 1st pseudo-concentric shell to the central combination: ca. 2.6; The size ratio of the 2nd pseudo-concentric shell to the 1st pseudoconcentric shell: ca. 2.1.

Subfamily CIRCODISCINAE Dumitrica, 1989
Remarks. As Dumitrica (1989) noted, the central combination of this subfamily has a larnacillid-type central structure, but the overall appearance resembles members of the Spongodiscoidea. Based on the definition of Type 1 coordinates, the flat disk surface is placed on the Sg-plane to orient the $\mathrm{Sg}$-axis vertical to the flat disk. The tunnel-like pylome is situated along one side of the $\mathrm{Pl}$-axis. The flat disk appears rounded-quadrangular, elliptical, and oblong. The Ug-or Pr-axis is parallel to the PI- or Lt-axis; the combination of axes under Type 1 and Type 2 coordinates differ among species. To account for their flat shape, we largely follow the terminology proposed by Ogane and Suzuki (2006) for flat-shaped radiolarians.

Genus CIRCODISCUS Kozlova in Petrushevskaya and Kozlova, 1972

Type species. Trematodiscus microporus Stöhr, 1880 (designated by Petrushevskaya and Kozlova, 1972).

Circodiscus amphitrites (Ehrenberg, 1854b)

Figure 31.1-2

nomen nudum

1854a Lithocyclia amphitrites. Ehrenberg, table.

*1854b Lithocyclia? amphitrites Ehrenberg, p. 244245.

1985 Lithocyclia? amphitrites Ehrenberg; Boltovskoy and Jankilevich, pl. 2, fig. 18.

1987 Ommatodiscus murrayi Dreyer; Dworetzky and Morley, pl. 2, fig. 6.

2009b Lithocyclia amphitrites Ehrenberg; Suzuki, Ogane, Aita, Sakai, and Lazarus, pl. 33, figs. 1a-1e (type specimen in the Ehrenberg collection; lectotype herein).

Description. Test is a flat ellipsoid disk in shape (the length ratio of the Ug-axis to the Pr-axis $=1.2-$ 1.3) with a larnacillid central combination and 3-4 latticed wide rings. The exact direction of the central combination is unknown. Each ring from the Frview shows a smoothly curved outline. The wall of each ring is thick, and pore frames are robust with distinctive circular to subcircular pores. Pores are irregularly distributed throughout the test; two or three pores tend to be aligned with the width direction of a ring. The width of the rings increases in outward (10 $\mu \mathrm{m}$ in the $1 \mathrm{st}$ ring to $20 \mu \mathrm{m}$ in the $3 \mathrm{rd}$ ring). Approximate 30 radial spines extend from the pillar beams on the Fr-plane.

Remarks. The type specimen of this species was illustrated in Suzuki et al. (2009b), and this specimen was designated herein as the lectotype. This lectotype was from surface sediment at a water depth of "10800' fathoms" (ca. 19,751 m) in the 

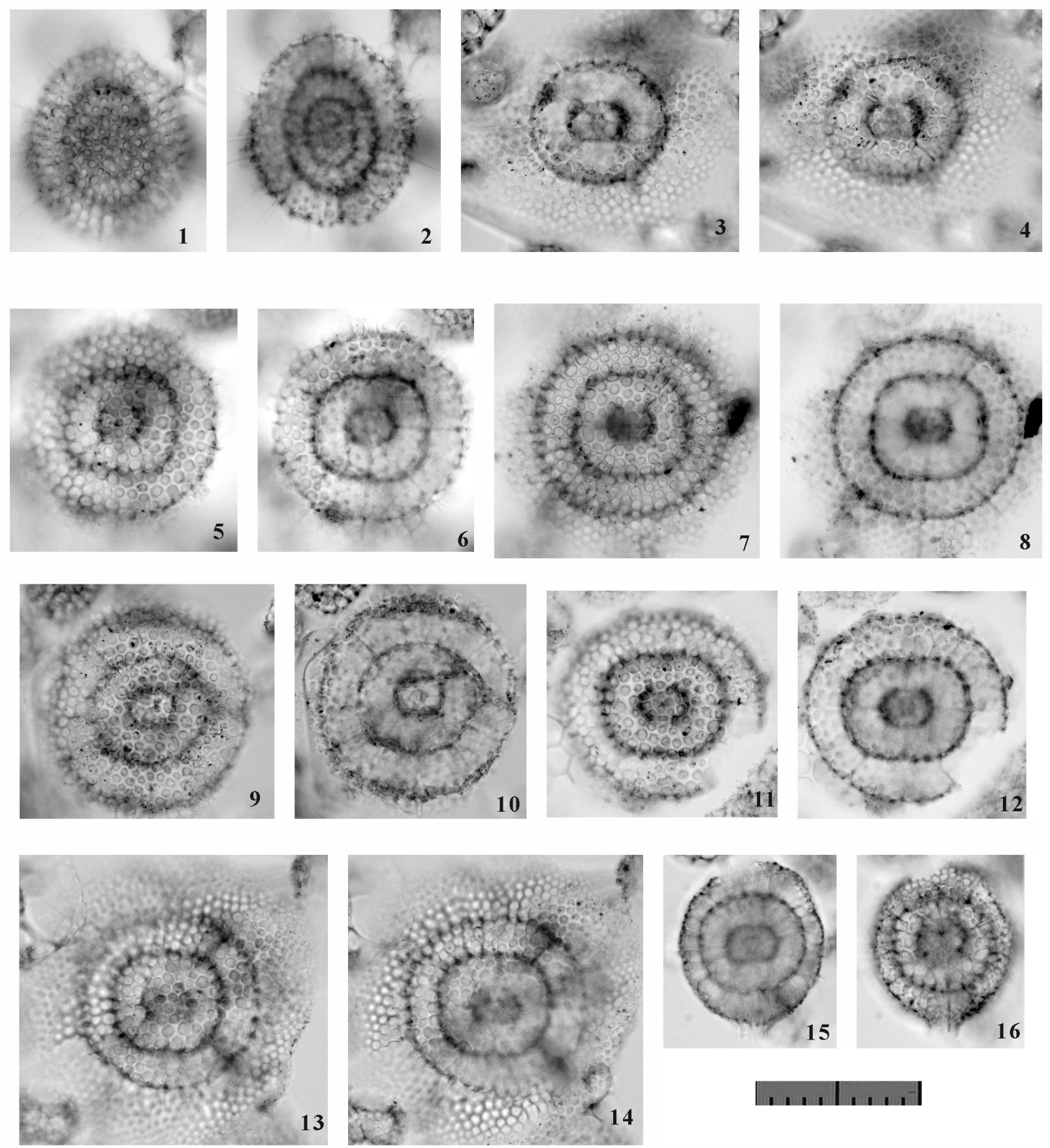

FIGURE 31. Photographs of the encountered morphotypes of Circodiscus. 1-2, Circodiscus amphitrites (Ehrenberg, 1854b); 3-4, Circodiscus biorbiculus n. sp.; 5-14, Circodiscus microporus (Stöhr, 1880); and 15-16, Circodiscus pseudomicroporus n. sp. All are Sg-view at Type1, Fr-view at Type 2. Scale bar equals $0.1 \mathrm{~mm}$. All specimens are from YDY05-01.

Bay of Biscay, Atlantic Ocean $\left(47^{\circ} 8 \mathrm{~N}, 7^{\circ} 8 \mathrm{~W}\right)$, presumed to be Holocene in age. Circodiscus amphitrites is easily distinguished from other Circodiscus species based on its longer elliptical outline, the gradually increasing width of the rings, and the thick wall of the test. The specific name "amphi- trites" is derived from the Greek god "amphitire" as a grammatically male noun.

Circodiscus biorbiculus n. sp.

Figure 31.3-4

zoobank.org/478A4DEB-55EB-4D5F-98DF-31AEEE9AB626 
aff. 1987 Lithocyclia heteropora Haeckel; Boltovskoy, pl. 1, fig. 12.

1991 Circodiscus spp. Group Takahashi, pl. 20, figs. 8-9 (only).

Etymology. The Latin prefix "bi" and male noun "orbiculus", meaning two disks. Grammatical male noun.

Holotype. Specimen in Figure 31.3-4 from the sample YDY05-01.

Description. Test consists of a larnacillid central combination, a rounded quadrangular 1st ring, a subcircular 2nd ring, and a peripheral velum. Based on the orientation of the central combination, the flat disk surface is parallel to the Sg-plane in Type 1 coordinates. The Lt-axis in Type 1 coordinates is parallel to the Ug-axis in Type 2 coordinates, and the Pl-axis is parallel to the Pr-axis. The 2nd ring is lattice, and shows a flat, convex lens shape. The peripheral velum is latticed and connected with the 2 nd ring by sharp constriction. The outline of the peripheral velum is irregular.

Remarks. Circodiscus biorbiculus n. sp. is only distinguishable from Circodiscus microporus based on the lack of a 3rd (or more) ring. Instead of a ring, a peripheral velum is developed in $C$. birobiculus $n$. $\mathrm{sp}$. that is wider than the width of the 3rd chamber (ring) of Circodiscus microporus, and consequently, there is no possibility of uncovering different ontogenetic stages of this single species. A chamber is a circular zone boredered by rings.

Dimensions. Based on the holotype specimen. Diameters of outermost shell along the PI- and Ltaxes: $9.6 \mu \mathrm{m}$ and $9.0 \mu \mathrm{m}$ (the central combination), $22.6 \mu \mathrm{m}$ and $36.2 \mu \mathrm{m}$ (1st ring), $74 \mu \mathrm{m}$ and $85 \mu \mathrm{m}$ (2nd ring), and $147 \mu \mathrm{m}$ and $166.4 \mu \mathrm{m}$ (the peripheral velum). The length ratio of the Lt-axis to the PIaxis: 0.94 (the central combination), 1.6 (1st ring), 1.1 (2nd ring), and 1.1 (the peripheral velum).

Circodiscus microporus (Stöhr, 1880) Figure 31.5-14

1880 Trematodiscus microporus Stöhr, p. 108, pl. 4, fig. 17.

1954 Spongodiscus a sp. Nakaseko, pl. 2, fig. 4.

1955 Ommatodiscus cf. stöhrii Haeckel (violation error in the species name for ICZN Article 35.2.2); Nakaseko, p. 94, pl. 7, fig. 4.

1972 Circodiscus microporus (Stöhr); Petrushevskaya and Kozlova, p. 526, pl. 19, figs. 1-7.

1976 Porodiscidae gen. et spp. indet. Berggren, Benson, Riedel, Sanfilippo, Schrader, and Tjalsma, pl. 12, fig. 8 (only).

1976 Porodiscus microporus (Stöhr); Renz, p. 109, pl. 3, fig. 15.
1978

1981

non 1983

1984b

1987

non 1991

1992

1992

1993

non 1996

non 1999

non 1999

2002

non 2003

2009

2009

2009

$2015 a$

$2015 b$

Remarks. The length ratio between the diameters of the Ug- and Pr-axes of the 2nd ring is similar to those of different specimens, and the shape of the 2nd ring shows a nearly circular outline of the rounded quadrangular appearance. Benson (1983) synonymized "Ommatodiscus pantanellii Carnevale, 1908" with Circodiscus microporus (Stöhr, 1880), but we separate out the former because no Circodiscus specimens with robust pylomate 3rd rings were found in our samples. The overall appearance of "Ommatodiscus murrayi Dreyer" reported by Takahashi and Honjo (1981) is similar to that of Circodiscus pseudomicroprus n. sp., but 
this specimen should be identified as $C$. microporus based on its rings with fine pores. The type image of the representative species shows small pores on the 2 nd and $3 r d$ rings, which are different from those of specimens previously identified as this species (e.g., Sharma and Ram, 2003). Circodiscus microporus differs from Circodiscus circularis (Campbell and Clark, 1944) because the rings are apparently wider in the former than in the latter.

\section{Circodiscus pseudomicroporus n. sp.}

Figure 31.15-16

\section{zoobank.org/67E17731-0450-40C7-9CFC-FE6C9E6176F6}

cf. 1991 Circodiscus spp. Group Takahashi, pl. 20, figs. 8-9 (only).

Etymology. As it is likely to be misidentified as Circodiscus microporous, this new species is named showing similarity to this species. The Latin word "porus" is a grammatical masculine noun, meaning pores.

Holotype. Specimen in Figure 31.15-16 from the sample YDY05-01.

Description. Test consists of a larnacillid central combination, a quadrangular 1st ring, an ellipsoid 2nd ring, and an ellipsoid 3rd ring with a bore pylome. Based on the orientation of the central combination, the flat disk surface is parallel to the Sg-plane in Type 1 coordinates. The Lt-axis in Type 1 coordinates is parallel to the Ug-axis of the 1st ring, and the $\mathrm{Pl}$-axis is parallel to the Pr-axis of the 1 st ring. The 2 nd chamber looks like a flat, convex lens. Pores on the 2 nd chamber are circular to subcircular and as large as 8-9 $\mu \mathrm{m}$ in diameter, with a thin pore frame. The 3rd ring is connected to the 2 nd ring by numerous pillar beams throughout the 2nd chamber. The 3rd ring resembles a flat convex lens with numerous small pores $(4-5 \mu \mathrm{m}$ in diameter). A bore pylome on the 3 rd ring is surrounded by a thin, porous wall, but there is no distinctive tunnel-like funnel inside the test. The shape of each ring changes from a quadrangular outline (the ratio of the $\mathrm{Lt}$-axis to the $\mathrm{Pl}$-axis $=1.4$ ), to a subcircular outline (the ratio is 1.1), and then to a vertically oblong outline (the ratio is 0.9 ). Several short radial spines extend from some of the pillar beams on the Sg-plane.

Remarks. Circodiscus pseudomicroprus n. sp. differs from all other Circodiscus species because of its distinctively large pores on the 1st chamber (ring). The number of rings in Circodiscus pseudomicroporus $\mathrm{n}$. $\mathrm{sp}$. is the same as number of rings in Circodiscus microporus (Stöhr, 1880), but the former taxon easily distinguished from the latter based on the former's larger pores on the 1st chamber (ring) and the smaller overall size.
Dimensions. Based on the holotype specimen. The diameters along the PI- and Lt-axes: $7.8 \mu \mathrm{m}$ and $8.3 \mu \mathrm{m}$ (the central combination), $22.1 \mu \mathrm{m}$ and $30.8 \mu \mathrm{m}$ (1st ring), $59 \mu \mathrm{m}$ and $65 \mu \mathrm{m}$ (2nd ring), and $100 \mu \mathrm{m}$ and $87 \mu \mathrm{m}$ (3rd ring). The length ratio of the Lt-axis to the Pl-axis: $1.1 \mu \mathrm{m}$ (the central combination), $1.4 \mu \mathrm{m}$ (1st ring), 1.1 (2nd ring), and $0.9 \mu \mathrm{m}$ (3rd ring). The width of the bore pylome on the 3rd ring: $16.5 \mu \mathrm{m}$.

Family THOLONIIDAE Haeckel, 1887 sensu

Dumitrica in De Wever et al., 2001

Genus THOLOMURA Haeckel, 1887 sensu

emend. Suzuki in Matsuzaki, Suzuki, and Nishi, $2015 a$

*1887 Tholomura Haeckel, p. 672.

2015a Tholomura Haeckel; Matsuzaki, Suzuki, and Nishi, p. 36 (See the full synonymy).

Type species. Tholomura (Tholomura) metallasson Haeckel, 1887 (SD by Campbell, 1954).

Description. Test consists of an S1a (microsphere) and several levels of three sets of domeshaped cupolas. A set of dome-shaped cupolas consists of twin cupolas positioned at opposite sides along one of the axes of Type 1 coordinates. Three sets of dome-shaped cupolas are mutually oriented to form one level of the test, equivalent to a pseudo-concentric shell. This mutually arranged cupola system is repeated in the same way to form successive pseudo-concentric shells. Rods extend from both sides of the S1a to pierce through the twin cupolas along the Lt-axis under Type 1 coordinates. Two types of radial spines are recognizable as polar spines and main spines. Polar spines extend along the Type 1 coordinate axes, whereas main spines pierce through the joint zones of the four cupolas. The development state of radial spines varies with different ontogenetic stages. The sutures between the cupolas develop in varying degrees.

Remarks. To identify Tholomura species, the apparent difference based on the orientation of the test and on ontogenetic growth stages must be carefully examined. Specifying the orientation of the test is essential to identify the specimen in the first stage. In the next step, the corresponding relationships among differently oriented specimens is determined based on the size of the same pseudoconcentric shells, pore patterns, and the development of the sutures between cupolas. This genus differs from the family Larnacillidae Haeckel, 1887, in having dome-shaped cupolas instead of girdles with gates. 

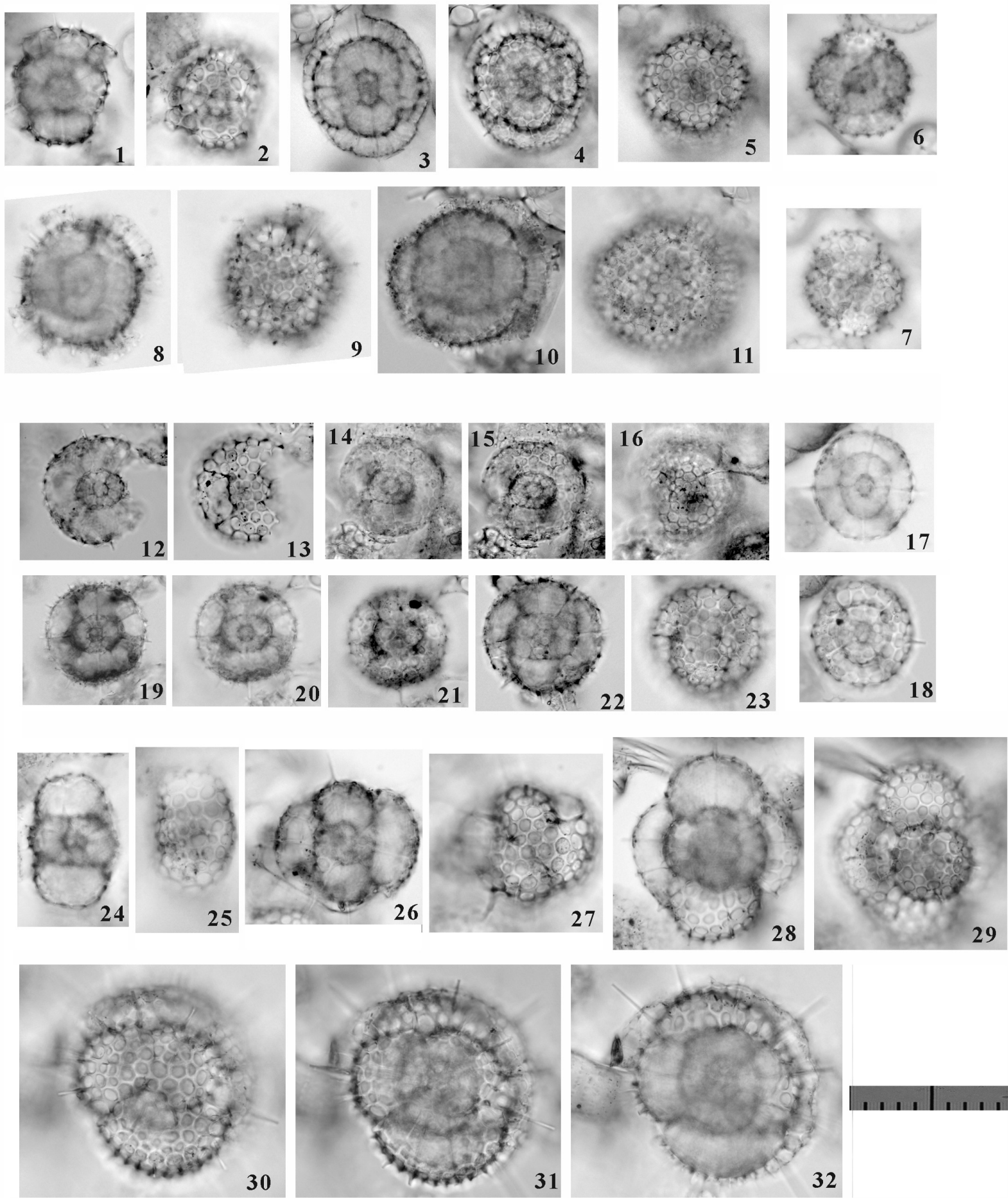

FIGURE 32. Photographs of the encountered morphotypes of Tholomura. 1-11, Tholomura hexonia (Haeckel, 1887); 12-23, Tholomura pilula n. sp.; 24-32, Tholomura polystyla (Chen, 1987). 1-16, 19-23, 26-32, PI-view at Type 1; 1718, 24-25, Lt-view at Type 1. Scale bar equals $0.1 \mathrm{~mm}$. All specimens are from YDY05-01. 
Tholomura hexonia (Haeckel, 1887)

Figure 32.1-11

1887 Amphitholus (Amphitholura) panicium Haeckel, p. 668, pl. 10, fig. 4.

1887 Amphitholonium tricolonium Haeckel, p. 669 , pl. 10, fig. 7.

*1887 Tholonium (Tholonilla) hexonium Haeckel, p. 679, pl. 10, fig. 17.

1887 Cubotholonium ellipsoides Haeckel, p. 682, pl. 10, fig. 15.

1992 Tholonium hexonium Haeckel; Sugiyama, Nobuhara, and Inoue, pl. 11, fig. 9.

1995 Larcospira haliomma (Ehrenberg); van de Paverd, p. 190, pl. 53, fig. 8 (only).

1995 Spongurus minor (Jørgensen); van de Paverd, p. 151-152, pl. 53, fig. 11 (only).

1999 Cubotholus sp. Sharma, Singh, and Rawal, p. 262, pl. 2, figs. 30-31.

2003 Cubotholus sp. Sharma and Ram, pl. 3, fig. 9.

2005 Cubotholus sp. A. Zapata and Olivares, p. 86, fig. 4.2-3.

Description. Test consists of a spherical S1a, an ellipsoid 1st pseudo-concentric shell, and two levels of three sets of twin, flat, dome-shaped cupolas. No gates are present. The sutures between cupolas are shallow. A transverse section of the cupolas along a given plane shows an elliptical outline. Pores of the cupolas are polygonal to rounded polygonal with relatively fine pore frames. Polar radial beams extend along both sides of the Lt-axis from the S1a, but they do not pierce the outermost cupolas. No major radial spines are present.

Remarks. Haeckel (1887) divided Tholomura hexonia (Haeckel, 1887) into five different "species" shown in the synonym list. These five "species" have common structures in the shapes and pore patterns of their cupolas, which suggests that they belong to the same species. "Amphitholus panicum Haeckel, 1887" is a vertical view of this species with two pseudo-concentric shells, and "AmphithoIonium tricolonium Haeckel, 1887" is a Lt-view of this species with three pseudo-concentric shells. "Tholonium hexonium" and "Cubotholonium ellipsoides" are PI-views of fully mature specimens. These "species" were simply named as specimens with a combination of different ontogenetic stages and orientations. Tholomura hexonia is similar to Tholomura polystyla (Chen, 1987) in that these two species have clearly depressed sutures between cupolas. The fully mature specimen of $T$. hexonia is distinguishable from $T$. polystyla based on the absence of robust main spines, but this criterion is not useful for specimens of younger ontogenetic stages. In juvenile specimens, the former can be distinguished from the latter by its relatively flat cupolas compared to those of $T$. polystyla (the length ratio of cupola width to its height: 1.7-3.3 in T. hexonia and 1.2-1.9 in T. polystyla). Because of differences in the size ratios between cupola width and height, the sutures between the cupolas are shallower in T. hexonia than in T. polystyla. The sizes of the equivalent pseudo-concentric shells also differ between these two species. This difference is difficult to apply practically for microscope identification of these two species, however.

Tholomura pilula $\mathrm{n} . \mathrm{sp}$.

Figure 32.12-23

zoobank.org/C9B27FD8-534C-4B0F-AC43-920FF7E69BB0

Etymology. The Latin feminine noun "pilula" (-ae), meaning a small sphere.

Holotype. Specimen in Figure 32.22-23 from the sample YDY05-01.

Description. Test is spherical in shape with an S1a (microsphere), an ellipsoid 1st pseudo-concentric shell, and a spherical 2nd pseudo-concentric shell. No gates are present. The S1a appears elliptical from the Lt-view and circular from the Pl-view. The 1st pseudo-concentric shell comprises two 1st girdle-like cupolas that develop along the $\mathrm{Lt}$-axis and two 2 nd girdle-like cupolas that develop along the Sg-axis; these four girdle-like cupolas are completely connected to each other to form a closed, latticed pseudo-concentric shell. The 1st pseudoconcentric shell looks elliptical from the PI- and Ltviews, and rounded quadrangular from the Sgview. Pores of the 1st pseudo-concentric shell are circular to sub-circular in shape with relatively fine pore frames. Polar beams, an apical rod and a basal rod emerge from the $\mathrm{S} 1 \mathrm{a}$ to pierce through the 1st pseudo-concentric shell. The 2nd pseudoconcentric shell comprises six cupolas to form a completely closed, latticed sphere. The 2nd pseudo-concentric shell is sub-spherical in shape. Six main cylindrical spines and eight polar spines extend linearly. The suture of the 2 nd pseudo-concentric shell is visible under transmitted light microscopy but does not form depressions. Pores of the 2nd pseudo-concentric shell are polygonal in shape with fine pore frames.

Remarks. Tholomura pilula n. sp. is easily distinguished from all other species of Tholomura because it has a nearly complete spherical pseudo-concentric shell without fine coverage. Tholomura pilula n. sp. differs from Tholomura hexonia (Haeckel, 1887) in that it has finer pores and apparent sutures between its cupolas. Tholomura pilula n. sp. appears to have three pseudo-concen- 
tric shells without clearly main or polar spines. These morphological characteristics may lead us to mistake specimens of this taxon as a member of Thecosphaera; however, T. pilua n. sp. is different from Thecosphaera in its pyloniid internal structure. Dimensions. Based on the holotype specimen. The length and width of the 1st pseudo-concentric shell: $38.8 \mu \mathrm{m}$ and $26.6 \mu \mathrm{m}$; The length and width of the 2nd pseudo-concentric shell: $68.8 \mu \mathrm{m}$ and $67.7 \mu \mathrm{m}$. The ratio of length to width: ca. 1.5 (1st pseudo-concentric shell) and ca. 1.0 (2nd pseudoconcentric shell).

Tholomura polystyla (Chen, 1987)

Figure 32.24-32

1973 Tholoniidae sp. Bjørklund, pl. 1, fig. R.

1974 Cubotholus sp. leda, pl. 3, fig. 5a-b.

1977 Cubotholus cf. rhombicus Haeckel; Casey and McMillen, pl. 1, fig. 14.

1978 Cubotholus rhombicus Haeckel; McMillen and Casey, pl. 3, fig. 19 (the same specimen with Casey and McMillen, 1977, pl. 1, fig. 14).

*1987 Cubotholonium polysytulum Chen, p. 225226, pl. 2, figs. 8-9.

1987 Amphitholonium transversarum Chen, p. 225, pl. 2, figs. 10-11.

1988 Amphitholonium transversarum Chen; Tan, p. 272-273, text-fig. 260.

1999 Amphitholonium transversarum Chen; Tan and Chen, p. 259, text-fig. 5.172.

1991 Tholomura metallasson Haeckel; Takahashi, p. 89, pl. 11, figs. 12-13.

1992 Larnacillidae? gen. et sp. sp. indet. A. Sugiyama, Nobuhara, and Inoue, pl. 11, figs. 5, 7-8.

1995 Amphitholus metallasson (Haeckel); van de Paverd, pl. 53, figs. 9-10, 12 ?

1998 Amphitholus metallasson (Haeckel); Danelian and Frydas, pl. 3, fig. 15.

2014d Tholomura polystyla (Cheng) (misspelling to the author's name); Matsuzaki, Nishi, Suzuki, Takashima, Kawate, and Sakai, pl. 2, fig. 9.

2015a Tholomura polystyla (Chen); Matsuzaki, Suzuki, and Nishi, p. 36-37, fig. 6.18 (Refer to Matsuzaki, Suzuki, and Nishi [2015a] for other synonym lists).

Description. Test consists of a spherical S1a (microsphere), an ellipsoid 1st pseudo-concentric shell, and two levels of three sets of twin, relatively tall, dome-shaped cupolas. No gates are present. The sutures between cupolas are very deep. Transverse sections of the cupolas along a given plane show at least two large, subcircular outlines of cupolas. Pores of cupolas are polygonal to rounded polygonal with relatively fine pore frames. Polar beams extend along both sides of the Lt-axis from the S1a, but they do not pierce through the outermost cupolas. Fourteen straight, cylindrical main spines arise from the joint zones of the cupolas, but these main spines develop only in the latest stage of ontogenetic growth after the full development of two levels of three sets of twin dome-shaped cupolas.

Remarks. "Amphitholonium transversarum Chen, 1987" is a Pl-view of Tholomura polystyla (Chen, 1987), whereas "Cubotholonium polystylum Chen, 1987 " is a Lt-view of the same. The radial spines develop after the development of the 2nd pseudoconcentric shell, and consequently, it is unlikely that the presence/absence of radial spines could be effectively applied in as a taxonomic criterion. Tholomura polystyla differs from Tholomura hexonia in having the very deep sutures between the cupolas, the more spherical dome-shaped cupolas (the length ratio of cupola width to height $=1.7-3.3$ for T. hexonia and 1.2-1.9 for T. polystyla).

\section{CONCLUSIONS}

All pylonioid species encountered in the surface samples from the northeastern Indian Ocean have been described with consideration given to ontogenetic morphological changes, intra-species variation, and the similarity of specimens to the holotypes of species. The pylonioids were classified into 10 genera and 34 species/subspecies. Of these, three new genera (Sphaeropylolena n. gen., Sphaerolarnacillium n. gen. and Qiuripylolena n. gen.) and 20 new species/subspecies (Larcospira teres n. sp., L. tetragonicentrum n. sp., Larcopyle buetschlii chenmuhongi $\mathrm{n}$. subsp., L. buetschlii orion n. subsp., L. molle n. sp., L. eccentricanoides n. sp., L. pulchella n. sp., Sphaeropylolena laxa n. sp., S. tenellispinosa n. sp., Phorticium itakii n. sp., $P$. scitulum n. sp., Sphaerolarnacillium cochleatum n. sp., S. exactum n. sp., S. tanzhiyuani n. sp., Qiuripylolena chikuchik n. sp., Q. pompon n. sp., Q.? multiconcentrica n. sp., Circodiscus biorbiculus n. sp., C. pseudomicroporus n. sp., and Tholomura pilula n. sp.) were described. Based on this taxonomic work, all pylonioid specimens illustrated in references archived at Tohoku University were reidentified, as shown in the synonym list. This list revealed that commonly recorded taxa such as "Tetrapyle octacantha", "Octopyle stenozona", "Schizomma quadrilobum", "Larcospira quadrangula", "Tholospira cervicornis" and "Larcopyle buetschlii" had been mixed with different species. From 
our taxonomic work, we conclude that (1) true $T$. octacantha are rare in both the Pacific and Indian oceans, (2) true Tetrapyle stenozona was not found in the Indian Ocean so far, (3) "Schizomma quadrilobum" is a group of juvenile Tetrapyle specimens, (4) true specimens of "Larcopyle quadrangula" are rarely illustrated, (5) the current usage of "Tholospira cervicornis" is different from the topotypic specimens, and (6) "Larcopyle buetschlii" from the Sea of Japan is not found in the Indian Ocean. This comprehensive examination of the Pylonioidea has also indicated a possibility that several Pylonioid species are absent from the Indian Ocean: Larcopyle dendrophora (Haeckel, 1887) [= Tholospira in the original description], Pylodiscus dodecantha (Haeckel, 1887) [= Hexapyle], Pylonium scutatum Chen and Tan, 1999, Pylospira octopyle Haeckel, 1887, Tetrapyle hexagona (Tan and Chen, 1990) [= Octopyle], Pylozonium polyacanthum Chen and Tan, 1996, Phorticium clevei (Jørgensen, 1899) [= Tetrapylonium], Phorticium polysytle (Chen, 1987) [= Octopyle], Tetrrapylonium pyrum Tan and Chen, 1990, Tetrapyle roundospinosa Tan, 1993, and Tetrapylonium strobilinum Tan and Chen, 1990. This finding suggests that identifying pylonioids at the species level have useful applications for oceanographic and paleoceanographic research.

\section{ACKNOWLEDGMENTS}

We thank the captain, crew, and scientists of R/V Shiyan 1 for their efforts in collecting the samples during the cruise of Eastern Indian Ocean in spring 2010. We thank two anonymous reviewers for their very helpful comments and suggestions. We thank the Chinese Academy of Sciences for sponsoring L.L. Zhang's visit to Tohoku University from September 30, 2015, to September 26, 2016. This work was supported by the National Natural Science Foundation of China (Grants No. 41576044, 91228207, 41476037, and 41276051) and the Strategic Priority Research Program of the Chinese Academy of Sciences (No. XDA11030104) for L.L. Zhang and by the Japan Society for the Promotion of Science KAKENHI Grant No. K16K074750 for N. Suzuki.

\section{REFERENCES}

Ahmad, S.M., Zheng, H.B., Raza, W., Zhou, B., Lone, M.A., Raza, T., and Suseela, G. 2012. Glacial to Holocene changes in the surface and deep waters of the northeast Indian Ocean. Marine Geology, 329331:16-23.
Akers, W., Marolt, N., and Navarette, R. 1987. Late Miocene and early Pliocene siliceous microfossils from the Upper Monterey and Lower Siaquoc Formations, Sweeny Road, Santa Barbara County, California. Tulane Studies in Geology and Paleontology, 20:1112.

Alexandrovich, J.M. 1992. Radiolarians from Sites 794, 795, and 797 (Japan Sea), p. 291-307. In Alexandrovich, J.M. 1992. Radiolarians from Sites 794, 795, and 797 (Japan Sea), p. 291-307. In Tamaki, K.A., Ingle, J.C. Jr., von Breymann, M.T., Barron, J., and ODP Leg 127-128 Scientific Party. Proceedings of the Ocean Drilling Program, Scientific Results, Volumes. 127-128. Ocean Drilling Program, College Station.

Anma, R., Kawakami, S., and Yamamoto, Y. 2002. Structural profile of the Nankai accretionary prism and Calyptogena colonies alongthe Shionomisaki Submarine Canyon: Results of "SHINKAl" 6K\#522 and \#579 dives. JAMSTEC Journal of Deep Sea Research, 20:59-75. (In Japanese with English abstract)

Bak, Y.S., Lee, J.D., and Yun, H. 1996. Middle Miocene radiolarians from the Duho Formation in the Pohang Basin, Korea. Journal of the Paleontological Society of Korea, 12:225-261.

Bak, Y.S., Lee, J.D., and Yun, H. 1997. Radiolarian faunas from the Hagjeon Formation (middle Miocene) in the southern Pohang Basin, Korea. Journal of the Paleontological Society of Korea, 13:137-154.

Benson, R.N. 1983. Quaternary radiolarians from the mouth of the Gulf of California, Deep Sea Drilling Project Leg 65, p. 491-523. In Lewis, B.T.R., Robinson, P.T., Benson, R.N., Blackinton, G., Cambon, P., Day, R., Duennebier, F., Flower, M.F.J., GutiérrezEstrada, M., Hattner, J.G., Kudo, A.M., Morrison, M.A., Rangin, C., Salisbury, M.H., Schmincke, H.-U., Stephen, R.A., Zolotarev, B.P., and Amidei, R. (eds.), Initial Reports of the Deep Sea Drilling Project, Volume. 65. U.S. Government Printing Office, Washington, D.C.

Berggren, W.A., Benson, R.H., Riedel, W.R., Sanfilippo, A., Schrader, H.J., and Tjalsma, R.C. 1976. The El Cuervo section (Andalusia, Spain). Micropaleontologic anatomy of an early late Miocene lower bathyal deposit. Marine Micropaleontology, 1:195-247.

Bjørklund, K.R. 1973. Radiolarians from the surface sediments in Lindåspollene, western Norway. Sarsia, 53:71-75.

Bjørklund, K.R. and de Ruiter, R. 1987. Radiolarian preservation in eastern Mediterranean anoxic sediments. Marine Geology, 75:271-281.

Blueford, J.R., Gonzales, J.J., and Scoy, K.V. 1990. Comparing radiolarian and diatom diversity and abundance from the Northeast Pacific. Marine Micropaleontology, 15:219-232.

Boltovskoy, D. 1987. Sedimentary record of radiolarian biogeography in the equatorial to antarctic western Pacific Ocean. Micropaleontology, 33:267-281. 
Boltovskoy, D. and Jankilevich, S.S. 1985. Radiolarian distribution in east equatorial Pacific plankton. Oceanologica Acta, 8:101-123.

Boltovskoy, D., Kling, S.A., Takahashi, K., and Bjørklund, K. 2010. World atlas of distribution of recent Polycystina (Radiolaria). Palaeontologia Electronica, 13.3.18A:1-230. palaeo-electronica.org/2010_3/215/ index.html.

Boltovskoy, D. and Riedel, W.R. 1980. Polycystine Radiolaria from the southwestern Atlantic Ocean plankton. Revista Española de Micropaleontología, 12:99146.

Brathauer, U. 1996. Rekonstruktion quartärer Klimaänderungen im atlantischen Sektor des Südpolarmeeres anhand von Rdiolarien. Berichte zur Polarforschung, 216:1-163.

Cachon, J. and Cachon, M. 1985. Class Polycystinea, p. 283-295. In Lee, J.J., Hutner, S.H., and Bovee, E.C. (eds.), Illustrated Guide to the Protozoa. Society of Protozoologists, Lawrence.

Campbell, A.S. 1954. Radiolaria, p. D1-D163. In Moore, R.C. (ed.), Treatise on Invertebrate Paleontology, Part D Protista 3. Protozoa (Chiefly Radiolaria and Tintinnina). Geological Society of America and University of Kansas Press, Boulder, Colorado, and Lawrence, Kansas.

Campbell, A.S. and Clark, B.L. 1944. Miocene radiolarian faunas from southern California. Geological Society of America, Special Papers, 51:1-76.

Carnevale, P. 1908. Radiolarie e silicoflagellati di Bergonzano (Regio Emilia). Memorie del Reale Istituto Veneto di Scienze, Lettere ed Arti, 28:1-46.

Casey, R.E. 1971. Radiolarian as indicators of past and present water masses, p. 331-351. In Funnel, B.M. and Riedel, W.R. (eds.), The Micropaleontology of Oceans. Cambridge University Press, London.

Casey, R.E. and McMillen, K.J. 1977. Cenozoic radiolarians of the Atlantic basin and margins, p. 521-544. In Swain, F.M. (eds.), Stratigraphic Micropaleontology of Atlantic Basin and Borderlands. Development in Palaeontology and Stratigraphy. Volume 6. Elsevier, Amsterdam.

Cavalier-Smith, T. 1999. Principles of protein and lipid targeting in secondary symbiogenesis. Euglenoid, dinoflagellate, and sporozoan plastid origin and the eukaryote family tree. Journal of Eukaryotic Microbiology, 46:347-366.

Cavalier-Smith, T. 2002. The phagotrophic origin of eukaryotes and phylogenetic classification of Protozoa. International Journal of Systematic and Evolutionary Microbiology, 52:297-354.

Cavalier-Smith, T. 2003. Protist phylogeny and the highlevel classification of Protozoa. European Journal of Protistology, 39:338-348.

Chen, M.H. and Tan, Z.Y. 1989. Description of a new genus and 12 species of Radiolaria in sediments from the South China Sea. Tropic Oceanology, 8:1-9. (In Chinese with English abstract)
Chen, M.H. and Tan, Z.Y. 1996. Radiolaria from Surface Sediments of the Central and Northern South China Sea. Science Press, Beijing. (In Chinese with English abstract)

Chen, M.H., Zhang, L.L., Zhang Li.I., Xiang, R., and Lu, J. 2008. Preservation of radiolarian diversity and abundance in surface sediments of the South China Sea and its environmental implication. Journal of China University of Geosciences, 19:217-229.

Chen, W.B. 1987. Some new species of Radiolaria from surface sediments of the East China Sea and the South China Sea. Chinese Journal of Oceanology and Limnology, 5:222-227.

Cortese, G. and Abelmann, A. 2002. Radiolarian-based paleotemperatures during the last $160 \mathrm{kyr}$ at ODP Site 1089 (Southern Ocean, Atlantic Sector). Palaeogeography, Palaeoclimatology, Palaeoecology, 182:259-286.

Danelian, T. and Frydas, D. 1998. Late Quaternary polycystine radiolarians and silicoflagellates of a diatomaceous sapropel from the eastern Mediterranean, sites 969 and 971, p. 137-154. In Robertson, A.H.F., Emeis, K.C., Richter, C., and Camerlenghi, A. (eds.), Proceedings of the Ocean Drilling Program, Scientific Results, Volume 160. Ocean Drilling Program, College Station, TX.

De Wever, P., Dumitrica, P., Caulet, J.P., Nigrini, C., and Caridroit, M. 2001. Radiolarians in the Sedimentary Record. Gordon and Breach Science Publishers, Amsterdam.

Dolven, J.K., Bjørklund, K.R., and Itaki, T. 2014. Jørgensen's polycystine radiolarian slide collection and new species. Journal of Micropalaeontology, 33:2158.

Dowing, D. 2009. Dictionary of Mathematics Terms (third edition). Barrons's Education Series, Inc., New Work.

Dreyer, F. 1889. Die Pylombildungen in vergleichendanatomischer und entwicklungs-geschichtlicher Beziehung bei Radiolarien und bei Protisten überhaupt, nebst System und Beschreibung neuer und der bis jetzt bekannten pylomatischen Spummellarien. Jenaische Zeitschrift für Naturwissenschaft herausgegeben von der Medizinischnaturwissenschaftlichen Gesellschaft zu Jena, 23, Neue Folge, 16:77-214.

Dreyer F. 1890. Morphologische Radiolairenstudien. Die Tripoli von Caltanisetta (Steinbruch Gessolungo) auf Sizilien. Jenaische Zeitschrift für Naturwissenschaft herausgegeben von der medizinisch-naturwissenschaftlichen Gesellschaft zu Jena 24, Neue Folge, 17:471-548.

Dumitrica, P. 1988. New families and subfamilies of Pyloniacea (Radiolaria). Revue de Micropaléontologie, 31:178-195.

Dumitrica, P. 1989. Internal skeletal structure of the superfamily Pyloniacea (Radiolaria), a basis of a new systematics. Revista Española de Micropaleontología, 21:207-264. 
Dumitrica, P. 1991. Cenozoic Pyloniacea (Radiolaria) with a fine-gated microsphere. Revue de Micropaléontologie, 34:35-56.

Dworetzky, B.A. and Morley, J.J. 1987. Vertical distribution of Radiolaria in the eastern equational Atlantic: Analysis of a multiple series of closely-spaced plankton tows. Marine Micropaleontology, 12:1-19.

Ehrenberg, C.G. 1839. Über die Bildung der Kreidefelsen und des Kreidemergels durch unsichtbare Organismen. Abhandlungen der Königlichen Akademie der Wissenschaften zu Berlin, 1838:59-147.

Ehrenberg, C.G. 1854a. Systematische Charakteristik der neuen mikroskopischen Organismen des tiefen Atlantischen Oceans. Bericht über die zur Bekanntmachung geeigneten Verhandlungen der Königlich Preußischen Akademie der Wissenschaften zu Berlin, 1854:236-250.

Ehrenberg, C.G. 1854b. Mikrogeologie. Voss, Leipzig.

Ehrenberg, C.G. 1861a. Über die organischen und unorganischen Mischungsverhältnisse des Meeresgrundes in 19800 Fuss Tiefe nach Lieut. Brookes Messung. Monatsberichte der Königlich Preußischen Akademie der Wissenschaften zu Berlin, 1860:765774.

Ehrenberg, C.G. 1861b. Über den Tiefgrund des stillen Oceans zwischen Californien und den SandwichInseln aus bis 15600' Tiefe nach Lieut. Brooke. Monatsberichte der Königlich Preußischen Akademie der Wissenschaften zu Berlin, 1860:819-834.

Ehrenberg, C.G. 1862. Über die Tiefgrund-Verhältnisse des Oceans am Eingange der Davisstraße und bei Island. Monatsberichte der Königlich Preußischen Akademie der Wissenschaften zu Berlin, 1861:275315.

Ehrenberg, C.G. 1876. Fortsetzung der mikrogeologischen Studien als Gesammt-Übersicht der mikroskopischen Paläontologie gleichartig analysirter Gebirgsarten der Erde, mit specieller Rücksicht auf den Polycystinen-Mergel von Barbados. Abhandlungen der Königlichen Akademie der Wissenschaften zu Berlin, 1875:1-226.

Fujioka, S. 1990. Illustrations of the Plankton of the Kuroshio Waters: Plankton in Amami-Oshima Island Coastal Waters. Nagasakiken-Shuppan Bunka-kyoukai, Nagasaki. (In Japanese with English title)

Gupta, S.M. 2002. Pyloniid stratigraphy - a new tool to date tropical radiolarian ooze from the central Indian Ocean. Marine Geology, 184:85-93.

Gupta, S.M. 2003. Orbital frequencies in radiolarian assemblages of the central Indian Ocean: implications on the Indian summer monsoon. Palaeogeography, Palaeoclimatology, Palaeoecology, 197:97-112.

Gupta, S.M. and Srinivasan, M.S. 1992. Late Miocene radiolarian biostratigraphy and paleoceanography of the Sawai Bay Formation, Neil Island, Andamans, India. Micropaleontology, 38:209-235.

Haeckel, E. 1862. Die Radiolarien (Rhizopoda Radiaria). Eine Monographie. Tafel 1. Reimer, Berlin.
Haeckel, E. 1882. Entwurf eines Radiolarien-Systems auf Grund von Studien der Challenger-Radiolarien. Jenaische Zeitschrift für Naturwissenschaft herausgegeben von der Medizinisch-naturwissenschaftlichen Gesellschaft zu Jena, 15:418-472.

Haeckel, E. 1884. Über die Ordnungen der Radiolarien. Sitzungsberichte der Jenaischen Gesellschaft für Medicin und Naturwissenschaft, 1883:18-36.

Haeckel, E. 1887. Report on the Radiolaria collected by H. M. S. Challenger during the years 1873-1876. Report on the Scientific Results of the Voyage of $H$. M. S. Challenger during the Year 1873-1876, Zoology, 18:1-1803.

Haslett, S.K. 1992. Early Pleistocene glacial-interglacial radiolarian assemblages from the eastern equatorial Pacific. Journal of Plankton Research, 14:15531563.

Haslett, S.K. 1994. High-resolution radiolarian abundance data through the late Pliocene Olduvai subchron (1.75-2Ma) of ODP Hole 667A (Panama Basin, eastern equatorial Pacific). Revista Española de Micropaleontología, 26:127-162.

Haslett, S.K. 1996. Radiolarian faunal data through the Plio-Pleistocene Olduvai magnetosubchron of ODP Leg 138 sites 847, 850 and 851 (eastern Equatorial Pacific). Revista Española de Micropaleontología, 28:81-112.

Hatakeda, K. and Bjørklund, K.R. 2009. Polycystine radiolarian assemblages from IODP Expedition 306 Site U1313 and Site U1314, a preliminary result. News of Osaka Micropaleontologists (NOM), Special Volume, 14:91-108.

Hernández-Almeida, I., Bjørklund, K.R., Sierro, F.J., Filippelli, G.M., Cacho, I., and Flores, J.A. 2013. A high resolution opal and radiolarian record from the subpolar North Atlantic during the Mid-Pleistocene Transition (1069-779 ka): Palaeoceanographic implications. Palaeogeography, Palaeoclimatology, Palaeoecology, 391:49-70.

Hertwig, R. 1879. Der Organismus der Radiolarien. Gustav Fischer, Jena.

Hu, W.F., Zhang, L.L., Chen, M.H., Zeng, L.L., Zhou, W.H., Xiang, R., Zhang, Q., and Liu, S.H. 2015. Distribution of living radiolarians in spring in the South China Sea and its responses to environmental factors. Science China: Earth Sciences, 58(2): 270-285.

Hull, D.M. 1993. Quaternary, Eocene, and Cretaceous radiolarians from the Hawaiian Arch, northern equatorial Pacific Ocean, p. 3-25. In Wilkens, R.H., Firth, J., Bender, J., and ODP Leg 136 Scientific Party, Proceedings of the Ocean Drilling Program, Scientific Results, Volume 136. Ocean Drilling Program, College Station, TX.

leda, K. 1974. Recent radiolarians from the N-5 core in the East China Sea. Bulletin of the Technical Laboratory, JAPEX, 18:77-90. (In Japanese)

lijima, K., Takahashi, K., Ittekkot, V., and Nair, R.R. 1994. Preliminary results on seasonal changes of radiolarian fluxes in the monsoonal environment in the Ara- 
bian Sea. Proceedings of Hokkaido Tokai University, Science and Engineering, 7:29-36.

Ikenoue, T., Takahashi, K., and Tanaka, S. 2012. Fifteen year time-series of radiolarian fluxes and environmental conditions in the Bering Sea and the central subarctic Pacific, 1990-2005. Deep Sea Research II: Topical Studies in Oceanography, 61:17-49.

Ishitani, Y. and Takahashi, K. 2007. The vertical distribution of Radiolaria in the waters surrounding Japan. Marine Micropaleontology, 65:113-136.

Itaki, T. 2001. Radiolarian faunal changes in the eastern Japan Sea during the last 30 kyr. News of Osaka Micropaleontologists (NOM), Special Volume, 12:359-374. (In Japanese with English abstract)

Itaki, T. 2003. Depth-related radiolarian assemblage in the water column and surface sediments of the Japan Sea. Marine Micropaleontology, 47:253-270.

Itaki, T. 2009. Last Glacial to Holocene polycystine radiolarians from the Japan Sea. News of Osaka Micropaleontologists (NOM), Special Volume, 14:43-89. (In Japanese with English abstract)

Itaki, T. 2016. Size and morphological variations of the radiolarian Larcopyle buetschlii Dreyer in the Japan Sea and its depth distributuion in the water column. News of Osaka Micropaleontologists (NOM), Special Volume, 16: 41-59. (In Japanese with English abstract)

Itaki, T. and Ikehara, K. 2003. Radiolarian biozonation for the upper Quaternary in the Japan Sea. Journal of the Geological Society of Japan, 109:96-105.

Itaki, T., Ikehara, K., Motoyama, I., and Hasegawa, S. 2004. Abrupt ventilation changes in the Japan Sea over the last $30 \mathrm{ky}$ : Evidence from deep-dwelling radiolarians. Palaeogeography, Palaeoclimatology, Palaeoecology, 208:263-278.

Itaki, T., Kimoto, K., and Hasegawa, S. 2010. Polycystine radiolarians in the Tsushima Strait in autumn of 2006. Paleontological Research, 14:19-32.

Itaki, T., Komatsu, N., and Motoyama, I. 2007. Orbitaland millennialscale changes of radiolarian assemblages during the last 220 kyrs in the Japan Sea. Palaeogeography, Palaeoclimatology, Palaeoecology, 247:115-130.

Itaki, T., Matsuoka, A., Yoshida, K., Machidori, S., Shinzawa, M., and Todo, T. 2003. Late spring radiolarian fauna in the surface water off Tassha, Aikawa Town, Sado Island, central Japan. Scientific Reports of Niigata University, Series E, Geology and Mineralogy, 18:41-51.

Itaki, T., Minoshima, K., and Kawahata, H. 2008. Radiolarian flux at an IMAGES site at the western margin of the subarctic Pacific and its seasonal relationship to the Oyashio cold and Tsugaru warm currents. Marine Geology, 255:131-148.

Johnson, D.A. and Nigrini, C.A. 1980. Radiolarian biogeography in surface sediments of the western Indian Ocean. Marine Micropaleontology, 5:111-152.
Jørgensen, E. 1899. Protophyten und Protozoën im Plankton aus der norwegischen Westküste. Bergens Museums Åarbog, 1899:51-95.

Jørgensen, E. 1905. The protist plankton and diatoms in bottom samples: Radiolaria, p. 49-151. In Nurdgaard, O. (ed.), Hydrographical and Biological Investigation in Norwegian Fjords. Bergens Museum, Bergen.

Jyothibabu, R., Vinayachandran, P.N., Madhu, N.V., Robin, R.S., Karnan, C., Jagadeesan, L., and Anjusha, A. 2015. Phytoplankton size structure in the southern Bay of Bengal modified by the Summer Monsoon Current and associated eddies: Implications on the vertical biogenic flux. Journal of Marine Systems, 143:98-119.

Kamikuri, S., Motoyama, I., and Nishimura, A. 2008. Radiolarian assemblages in surface sediments along longitude $175^{\circ} \mathrm{E}$ in the Pacific Ocean. Marine Micropaleontology, 69:151-172.

Kawagata, S., Hayward, B.W., and Gupta, A.K., 2006. Benthic foraminiferal extinctions linked to late Pliocenc-Pleistocene deep-sea circulation changes in the northern Indian Ocean (ODP) Sites 722 and 758). Marine Micropaleontology, 58:219-242.

Kim, K.H. and Kim, C.S. 1994. Paleoenvironmental study using radiolarians from KODOS 91-1 area in Pacific deep seabed. Journal of the Paleontological Society of Korea, 10:170-194.

Kim, K.H., Park, J.H., and Park, C.K. 1994. A study on the radiolarian fauna in KODOS (Korea Deep Ocean Study) 94 area, Northeast Pacific. Journal of the Paleontological Society of Korea, 10:257-275.

Kling, S.A. 1977. Local and regional imprints on radiolarian assemblages from California coastal basin sediments. Marine Micropaleontology, 2:207-221.

Kling, S.A. 1979. Vertical distribution of polycystine radiolarians in the central North Pacific. Marine Micropaleontology, 4:295-318.

Kozlova, G.E. 1967. The structure patterns of the skeleton of radiolarians from the Family Porodiscidae. Zoologicheskiy Zhurnal, 46:1163-1172. (In Russian with English abstract).

Kozur, H. and Mostler, H. 1979. Beiträge zur Erforschung der mesozoischen Radiolarien. Teil III: Die Oberfamilien Actinommacea Haeckel 1862 emend. Artiscacea Haeckel 1882, Multiarcusellacea nov. der Spumellaria und triassische Nassellaria. Geologisch-Paläontologische Mitteilungen Innsbruck, 9:1-132.

Kruglikova, S.B. 1978. New radiolarian species from the Miocene to Holocene in the equatorial Pacific, p. 8790 and p. 214-215, pls. 21-27. In Zhuze, A.P. (ed.), Marine Micropaleontology (Diatoms, Radiolarians, Silicoflagellates, Foraminifers and Calcareous Nannoplanktons). Akademiya Nauk SSSR, Okeanograficheskaya Komissiya, Nauka, Moskva. (In Russian; original title translated)

Kršinic, F. and Kršinic, A. 2012. Radiolarians in the Adriatic Sea plankton (eastern Mediterranean). Acta Adriatica, 53:187-210. 
Kurihara, T. and Matsuoka, A. 2010. Living radiolarian fauna of late autumn (November 13, 2008) in surface-subsurface waters of the Japan Sea off Tassha, Sado Island, central Japan. Science Reports of Niigata University (Geology), 25:83-92.

Kurihara, T. and Matsuoka, A. 2011. Living radiolarians sampled on 7 June 2010 in surface-subsurface waters of the Japan Sea off Tassha, Sado Island, central Japan. Science Reports of Niigata University (Geology), 26:53-60.

Kurihara, T., Shimotani, T., and Matsuoka, A. 2006. Water temperature, salinity, algal-chlorophyll profiles and radiolarian fauna in the subsurface waters in early June, off Tassha, Sado Island, central Japan. Science Reports of Niigata University, Series $E$ (Geology), 21:31-46.

Kurihara, T., Uchida, K., Shimotani, T., and Matsuoka, A. 2007. Radiolarian faunas and water properties in surface and subsurface waters of the Japan Sea in September 2005, off Tassha, Sado Island, central Japan. Science Reports of Niigata University, Series $E$ (Geology), 22:43-56.

Lazarus, D., Faust, K., and Popova-Goll, I. 2005. New species of prunoid radiolarians from the Antarctic Neogene. Journal of Micropalaeontology, 24:97-121.

Levyikina, I.E. 1986. Stratigraphy of Neogene deposits in the Northwest Pacific according to radiolarians. Ordena Trudovogo Krasnogo Znameni Geologicheskiy Institut Akademii Nauk SSSR, 413:1-117. (In Russian with English abstract)

Ling, H.Y. 1972. Polycystine Radiolaria from surface sediments of the South China Sea and the adjacent seas of Taiwan. Acta Oceanographica Taiwanica, 2:159178.

Ling, H.Y. 1992. Radiolarians from the Sea of Japan: Leg 128, p. 225-236. In Pisciotto, K.A., Ingle, J.C. Jr., von Breymann, M.T., Barron, J., and ODP Leg 128 Scientific Party. Proceedings of the Ocean Drilling Program, Scientific Results, Volumes. 127-128. Ocean Drilling Program, College Station.

Ling, H.Y. and Kobayashi, H. 1992. Geological significance of siliceous microfossils from Dogo, Oki Islands, p. 439-447. In Ishizaki, K. and Saito, T. (eds.), Centenary of Japanese Micropaleontology. Terra Scientific Publishing Company, Tokyo.

Lombari, G. and Boden, G. 1985. Modern radiolarian global distributions. Cushman Foundation for Foraminiferal Research, Special Publication, 16A:1-125.

Matsuoka, A. 1993. Living radiolarians around the Sesoko Island, Okinawa Prefecture. Fossils (Palaeontological Society of Japan), 54:1-9. (In Japanese with English abstract)

Matsuoka, A. 2009. Late autumn living radiolarian fauna from subtropical surface waters in the East China Sea off Sesoko Island, Okinawa, Southwest Japan. News of Osaka Micropaleontologists (NOM), Special Volume, 14:11-29.

Matsuoka, A., Shinzawa, M., Yoshida, K., Machidori, S., Kurita, H., and Todo, T. 2002. Early summer radiolar- ian fauna in surface waters off Tassha, Aikawa Town, Sado Island, central Japan. Science Reports of Niigata University, Series E, Geology and Mineralogy, 17:17-25.

Matsuoka, A., Yoshida, K., Hasegawa, S., Shinzawa, M., Tamura, K., Sakumoto, T., Yabe, H., Niikawa, I., and Tateishi, M. 2001. Temperature profile and radiolarian fauna in surface waters off Tassha, Aikawa Town, Sado Island, central Japan. Science Reports of Niigata University, Series E, Geology and Mineralogy, 16:83-93.

Matsuzaki, K.M., Itaki, T., and Kimoto, K. 2016. Vertical distribution of polycystine radiolarians in the northern East China Sea. Marine Micropaleontology, 125:6684.

Matsuzaki, K.M., Nishi, H., Hayashi, H., Suzuki, N., Ikehara, M., Gyawali, B.R., Tanaka, T., and Takashima, R. 2014a. Radiolarian biostratigraphic scheme and stable oxygen isotope stratigraphy in southern Japan (IODP Expedition 315 Site C0001). Newsletters on Stratigraphy, 47:107-130.

Matsuzaki, K.M., Nishi, H., Suzuki, N., Cortese, G., Eynaud, F., Takashima, R., Kawate, Y., and Sakai, T. 2014b. Paleoceanographic history of the northwestern Pacific Ocean over the past $740 \mathrm{kyr}$, discerned from radiolarian fauna. Palaeogeography, Palaeoclimatology, Palaeoecology, 396:26-40.

Matsuzaki, K.M., Nishi, H., Suzuki, N., Kawate, Y., Takashima, R., and Sakai, T., 2014c. Cycladophora davisiana abundances as a paleoceanographic and stratigraphic tool in high latitude siliceous sediments. Marine Micropaleontology, 106:1-9.

Matsuzaki, K.M., Nishi, H., Suzuki, N., Takashima, R., Kawate, Y., and Sakai, T. 2014d. Middle to late Pleistocene radiolarian biostratigraphy in the water mixed region of the Kuroshio and Oyashio currents, northeastern margin of Japan (JAMSTEC Hole 902C90001C). Journal of Micropalaeontology, 33:205222.

Matsuzaki, K.M., Suzuki, N., and Nishi, H. 2015a. Middle to upper Pleistocene polycystine radiolarians from Hole 902-C9001C, northwestern Pacific. Paleontological Research, 19(s1):1-77.

Matsuzaki, K.M., Suzuki, N., Nishi, H., Hayashi, H., Gyawali, B.R., Takashima, R., and Ikehara, M. 2015b. Early to Middle Pleistocene paleoceanographic history of southern Japan based on radiolarian data from IODP Exp. 314/315 Sites C0001 and C0002. Marine Micropaleontology, 118:17-33.

McMillen, K.J. and Casey, R.E. 1978. Distribution of living polycystine radiolarians in the Gulf of Mexico and Caribbean Sea, and comparison with the sedimentary record. Marine Micropaleontology, 3:121-145.

Molina-Cruz, A. 1977. Radiolarian assemblages and their relationship to the oceanography of the subtropical southeastern Pacific. Marine Micropaleontology, 2:315-352.

Molina-Cruz, A. 1982. Radiolarians in the Gulf of California: Deep Sea Drilling Project Leg 64, p. 983-1002. In 
Curray, J.R., Moore, D.G., and DSDP Leg 164 participants. Initial Reports of the Deep Sea Drilling Project, Volume 64. U.S. Government Printing Office, Washington D.C.

Molina-Cruz, A., Welling, L., and Caudillo-Bohorquez, A. 1999. Radiolarian distribution in the water column, southern Gulf of California, and its implication in thanatocoenose constitution. Marine Micropaleontology, 37:149-171.

Morley, J.J. 1985. Radiolarians from the Northwest Pacific, Deep Sea Drilling Project Leg 86, p. 399-422. In Heath, G.R., Burckle, L.H., and DSDP Leg 86 participants. Initial Reports of the Deep Sea Drilling Project, Volumes 86. U.S. Government Printing Office, Washington, D.C.

Morley, J.J. and Kohl, B. 1986. Radiolarians from Deep Sea Drilling Project Leg 96, p. 649-656. In Scientific Party (ed.), Initial Reports of the Deep Sea Drilling Project, Volumes 96. U.S. Government Printing Office, Washington D.C.

Motoyama, I. 1996. Late Neogene radiolarian biostratigraphy in the subarctic Northwest Pacific. Micropaleontology, 42:221-262.

Motoyama, I. and Kawamura, K. 2009. Miocene geology and radiolarian biostratigraphy of the Hobetsu area, Hokkaido, Japan. Bulletin of the Hobetsu Museum, 24:1-18. (In Japanese with English abstract)

Motoyama, I. and Nagamori, H. 2006. Radiolarians from the Pliocene of the Hokushin district, Nagano Prefecture, Japan. Journal of the Geological Society of Japan, 112:541-548. (In Japanese with English abstract)

Motoyama, I. and Nishimura, A. 2005. Distribution of radiolarians in the North Pacific surface sediments along the $175^{\circ} \mathrm{E}$ meridian. Paleontological Research, 9:95-117.

Motoyama, I., Yamada, Y., Hoshiba, M., and Itaki, T. 2016. Radiolarian assemblages in surface sediments of the Japan Sea. Paleontological Research, 20:176206.

Müller, J. 1859. Über die Thalassicollen, Polycystinen und Acanthometren des Mittelmeeres. Abhandlungen der Königlichen Akademie der Wissenschaften zu Berlin, 1858:1-62.

Mullineaux, L.S. and Westberg-Smith, M.J. 1986. Radiolarians as paleoceanographic indicators in the Miocene Monterey Formation, Upper Newport Bay, California. Micropaleontology, 32:48-71.

Murphy, D.B. 2001. Fundamentals of Light Microscopy and Electronic Imaging. John Wiley \& Sons, Inc., New Work.

Nakaseko, K. 1954. Preliminary report of Miocene radiolarian faunas from southern Toyama Prefecture. Science Reports, South and North Colleges, Osaka University, 3:107-118. (In Japanese)

Nakaseko, K. 1955. Miocene radiolarian fossil assemblage from the southern Toyama Prefecture in Japan. Science Reports, South and North Colleges, Osaka University, 4:65-127.
Nakaseko, K. and Nishimura, A. 1982. Radiolaria from the bottom sediments of the Bellingshausen Basin in the Antarctic Sea. Report of the Technology Research Center, J.N.O.C., 16:91-244.

Nigrini, C.A. 1970. Radiolarian assemblages in the North Pacific and their application to a study of Quaternary sediments in Core V 20-130. Geological Society of America Memoir, 126:139-175.

Nigrini, C.A. and Lombari, G. 1984. A guide to Miocene Radiolaria. Cushman Foundation for Foraminiferal Research, Special, Publication, 22:1-220.

Nigrini, C.A. and Moore, T. 1979. A guide to modern Radiolaria. Cushman Foundation for Foraminiferal Research, Special Publication, 16:N1-N260.

Nishimura, A. and Yamauchi, M. 1984a. Radiolaria fossils in the drilling core samples at the Kansai International Airport in Osaka Bay: Geological survey to the base at Kansai International Airport, p. 69-75. In Geological Survey Group to the Base at Kansai International Airport (ed.), Report of Laboratory Calamitic Science. Calamity Science Institute, Osaka. (In Japanese with English title)

Nishimura, A. and Yamauchi, M. 1984b. Radiolarians from the Nankai Trough in the Northwest Pacific. News of Osaka Micropaleotologists (NOM), Special Volume, 6:1-148.

Ogane, K. and Suzuki, N. 2006. Morphological terms describing discoidal radiolarians. Revue de Micropaléontologíe, 49:97-104.

Okazaki, Y., Takahashi, K., and Asahi, H. 2008. Temporal flux of radiolarians along the W-E transect in the central and western equatorial Pacific, 1999-2002. Micropaleontology, 54:71-86.

Okazaki, Y., Takahashi, K., Itaki, T., and Kawasaki, Y. 2004. Comparison of radiolarian vertical distributions in the Okhotsk Sea near the Kuril Islands and in the northwestern North Pacific off Hokkaido Island. Marine Micropaleontology, 51:257-284.

Okazaki, Y., Takahashi, K., Onodera, J., and Honda, M.C. 2005. Temporal and spatial flux changes of radiolarians in the northwestern Pacific Ocean during 1997-2000. Deep Sea Research II: Tropical Studies in Oceanography, 52:2240-2274.

Okazaki, Y., Takahashi, K., Yoshitani, H., Nakatsuka, T., Ikehara, M., and Wakatsuchi, M. 2003. Radiolarians under the seasonally sea ice covered conditions in the Okhotsk Sea: Flux and their implications for paleoceanography. Marine Micropaleontology, 49:195230.

Pandey, J.B. 2011. Biostratigraphy and Paleoceanography of Pliocene-Pleistocene Radiolaria-ODP Leg 119 Site 745. Lambert Academic Publishing, Saarbrucken.

Peng, S.Q., Qian, Y.K., Lumpkin, R., Du, Y., Wang, D.X., and Li, P. 2015. Characteristics of the Near-Surface Currents in the Indian Ocean as Deduced from Satellite-Tracked Surface Drifters. Part I: Pseudo-Eulerian Statistics. Journal of Physical Oceanography, 45(2):441-458. 
Petrushevskaya, M.G. and Kozlova, G.E. 1972. Radiolaria: Leg 14, Deep Sea Drilling Project, p. 459-648. In Hayes, D.E., Pimm, A.C., and DSDP Leg 14 participants. Initial Reports of the Deep Sea Drilling Project, Volume 14. U.S. Government Printing Office, Washington, D.C.

Poluzzi, A. 1982. I radiolari Quaternari di un ambiente idrotermale del mar Tirreno. Memorie della Società Italiana di Scienze Naturali e del Museo Civico di Storia Naturale di Milano, 23:47-72.

Popofsky, A. 1912. Die Sphaerellarien des Warmwassergebietes. Deutsche Südpolar-Expedition 1901-1903, Zoologie, 13:73-159.

Prasannakumar, R., Muraleedharan, P.M., Prasad, T.G., Gauns, M., Ramalah, N., DeSousa, S.N., Sardessai, S., and Madhupratap, M. 2002. Why Bay of Bengal is less productive during summer monsoon compared to the Arabian Sea. Geophysical Research Letters, 29:2235.

Renz, G.W. 1976. The distribution and ecology of Radiolaria in the central Pacific: plankton and surface sediments. Bulletin of the Scripps Institution of Oceanography, University of California, 22:1-267.

Riedel, W.R. 1953. Mesozoic and late Tertiary Radiolaria of Rotti. Journal of Paleontology, 27:805-813.

Riedel, W.R. and Sanfilippo, A. 1978. Radiolaria. Utrecht Micropaleontological Bulletins, 17:81-128.

Robson, S. 1983. The distribution of Recent Radiolaria in surficial sediments of the continental margin off northern Namibia. Journal of Micropalaeontology, 2:31-38.

Sakai, T., Suzuki, N., Ogane, K., Lazarus, D., Breidbach, O., and Bach, T. 2009. Haeckel's Messina radiolarian collection housed in the Ernst-Haeckel-Haus. National Museum of Nature and Science Monographs, 40:47-54, 23 pls.

Sashida, K. and Kurihara, T. 1999. Recent radiolarian faunas in the surface water off the coast of Shimoda, Izu Peninsula, Japan. Science Reports of the Institute of Geoscience, University of Tsukuba, Section B, Geological Sciences, 20:115-144.

Sashida, K. and Uematsu, H. 1994. Living Radiolaria in the surface water off the coast of Shimoda, Izu Peninsula, Japan. Annual Report of the Institute of Geoscience, the University of Tsukuba, 20:39-44.

Sharma, V. and Ram, M.P. 2003. Early to middle Miocene radiolarian assemblages and biostratigraphy, Andaman Islands, northeast Indian Ocean. Journal of the Palaeontological Society of India, 48:1-39.

Sharma, V. and Sharma, G.K. 1988. Radiolaria from Neil Island, Andaman Sea, and their distributional characteristics. Journal of the Palaeontological Society of India, 33:7-19.

Sharma, V. and Singh, S. 1993. Radiolarian biostratigraphy of early Pliocene sequence, Car Nicobar Island, Northeast Indian Ocean. Journal of the Geological Society of India, 41:199-213.
Sharma, V., Singh, S., and Rawal, N. 1999. Early middle Miocene Radiolaria from Nicobar Islands, Northeast Indian Ocean. Micropaleontology, 45:251-277.

Shinjo, R., Motoyama, I., Nakamura, M., Takaki, Y., Nishida, H., Morii, Y., and Tanaka, H. 1998. Report on RN97 Cruise by T/S Nagasaki Maru in the southern Okinawa Trough. Bulletin of the College of Science University of the Ryukyus, 65:39-51.

Sono, A., Suzuki, N., Yoshimura, E., Kano, H., and Takeda, K. 2009. Radiolarian faunal changes in the mid-latitudinal North Pacific over the past 6.4 m.y. (ODP Leg 198, Site 1210, Shatsky Rise). News of Osaka Micropaleontologists (NOM), Special Volume, 14:143-181. (In Japanese with English abstract)

Srinivasan, M.S., Lombari, G., and Dave, A. 1983. Early Miocene planktonic foraminiferal and radiolarian zonations, Colerook Island, Andaman Sea. Journal of the Geological Society of India, 24:1-18.

Stöhr, E. 1880. Die Radiolarienfauna der Tripoli von Grotte, Provinz Girgenti in Sicilien. Palaeontographica, 26:69-124.

Sugano, T. 1937. List of radiolarians from the inshore along the Japanese Islands (the first report). Journal of Fisheries, 42:54-72. (In Japanese)

Sugiyama, K., Nobuhara, T., and Inoue, K. 1992. Preliminary report on Pliocene radiolarians from the Nobori Formation, Tonohama Group, Shikoku, southwest Japan. Journal of Earth and Planetary Sciences, Nagoya University, 39:1-30.

Suzuki, N., Ogane, K., Aita, Y., Kato, M., Sakai, S., Kurihara, T., Matsuoka, A., Ohtsuka, S., Go, A., Nakaguchi, K., Yamaguchi, S., Takahashi, T., and Tuji, A. 2009a. Distribution patterns of the radiolarian nuclei and symbionts using DAPI-fluorescence. Bulletin of the National Museum of Nature and Science, Series $B$ (Botany), 35:169-182.

Suzuki, N., Ogane, K., Aita, Y., Sakai, T., and Lazarus, D. 2009b. Reexamination of Ehrenberg's Neogene radiolarian collections and its impact on taxonomic stability. National Museum of Nature and Science Monographs, 40:87-96, 77 pls.

Suzuki, N., Ogane, K., and Chiba, K. 2009c. Middle Eocene polycystine radiolarians from the Site 1172, Leg 189, Southwest Pacific. News of Osaka Micropaleontologists (NOM), Special Volume, 14:239-296.

Suzuki, N., Ogawa, K., Ogane, K., and Tuji, A. 2013. Patchwork silicification and disposal activity of siliceous fragments of a polycystine radiolarian. Revue de Micropaléontologie, 56:63-74.

Suzuki, S. and Kanie, Y. 2010. Radiolarian biostratigraphy from the Hayama Group and the Miura Group in south-eastern Kanagawa Prefecture, Japan. Science Report of the Yokosuka City Museum, 57:1-17. (In Japanese with English abstract).

Suzuki, S. and Kanie, Y. 2012. Radiolarian biostratigraphy of the Pliocene Ikego Formation, eastern Kanagawa Prefecture. Research Report of the Kanagawa Prefectural Museum, Natural History, 14:127-136. (In Japanese with English abstract) 
Takahashi, K. 1991. Radiolaria: Flux, ecology, and taxonomy in the Pacific and Atlantic. Ocean Biocoenosis Series, 3:1-301.

Takahashi, K. and Honjo, S. 1981. Vertical flux of Radiolaria: A taxon-quantitative sediment trap study from the western tropical Atlantic. Micropaleontology, 7:140-190.

Taketani, Y. and Aita, Y. 1991. Miocene Radiolaria from the Kubota Formation, Tanagura area, northeast Honshu, Japan. Bulletin of the Fukushima Museum, 5:1-51. (In Japanese with English abstract)

Tan, Z.Y. 1993. The spumellarian Radiolaria of the Xisha Islands. Studia Marina Sinica, 34:181-226. (In Chinese with English abstract)

Tan, Z.Y. 1998. Fauna Sinica: Phylum Protozoa, Class Sarcodina, Order Acantharia, Order Spumellaria. Science Press, Beijing. (In Chinese)

Tan, Z.Y. and Chen, M.H. 1990. Some new revisions of Pyloniidae. Chinese Journal of Oceanology and Limnology, 8:109-125.

Tan, Z.Y. and Chen, M.H. 1999. Offshore Radiolaria in China. Science Press, Beijing. (In Chinese with English abstract)

Tan, Z.Y. and Tchang, T.R. 1976. Studies on the Radiolaria of the East China Sea. II. Spumellaria, Nassellaria, Phaeodaria, Sticholonchea. Studia Marina Sinica, 11:217-310. (In Chinese with English abstract)

Tanaka, S. and Takahashi, K. 2008. Detailed vertical distribution of radiolarian assemblage $(0-3000 \mathrm{~m}$, fifteen layers) in the central subarctic Pacific, June 2006. Memoirs of the Faculty of Science, Kyushu University, Series D, Earth and Planetary Sciences, $32: 49-72$.
Van de Paverd, P.J. 1995. Recent Polycystine Radiolarian from the Snellius-II Expedition. Paleontological Museum, University of Oslo, Oslo.

Yamauchi, M. 1986. The distribution of radiolarian assemblages in surface sediments from the northwestern Pacific. News of Osaka Micropaleontologists (NOM), Special Volume, 7:141-156. (In Japanese with English abstract)

Yeh, K.Y. and Cheng, Y.N. 1990. Radiolaria in surface sediments from marginal basin off southwest Taiwan. Bulletin of National Museum of Natural Science, 2:65-87.

You, Y. 2000. Implications of the deep circulation and verntilation of the Indian Ocean on the renewal mechanism of North Atlantic Deep Water. Journal of Geophysical Research, 105:23895-23926.

Warren, B.A. 1981. Transition hydrographic section at Lat. $18^{\circ} \mathrm{S}$ : Property distribution and circulation in the South Indian Ocean. Deep-Sea Research, 28:759788.

Vinayachandran, P.N., Shankar, D., Vernekar, S., Sandeep, K.K., Amol, P., Neema, C.P., and Chatterjee, A. 2013. A summer monsoon pump to keep the Bay of Bengal salty. Geophysical Research Letters, 40:1777-1782.

Zapata, J. and Olivares, J. 2005. Radiolarios (Protozoa, Actinopoda) sedimentados en el Puerto de Caldera (270.'S; 7051W), Chile. Gayana, 69:78-93.

Zhang, L.L., Chen, M.H., Xiang, R., Zhang, J.L., Liu, Ch.J., Huang, L.M., and Lu, J. 2009. Distribution of polycystine radiolarians in the northern South China Sea in September 2005. Marine Micropaleontology, 70:20-38. 